Aus der Abteilung Neuropathologie

(Prof. Dr. med. W. Brück)

im Zentrum Pathologie

der Medizinischen Fakultät der Universität Göttingen

\title{
Untersuchungen zur Rekrutierung myeloischer Zellen in einem Tiermodell der Alzheimerschen Erkrankung
}

\author{
Inaugural - Dissertation \\ zur Erlangung des Doktorgrades \\ der Medizinischen Fakultät \\ der Georg - August - Universität zu Göttingen
}

vorgelegt von

Bernhard Martin Schlevogt

aus Nürnberg

Göttingen 2011 
Dekan: Prof. Dr. med. C. Frömmel

I. Berichterstatter: Prof. Dr. med. M. Prinz

II. Berichterstatter/in: Prof. Dr. rer. nat. Reichardt

III. Berichterstatter/in: Prof. Dr. med., Dr. rer. nat. Crozier

Tag der mündlichen Prüfung: 15.02.2012 


\section{Inhaltsverzeichnis}

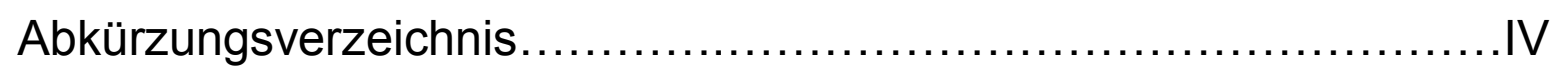

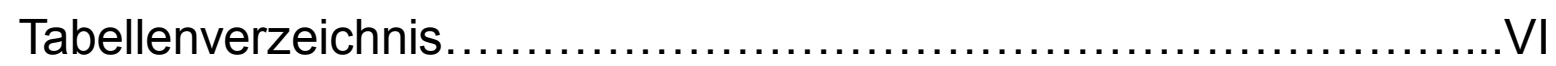

Abbildungsverzeichnis ..................................................

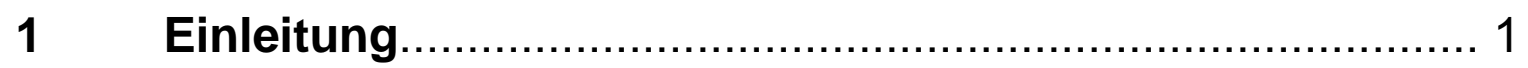

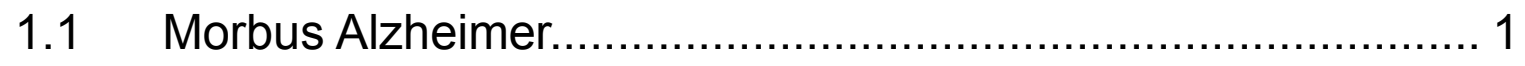

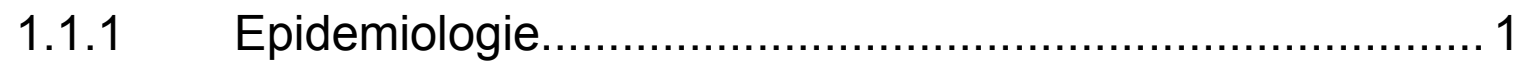

1.1.2 Risikofaktoren und Genetik................................ 1

1.1.3 Symptome

1.1.4 Amyloidhypothese und Pathophysiologie..................... 2

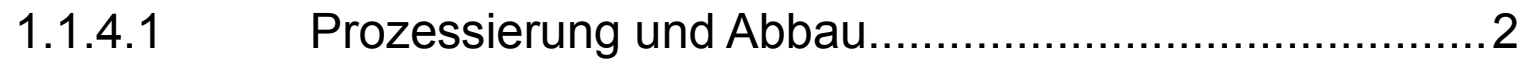

1.1.4.2 Toxizität...................................................... 4

1.1.5 Neuropathologische Veränderungen........................ 4

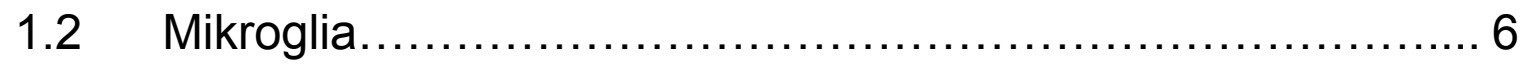

1.2.1 Morphologie, Aktivierung und Funktion …….............. 6

1.2.2 Mononukleäre Phagozyten.......................................

1.2.3 Rolle der residenten Mikroglia beim Morbus Alzheimer......9

1.2.4 Rolle der mononukleären Phagozyten beim Morbus Alzheimer

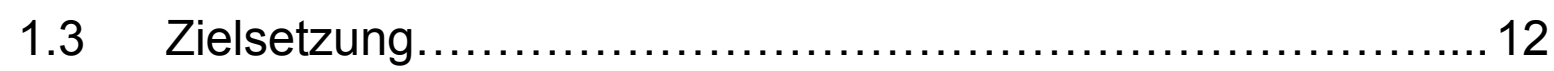

2 Materialien und Methoden....................................... 13

2.1 Chemikalien, Enzyme, Antikörper, Reinigungssysteme und Tiere 13

2.2 Das APP ${ }^{\text {swe }} /$ PS1-dE9 - Tiermodell des Morbus Alzheimer........14

2.3 Herstellung von Knochenmarkschimären.........................16

2.4 Durchflusszytometrie............................................ 18 


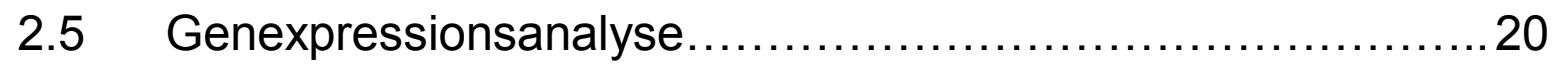

2.6 Enzyme - linked immunosorbent assay (ELISA) ................ 22

$2.7 \quad$ Western Blot.................................................. 23

2.8 Immunfluoreszenz auf Gefrierschnitten........................23

2.9 Genotypisierung.......................................................... 25

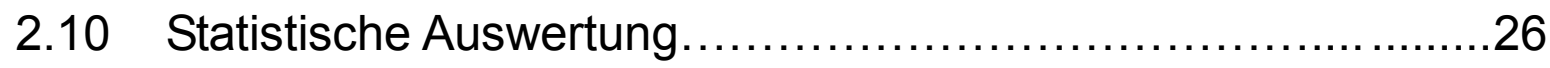

$3 \quad$ Experimente und Ergebnisse ........................................ 27

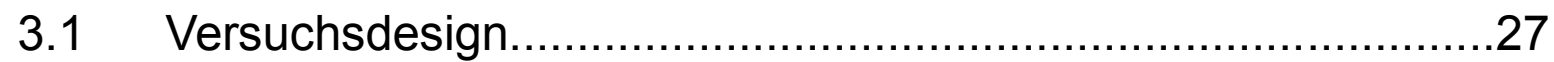

3.2 Ly-6C $\mathrm{C}^{\text {hi }}$ - Monozyten sind die Vorläuferzellen der mononukleären Phagozyten im APP swe/PS1 - Gehirn.................................... 28

3.2.1 Massive Reduktion der Ly-6C ${ }^{\text {hi }}$ - Monozyten bei CCR2 defizientem Knochenmark..............................................28

3.2.2 Ly-6C $\mathrm{C}^{\text {hi }}$ - Monozyten migrieren in APP ${ }^{\text {swe/PS1 }}-$ Gehirne........29

3.3 Die Einwanderung von Ly-6C ${ }^{\text {hi }}$ - Monozyten ins ZNS ist abhängig von der Gewebekonditionierung......................................... 30

3.3.1 Stabiler Chimärismus in den Chimären........................30

3.3.2 Die Einwanderung von Ly-6C ${ }^{\text {hi }}$ - Monozyten ins ZNS bedarf vorheriger Bestrahlung.

3.3.3 Schwache Assoziation von mononukleären Phagozyten mit Amyloidplaques........................................................... 34

3.4 Die Gewebekonditionierung verändert das Hirnmilieu...............35

3.4.1 Veränderungen des zellulären Netzwerks und Reduktion der Mikroglia infolge der Bestrahlung.................................... 35

3.4.2 Unterschiede in der Reaktion der Mikroglia auf Amyloidplaques................................................................ 37

3.4.3 Veränderungen der Mikrogliamorphologie....................... 39

3.4.4 Veränderungen der Genexpression............................... 41

3.5 Reduktion des A $\beta$ - Gehalts im APP ${ }^{\text {swe/PS1 }}$ - Gehirn durch 


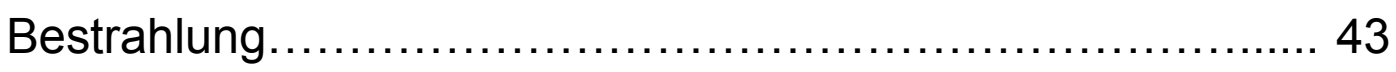

3.6 Mononukleäre Phagozyten sind nicht ursächlich für die Reduktion $\operatorname{des} A \beta$ - Gehalts im APP ${ }^{\text {swe/PS1 }}$ - Gehirn........................... 45

4 Diskussion.............................................................. 47

$5 \quad$ Zusammenfassung.................................................... 57

$6 \quad$ Literaturverzeichnis................................................. 59 


\section{Abkürzungsverzeichnis}

ACT $\beta$

APC

ApoE

$\mathrm{APP}^{\text {swe }}$

$A \beta$

BACE1

CCR2

CDNA

CXCR1

DAPI

DMEM

dNTP

EDTA

EGFP

ELISA

FCS

FITC

GAPDH

Gy

lba-1

IL-1

iNOS

$\mathrm{IP}-10=\mathrm{CXCL} 10$

LOAD

Ly-6C

MCP-1

$\mathrm{MeV}$

MIP-1 $\alpha=$ CCL3 engl. Beta-Actin

Allophycocyanin

Apolipoprotein E

engl. Amyloid Precursor Protein Swedish Mutation

Amyloid - Beta

engl. beta - site of APP cleaving enzyme $=\beta$ - Sekretase

CC - Motiv - Chemokinrezeptor 2

engl. Complementary DNA

CXC - Motiv - Chemokinrezeptor 1

4',6 - Diamidin - 2 - Phenylindol

engl. Dulbecco's Modified Eagle's Medium

Desoxyribonukleosidtriphosphat

engl. Ethylenediaminetetraacetic acid

engl. Enhanced Green Fluorescent Protein

engl. Enzyme - linked Immunosorbent Assay

engl. Fetal Calf Serum

Fluoresceinisothiocyanat

Glycerinaldehyd - 3 - phosphat - Dehydrogenase

Gray

engl. Ionized calcium binding adaptor molecule 1

Interleukin 1

engl. inducible NO - Synthetase

engl. Interferon - gamma induced Protein $=\mathrm{CXC}-$ Motiv Ligand 10

engl. Late Onset Alzheimer Disease

engl. Lymphocyte antigen $6 \mathrm{C}$

engl. Monocyte Chemotactic Protein 1

Megaelektronenvolt

engl. Macrophage Inflammatory Protein $1 \alpha=C C-$ Motiv - 
Ligand 3

mRNA engl. messenger Ribonucleic Acid

PBS engl. Phosphate Buffered Saline

PE

Phycoerythrin

PerCP

Peridinin Chlorophyll Protein

PFA

Paraformaldehyd

PHF

engl. Paired Helical Filament

$\operatorname{PrPc}$

engl. Prion Protein cellular

PS1/2

Präsenilin $1 / 2$

qRT - PCR

engl. quantitative Reverse Transcription Polymerase Chain

Reaction

SDS

engl. Sodium Dodecyl Sulphate

SRA

engl. Scavenger Receptor $A$

TAE

Tris - Acetat - EDTA - Puffer

TLR

engl. Toll Like Receptor

Taq - Polymerase

Thermus - aquaticus - Polymerase

TGF- $\beta 1$

engl. Transforming Growth Factor - Beta 1

TNF- $\alpha$

engl. Tumor Necrosis Factor - alpha

ZNS

Zentrales Nervensystem

$\beta-C T F$

engl. Beta - C - Terminal Fragment 
Tabellenverzeichnis

Tabelle 1: Bei der Durchflusszytometrie verwendete Fluoreszenzantikörper............ 19

Tabelle 2: Eigenschaften der verwendeten Fluorochrome..................................... 20

Tabelle 3: Primersequenzen und Hybridisierungstemperaturen für die quantitative Reverse - Transkriptase - Polymerase - Kettenreaktion...........................22

Tabelle 4: Primersequenzen und Hybridisierungstemperaturen für die Genotypisierungs - Polymerase - Kettenreaktion..................................26 
Abbildungsverzeichnis

Abbildung 1: Schematische Darstellung der amyloidogenen und nicht amyloidogenen APP - Prozessierung

Abbildung 2:Schematische Darstellung der verschiedenen Knochenmarkschimären und ihrer Injektions - und Bestrahlungsmodalitäten..

Abbildung 3: Zeitlicher Ablauf der Knochenmarksrekonstitution

Abbildung 4: Aufteilung des Hirngewebes für verschiedene Analysen. 27

Abbildung 5: Blutchimärismus von inflammatorischen Monozyten in $\mathrm{CCR}^{-/-}$- GFP $\rightarrow$ APP $^{\text {swe/PS1 }}$ - Chimären. 28

Abbildung 6: Immunhistochemische Untersuchung der Gehirne von CCR2 ${ }^{-1-}$ - GFP $\rightarrow$ APP ${ }^{\text {swelPS1 }}$ - Chimären. 29

Abbildung 7: Semiquantitative Analyse der mononukleären Phagozyten im Gehirn von $\mathrm{CCR2}^{-l-}$ - GFP $\rightarrow \mathrm{APP}^{\text {swe/PS1 }}$ - Chimären und deren Plaqueassoziation........ 30

Abbildung 8: Blutchimärismus von inflammatorischen Monozyten in geschützt bestrahlten APP ${ }^{\text {swe/PS1 }}$ - Chimären.

Abbildung 9: Blutchimärismus verschiedener Zelllinien in geschützt bestrahlten APP ${ }^{\text {swe/PS1 }}$ - Chimären.

Abbildung 10: Immunhistochemische und semiquantitative Untersuchung der Gehirne und Rückenmarke von geschützt bestrahlten APP ${ }^{\text {swe/PS1 }}$ Chimären.

Abbildung 11: Semiquantitative Untersuchung der Plaqueassoziation von mononukleären Phagozyten in geschützt bestrahlten APP ${ }^{\text {swelPS1 }}$ - Chimären.... 34

Abbildung 12: Morphologische Veränderungen des Mikroglianetzwerks in geschützt bestrahlten APP ${ }^{\text {swe/PS1 }}$ - Chimären............................................................... 35

Abbildung 13: Semiquantitative Untersuchung der $\mathrm{Iba}-1^{+}-$Mikroglia in geschützt bestrahlten APP ${ }^{\text {swe/PS1 }}$ - Chimären................................................................... 36

Abbildung 14: Semiquantitative Untersuchung der plaqueassoziierten Mikroglia in geschützt bestrahlten APP ${ }^{\text {swe/PS1 }}$ - Chimären

Abbildung 15: Morphologische Veränderungen der plaqueassoziierten Mikroglia in ungeschützt bestrahlten APP ${ }^{\text {swe/PS1 }}$ - Chimären.

Abbildung 16: Quantifizierung der nicht - plaqueassoziierten Mikroglia mit

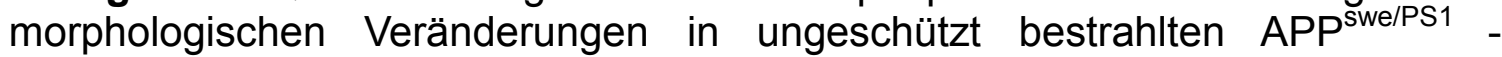
Chimären. 
Abbildung 17: Morphologische Veränderungen der nicht - plaqueassoziierten Mikroglia in ungeschützt bestrahlten APP ${ }^{\text {swe/PS1 }}$ - Chimären...........................40

Abbildung 18: Morphologische Veränderungen der mononukleären $\mathrm{GFP}^{+}$Phagozyten in APP ${ }^{\text {swe/PS1 }}$ - Chimären.................................................. 41

Abbildung 19: Veränderte Genexpression von Zytokinen und Chemokinen im Gehirn von ungeschützt bestrahlten APP ${ }^{\text {swe/PS1 }}$ - Chimären........................... 42

Abbildung 20: Biochemische Quantifizierung des $A \beta$ und seiner Anaboliten im Gehirn von ungeschützt bestrahlten APP ${ }^{\text {swe/PS1 }}$ - Chimären........................... 44

Abbildung 21: Semiquantitative Untersuchung der $A \beta$ - immunreaktiven Fläche im Gehirn von ungeschützt bestrahlten APP ${ }^{\text {swe/PS1 }}$ - Chimären.

Abbildung 22: Biochemische Quantifizierung des $A \beta$ und seiner Anaboliten im Gehirn von $\mathrm{CCR}^{-/-}$- GFP $\rightarrow \mathrm{APP}^{\text {swe/PS1 }}$ - Chimären. 


\section{Einleitung}

\subsection{Morbus Alzheimer}

\subsubsection{Epidemiologie}

Der Morbus Alzheimer ist mit einem Anteil von $70 \%$ die häufigste Ursache für eine Demenz, gefolgt von der Vaskulären Demenz mit $17 \%$. Die verbleibenden $13 \%$ teilen sich die Parkinson - Demenz, die Lewy - Körper - Demenz, die Frontotemporale Demenz und der Normaldruckhydrozephalus (Alzheimer's Association 2009). Die Prävalenz des Morbus Alzheimer in Deutschland beträgt für Menschen im Alter zwischen 65 und 100 Jahren 33 \% für Männer und 45 \% für Frauen (Jellinger 2001) und weist auf der ganzen Welt keine größeren Unterschiede auf (Qiu CX et al. 2007). Durch eine Zunahme der Lebenserwartung wird sich die Zahl der Betroffenen weiter steigern, so dass sich bei dieser Erkrankung, deren wichtigster Risikofaktor das Alter ist, eine stark zunehmende Belastung des Gesundheitssystems ergibt. Aufgrund der höheren weiblichen Lebenserwartung leiden $16 \%$ aller Frauen über 71 Jahren, aber nur $11 \%$ aller Männer an einem Morbus Alzheimer (Alzheimer's Association 2009).

\subsubsection{Risikofaktoren und Genetik}

Der einzige bekannte genetische Risikofaktor der spontanen Form des Morbus Alzheimer (Late Onset Alzheimer Disease, LOAD) ist das ApoE- $\varepsilon 4$ - Allel, welches unter anderem eine Rolle im Lipidmetabolismus spielt und im Gehirn von Mikroglia und Astrozyten exprimiert wird (Strittmatter et al. 1993). Für Personen, die homozygot für das ApoE-ع4 - Allel sind (3\% der Bevölkerung), erhöht sich die Erkrankungswahrscheinlichkeit auf 90 \% bis zum Alter von 80 Jahren (Corder et al. 1993). Protektiv wirkt sich ein hohes Bildungsniveau durch eine kognitive Reserve aus (Mortimer et al. 2005).

Neben der spontanen Variante gibt es auch familäre Formen des Morbus Alzheimer, die durch einen autosomal - dominanten Erbgang und einen Erkrankungsbeginn zum Teil weit vor dem 65. Lebensjahr gekennzeichnet sind. Diese Variante macht zwar weniger als $1 \%$ aller Erkrankungen aus, doch hat sie, weil sie pathologisch und klinisch, mit Ausnahme des verfrühten Krankheitsbeginns, nicht von der spontanen Variante unterscheidbar ist, wichtige Einblicke zum Verständnis der Pathophysiologie 
gegeben. Mittlerweile sind über 20 krankheitsassoziierte Mutationen im Gen für das Amyloid Precursor Protein (APP) und über 130 Mutationen im Präsenilin - Gen 1 und 2 (PS1/2) beschrieben worden (Götz und Ittner 2008). Auf das APP - Gen ist man aufmerksam geworden, weil es auf Chromosom 21 liegt und man bei Trisomie - 21 Patienten eine Demenz mit neuropathologischen Veränderung ähnlich dem Morbus Alzheimer beobachtet hat, was man durch die 1,5 - fache Erhöhung der APP Genexpression erklärt (Tanzi und Bertram 2005).

\subsubsection{Symptome}

Wichtigstes klinisches Merkmal ist die progrediente Verschlechterung der Gedächtnisfunktion, welche bereits zu einem sehr frühen Krankheitsstadium auftritt. Im Verlauf zeigen sich Störungen höherer geistiger Funktionen wie Orientierungsstörungen, Sprachstörungen, Persönlichkeitsveränderungen bis hin zu psychiatrischen Symptomen, wie depressive Verstimmungen, paranoide Psychosen, Aggressivität und Unruhe. Im späten Stadium der Erkrankung kommen neurologische Herdsymptome wie Paresen, Hyperreflexie und Inkontinenz hinzu. Typisch ist, dass es den Patienten bei oberflächlicher Betrachtung lange gelingt, die Fassade eines psychiatrisch unauffälligen Menschen zu erhalten. Zur Abgrenzung von anderen Demenzen ist, neben der spezifischen Symptomkonstellation, die Tatsache wichtig, dass meist eine stetige Progredienz im Gegensatz zu einer fluktuierenden Symptomatik vorliegt (Möller et al. 2009).

\subsubsection{Amyloidhypothese und Pathophysiologie}

\subsubsection{Prozessierung und Abbau}

Die Amyloidhypothese besagt, dass ein Ungleichgewicht von $A \beta$ - Produktion und Abbau sowie die daraus folgende $A \beta$ - Akkumulation und - Aggregation die primären Ereignisse sind, die alle weiteren neuropathologischen Veränderungen wie z. B. das Auftreten von neurofibrillären Tangles und den Nervenzellverlust zur Folge haben (Hardy und Selkoe 2002). A $\beta$ ist ein Spaltprodukt des Amyloid Precurser Proteins (APP), welches als integrales Membranprotein ubiquitär im Körper exprimiert wird (Kumar et al. 2009). Das APP und seine Spaltprodukte erfüllen vielfältige physiologische Aufgaben, wie die Regulation des Überlebens und der Migration von Neuronen während der Gehirnentwicklung (Kim und Tsai 2009). An der 
Prozessierung des APP sind verschiedene Sekretasen beteiligt (Abb. 1). Nach Internalisierung des APP entstehen im Endosom durch die $\beta$ - Sekretase (BACE1) zunächst die beiden Fragmente APP-s $\beta$ und $\beta$-CTF. Der $y$ - Sekretase - Komplex, zusammengesetzt aus den 4 Untereinheiten Präsenilin1 oder 2, Nicastrin, APH1 und PEN2, setzt nun aus dem $\beta$-CTF durch intramembranöse Spaltung das $A \beta$ frei. Es hängt vom genauen Angriffspunkt der $\gamma$ - Sekretase $a b$, ob hierbei das $A \beta_{40}$ oder das $A \beta_{42}$ in den Extrazellulärraum sezerniert wird. $A \beta_{42}$ hat dabei eine deutlich stärkere Neigung zur Aggregation (Jarrett et al. 1993).

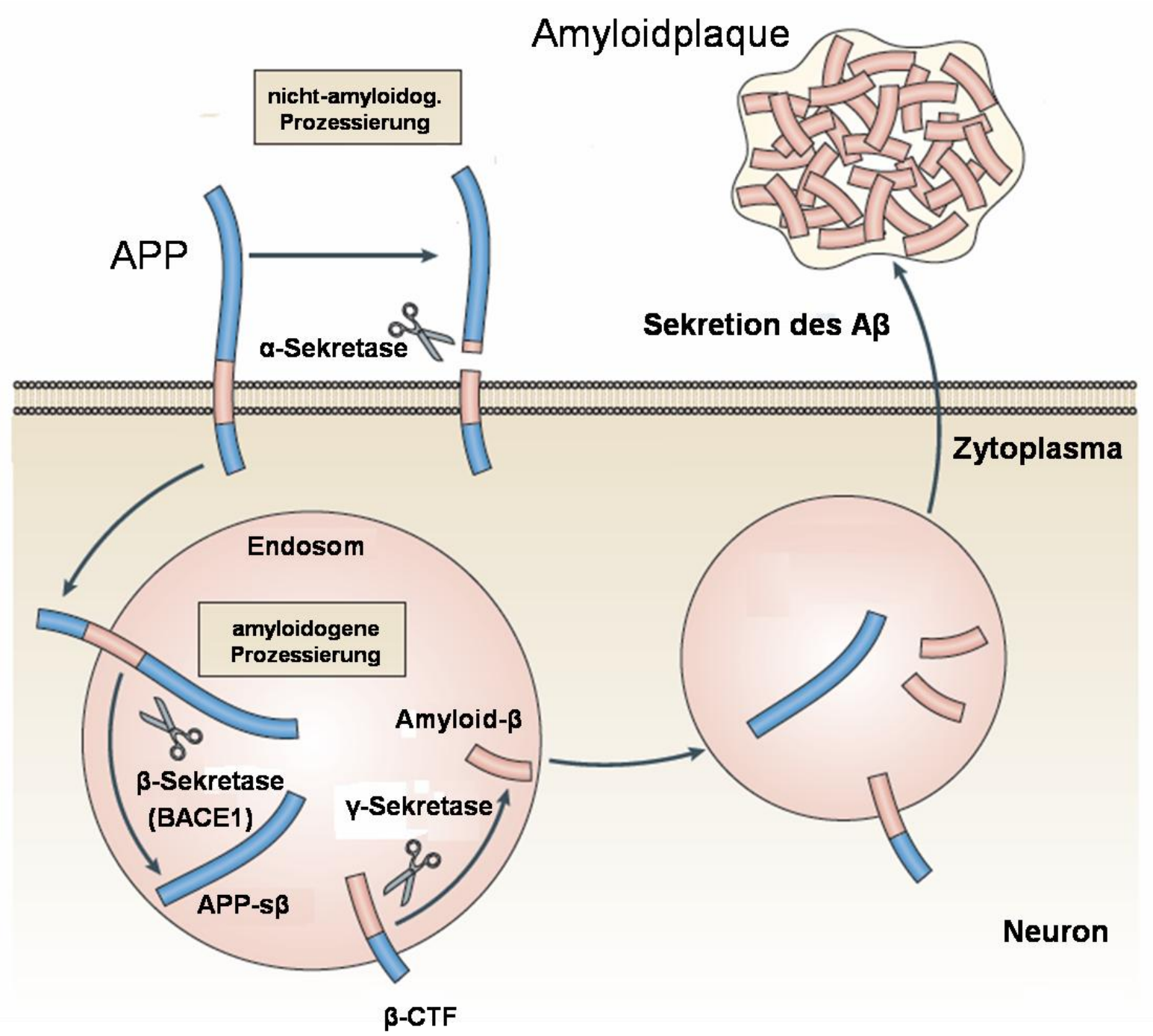

Abbildung 1: Die amyloidogene und nicht - amyloidogene APP - Prozessierung mit Bezeichnung der beteiligten Sekretasen und Spaltprodukte (modifiziert nach Rivest 2009, S. 435).

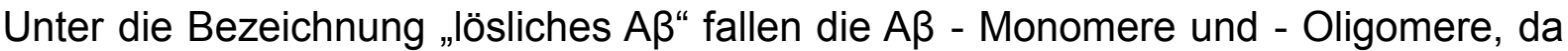
sie nach Zentrifugation in wässriger Lösung bleiben. Im Pellet befindet sich das 
unlösliche, fibrilläre $A \beta$ (Irvine et al. 2008). Die $\alpha$ - Sekretasen spalten das APP genau in der $A \beta$ - Region, sodass auf diesem Wege kein $A \beta$ mehr entstehen kann (Rivest 2009, Haass und Selkoe 2007).

Abgebaut wird das $A \beta$ durch proteolytische Enzyme und Phagozytose (Weiner und Frenkel 2006), was später eingehender erläutert wird. Ein zusätzlicher Mechanismus $\operatorname{der} A \beta$ - Elimination ist der Transport des $A \beta$ über die Bluthirnschranke in den Blutkreislauf (Deane et al. 2009).

\subsubsection{Toxizität}

Es ist nicht bekannt, auf welche Weise die Akkumulation von $A \beta$ zur Entwicklung kognitiver Defizite führt. Vermutlich setzt sich die Toxizität aus einer Vielzahl verschiedener Faktoren zusammen. Von den $A \beta$ - Aggregaten stehen besonders die Oligomere in Verdacht, für die Toxizität verantwortlich zu sein (Götz und Ittner 2008). Nur sie können im Hippocampus die Langzeitpotenzierung hemmen, die ein Maß für synaptische Plastizität und damit ein Korrelat des Lernens ist (Walsh et al. 2002, Shankar et al. 2008). Dieser Effekt wird zum Beispiel von dem auf Neuronen exprimierten zellulären Prion Protein $\left(\mathrm{PrP}^{\mathrm{c}}\right)$ vermittelt (Laurén et al. 2009). Für die Toxizität der Plaques spricht, dass in ihrer Nähe die neuronalen Fortsätze vermehrt morphologische Auffälligkeiten aufweisen (Tsai et al. 2004) und es zur Fehlfunktion von Synapsen kommt (Stern et al. 2004). Zusätzlich besteht noch die Möglichkeit, dass Plaques als Reservoire für lösliches $A \beta$ dienen (Martins et al. 2005). Auch für die im Rahmen der Entzündungsreaktion entstehenden freien Sauerstoff - Radikale und Zytokine ist die Neurotoxizität zumindest in vitro belegt (Weiner und Frenkel 2006). Schließlich wurde gezeigt, dass die A $\beta$ - Toxizität auch von der Anwesenheit von Tau, einem beim Morbus Alzheimer ebenfalls pathologisch abgelagerten Protein, abhängig ist (Rapoport et al. 2002).

\subsubsection{Neuropathologische Veränderungen}

Der bayerische Psychiater und Neuropathologe Alois Alzheimer stellte 1907 erstmals die These auf, dass neuropathologische Veränderungen ursächlich für die Entwicklung einer Demenz seien; im Einzelnen hatte er Veränderungen beobachtet, die heute als Amyloidplaques und neurofibrilläre Tangles bezeichnet werden (Morris und Salmon 2007, Tanzi und Bertram 2005). 
Bei den neurofibrillären Tangles handelt es sich auch um Proteinaggregate, die allerdings intrazellulär in Zellkörper, Dendriten und Axonen von Neuronen beobachtet werden und zudem auch im Rahmen anderer neurodegenerativer Erkrankungen auftreten. Das den Aggregaten zugrundeliegende Protein heißt Tau und hat eine Funktion bei der Stabilisierung und Regulation der Mikrotubuli, die wichtiger Bestandteil des Zytoskeletts von Zellen und deshalb auch entscheidend für den axonalen Transport sind. Beim Morbus Alzheimer ist dieses Tau - Protein in einer abnormen Weise phosphoryliert, wodurch es sich zunächst zu Doppelsträngen (paired helical filaments, PHF) und dann zu den neurofibrillären Tangles zusammen lagern kann. Endpunkt der neurofibrillären Neurodegeneration sind die so genannten ghost tangles, welche die Stelle eines untergegangenen Neurons markieren, aber keine zelluläre Reaktion auslösen (Duyckaerts et al. 2009, Querfurth und LaFerla 2010). Die Ausbreitung der neurofibrillären Tangles folgt anatomischen Bahnen und beginnt zunächst im medialen Temporallappen (entorhinaler Kortex, Hippocampus) und weitet sich später auf den Isokortex aus (Braak und Braak 1991).

Ein weiteres wichtiges Kennzeichen der Alzheimerschen Erkrankung ist der massive Verlust von Neuronen, der mit der Volumenreduktion des entsprechenden Hirngebiets einhergeht (Kril et al. 2004). Diese Atrophie kann bereits makroskopisch oder mit Hilfe der Kernspintomographie am Patienten beurteilt werden. Sie ist vor allem an den Stellen ausgeprägt, wo auch neurofibrilläre Tangles entstehen, was auf einen pathophysiologischen Zusammenhang hindeutet (Whitwell et al. 2008).

Die Amyloidplaques sind extrazelluläre Aggregate, die sich überwiegend aus $A \beta$ Peptiden zusammensetzen. Die $A \beta$ - Monomere lagern sich beim Überschreiten gewisser Konzentrationsschwellenwerte zunächst zu Oligomeren, später zu Fibrillen zusammen. Diese ordnen sich innerhalb von 24 Stunden (Meyer - Luehmann et al. 2008) nach dem Prinzip der $\beta$ - Faltblattstruktur zu den mikroskopisch sichtbaren Plaques an (Querfurth und LaFerla 2010). Klassischerweise bestehen die Plaques aus einem dichten Kern und einer diffusen Peripherie (Halo). Die darüber hinaus auftretenden, diffusen Ablagerungen spielen pathophysiologisch keine Rolle (Perrin et al. 2009). Hervorzuheben ist, dass sich zum Teil auch im alternden Gehirn von gleichaltrigen nicht - dementen Menschen eine signifikante Erhöhung der Amyloidablagerungen feststellen lässt (Rodrigue et al. 2009). Amyloidplaques werden zunächst nur im Isokortex gefunden und im Verlauf dann im Hippocampus und entorhinalen Kortex und breiten sich schließlich auch im Dienzephalon, Hirnstamm 
und Kleinhirn aus (Thal et al. 2002). Die in der Umgebung der Plaques gelegenen Neurone weisen morphologische Veränderungen auf, die zum Ausdruck der neuritischen Plaques geführt haben (Duyckaerts et al. 2009). Die dystrophen Neuriten sind axonal und weisen vesikuläre Auftreibungen sowie eine abnorme Krümmung in Plaquenähe auf, was durch eine Störung des axonalen Transports erklärt wird (Serrano - Pozo et al. 2010, Stokin et al. 2005).

Ein weiteres plaqueassoziiertes Phänomen ist die lokale, zelluläre Reaktion, die sich durch die Rekrutierung und Aktivierung von Mikroglia und Astrozyten auszeichnet (Weiner und Frenkel 2006). Damit verbunden ist die Ausschüttung proinflammatorischer Mediatoren, wie beispielsweise der Zytokine IL-1 $\beta$, IL-6, TNF- $\alpha$, der Chemokine CCL2, CCL3 und CXCL10 (Akiyama et al. 2000) oder der Faktoren des Komplementsystems, wobei allerdings auch zum Teil ein neuronaler Ursprung zugrunde liegt (McGeer und McGeer 2001).

Es wurden verschiedene neuropathologische Kriterien entwickelt, die die Diagnose des Morbus Alzheimer mit hoher Wahrscheinlichkeit erlauben. Die CERAD - Kriterien umfassen eine semiquantitative Bestimmung der Dichte der neurititschen Plaques in definierten Hirnregionen. Altersadaptiert erfolgt schließlich die Einteilung in einen sicheren, wahrscheinlichen oder möglichen Morbus Alzheimer (Mirra et al. 1993). In der Stadieneinteilung nach Braak und Braak werden zusätzlich zu den Amyloidplaques auch die neurofibrillären Tangles quantifiziert, wobei hier auch die zeitliche und lokale Ausbreitung der verschiedenen alzheimertypischen Merkmale über das ZNS berücksichtigt wird (Braak und Braak 1991, Thal et al. 2000, Jellinger 2001).

\subsection{Mikroglia}

\subsubsection{Morphologie, Aktivierung und Funktion}

Mikroglia sind die residente Makrophagenpopulation des zentralen Nervensystems und repräsentieren etwa $10 \%$ der Zellen des ZNS (Weiner und Frenkel 2006). Morphologisch sind sie gekennzeichnet durch einen runden bis ovalen Kern und dünne, in alle Richtungen stark verzweigte Fortsätze. Diese sind im nicht - aktivierten Zustand hoch dynamisch und tasten die Umgebung kontinuierlich nach pathologischen Veränderungen ab (Nimmerjahn et al. 2005, Davalos et al. 2005). Treffen sie auf eine solche, verändert sich die Morphologie: Die Zahl der Fortsätze 
nimmt ab, der Zellkörper schwillt an und die proximalen Fortsätze werden dicker (Nimmerjahn et al. 2005). Außerdem wird die Expression bestimmter Oberflächenmarker beeinflusst und eine große Zahl von Signalmolekülen ausgeschüttet (Raivich et al. 1999). Allerdings kam man in den letzten Jahren vermehrt zur Erkenntnis, dass die Aktivierung von Mikroglia ein sehr heterogener Prozess ist. Entscheidend ist dabei, wodurch die Mikroglia aktiviert werden. So führt die Phagozytose von apoptotischen Zellen und Myelin über antiinflammatorische Zytokine wie IL-10 oder TGF- $\beta 1$ eher zu regenerativen Prozessen (alternative Aktivierung), wohingegen die Aktivierung durch bakterielle Antigene zu einer proinflammatorischen Immunantwort mit neurotoxischen Zytokinen und reaktiven Sauerstoffspezies führt (Hanisch und Kettenmann 2007, Colton 2009). Damit Mikroglia auf ein breites Spektrum an Pathogenen reagieren können, verfügen sie über ein großes Repertoire an Oberflächenrezeptoren, wie Toll - like - Rezeptoren, Purinorezeptoren oder Scavenger - Rezeptoren (Graeber und Streit 2010). Als zentraler Bestandteil des angeborenen Immunsystems im ZNS sind Mikroglia bei der Abwehr infektöser Erreger beteiligt, aber auch elementarer Bestandteil der Pathogenese von Autoimmunerkrankungen des ZNS und neurodegenerativen Erkrankungen.

\subsubsection{Mononukleäre Phagozyten}

Mononukleäre Phagozyten entstehen im Knochenmark und gehören zur myeloischen Zellreihe. Zu diesen werden drei Hauptpopulationen gezählt, wobei diese allerdings noch in diverse Untergruppen klassifiziert werden können: zirkulierende Monozyten, Gewebemakrophagen und dendritische Zellen (Geissmann et al. 2010). Im Gegensatz zu den ausdifferenzierten dendritischen Zellen und Gewebemakrophagen stellen Monozyten eine Vorläuferzellpopulation dar, die sich unter bestimmten physiologischen als auch pathologischen Bedingungen $\mathrm{zu}$ den ausgereiften Phagozyten differenzieren kann (Landsman und Jung 2007, Mildner et al. 2007). Unter den im weiteren Verlauf als mononukleäre Phagozyten bezeichneten Zellen sind in dieser Arbeit die bereits ins ZNS eingewanderten hämatopoietischen Zellen in Abgrenzung zu den im Blut zirkulierenden Monozyten zu verstehen. Auch die im ZNS lokalisierten Mikroglia fallen als Gewebemakrophagen in die Gruppe der mononukleären Phagozyten; ein mesenchymaler Ursprung der embryonal 
einwandernden Mikroglia ist allgemein akzeptiert (Prinz und Mildner 2010, Ginhoux et al. 2010). Im Gegensatz zu diesen embryonalen Mikroglia konnte mit Knochenmarkstransplantationen in Mäusen gezeigt werden, dass myeloische Zellen postnatal in das gesunde ZNS migrieren, um sich dort in mikrogliaartige Zellen zu differenzieren (Priller et al. 2001). Nach der Rekrutierung ins Gehirn entwickeln die mononukleären Phagozyten, die sich zunächst durch eine runde Morphologie auszeichnen, die für Mikroglia typische Ramifizierung und exprimieren dieselben Oberflächenmerkmale (Priller et al. 2001). Mit dieser Methode konnte in zahlreichen Tiermodellen von ZNS - Pathologien, wie dem Morbus Parkinson, der Multiplen Sklerose, dem Schlaganfall und der traumatischen neuronalen Schädigung eine erhöhte Anzahl Zellen mit hämatopoietischem Ursprung gefunden werden (Yong und Rivest 2009).

Inwieweit dies auch unter physiologischen Bedingungen geschieht, wird gegenwärtig kontrovers diskutiert (Prinz und Mildner 2010). Die Kritik basiert auf dem Fakt, dass bei den Knochenmarkstransplantationsexperimenten eine letale Bestrahlung des Rezipienten notwendig ist, um die endogenen hämatopoietischen Stammzellen im Knochenmark abzutöten. Erst nach dieser Konditionierung kann das neu transferierte Knochenmark anwachsen und proliferieren. Inzwischen wurde jedoch gezeigt, dass in Knochenmarkschimären, deren Kopf vor der Bestrahlung geschützt wurde, keine hämatopoietischen Zellen ins ZNS einwandern (Mildner et al. 2007). Auch in Parabioseexperimenten, bei denen die Blutkreisläufe zweier Mäuse miteinander verbunden wurden und eine der Mäuse einen genetischen Marker besitzt, der das Auffinden der Zellen im anderen Organismus erlaubt, konnten ebenfalls keine eingewanderten Zellen im ZNS gefunden werden (Ajami et al. 2007). Beide Studien legen nahe, dass die Einwanderung mononukleärer Phagozyten von den experimentellen Bedingungen abhängig ist und nicht physiologischerweise zur Population der residenten embryonalen Mikroglia beiträgt.

$\mathrm{Ob}$ es funktionelle Unterschiede zu den residenten embryonalen Mikroglia gibt, ist weitgehend unklar. In einer Studie konnte gezeigt werden, dass in einem Tiermodell der traumatischen Rückenmarksverletzung die mononukleären Phagozyten eine antiinflammatorische Rolle spielen und im Gegensatz zu den residenten Mikroglia an Reparaturvorgängen beteiligt sind (Shechter et al. 2009).

Die monozytären Vorläuferzellen dieser knochenmarksabgeleiteten, mikrogliaartigen Phagozyten im ZNS in der Maus werden als inflammatorische Monozyten bezeichnet 
und sind durch folgende Oberflächenproteine charakterisiert: Ly-6 $C^{\text {hi }}, C C R 2^{+}$, $\mathrm{CX}_{3} \mathrm{CR}^{\text {low }}$ (Mildner et al. 2007). Sie werden ausschließlich im Rahmen von entzündlichen Prozessen in periphere Organe rekrutiert. Ihnen gegenüber stehen die residenten Monozyten ( $\mathrm{Ly}-6 \mathrm{C}^{\text {low }}, \mathrm{CCR} 2^{-}, \mathrm{CX}_{3} \mathrm{CR} 1^{\text {hi }}$ ), die zum physiologischen Grundumsatz der Gewebemakrophagen wie zum Beispiel der Alveolarmakrophagen beitragen (Landsman und Jung 2007). Die genetische Ausschaltung des murinen Chemokinrezeptors CCR2 bewirkt, dass die inflammatorischen Monozyten im Blut drastisch reduziert sind, da sie das Knochenmark nicht verlassen können (Serbina und Pamer 2006). Dadurch hat man ein Werkzeug, das eine Aussage darüber ermöglicht, ob die inflammatorischen Monozyten als Vorläuferzellen für die mononukleären Phagozyten des ZNS dienen.

\subsubsection{Rolle der residenten Mikroglia beim Morbus Alzheimer}

Mikroglia migrieren innerhalb von 1 - 2 Tagen nach Plaqueentstehung zur Plaque und sezernieren Chemokine, die zu einer weiteren Rekrutierung von Mikroglia führen (Meyer - Luehmann et al. 2008, Rogers und Lue 2001). Die Aktivierung der Mikroglia durch $A \beta$ - Plaques ist mit morphologischen Veränderungen verbunden und hat sowohl nützliche als auch schädliche Auswirkungen (Weiner und Frenkel 2006).

Schädigenden Einfluss haben sie durch die zelluläre Reaktion, in deren Rahmen die induzierbare NO - Synthetase (iNOS) verstärkt exprimiert wird. Dies geschieht teils direkt durch fibrilläres $A \beta$, teils durch Vermittlung von TNF- $\alpha$ (Weiner und Frenkel 2006). NO gehört zu den freien Radikalen und löst in Neuronen in vivo und in vitro Apoptose aus (Weldon et al. 1998, Combs et al. 2001). Die freigesetzten inflammatorischen Zytokine, wie IL-1 $\beta$ und TNF- $\alpha$, reduzieren zusätzlich die phagozytotische Kapazität der Mikroglia (Koenigsknecht - Talboo und Landreth 2005).

$\mathrm{Zu}$ den nützlichen Eigenschaften der Mikroglia zählt die Fähigkeit $A \beta$ abzubauen. Mikroglia verfügen über ein breites Repertoire an Oberflächenrezeptoren für die $A \beta$ Phagozytose. Die Fc - und Komplement - Rezeptoren sind abhängig von der Antikörper - beziehungsweise Komplementbindung am $A \beta$. Die Phagozytose durch direkte Bindung des fibrillären $A \beta$ geschieht durch TLR2 und TLR4 in Kombination mit dem Korezeptor CD14 sowie $\alpha_{6} \beta_{1}$-Integrine und Scavenger - Rezeptoren der Gruppe A und B (Reed - Geaghan et al. 2009). Die Pinozytose von Iöslichem A $\beta$ 
durch Mikroglia ist ebenfalls beschrieben (Mandrekar et al. 2009). Mikroglia sezernieren außerdem Proteasen, wie Neprilysin oder Insulysin, die A $\beta$ - Monomere zersetzen können (Qiu WQ et al. 1998, Walsh et al. 2002, Meilandt et al. 2009)

Problematisch ist, dass die Mehrzahl dieser Phagozytose - Experimente nur in vitro durchgeführt wurde. In Alzheimertiermodellen konnte hingegen gezeigt werden, dass $\operatorname{der} A \beta$ - Abbau ineffektiv ist. Eine nahezu komplette Depletion der Mikroglia zeigte in einem Kurzzeit - in - vivo - Experiment in einem späten Stadium eines Alzheimertiermodells keinen Einfluss auf Plaquewachstum oder - reduktion (Grathwohl et al. 2009). Auch auf zellbiologischer Ebene wurde gezeigt, dass eine Degradation von phagozytiertem, fibrillärem $A \beta$ nicht erfolgreich ist und zu strukturellem Schaden der Lysosomen mit Freisetzung lysosomaler Proteasen ins Zytoplasma und sukzessiver proinflammatorischer Reaktion führt (Halle et al. 2008). Eine mögliche Erklärung für diese Dysfunktion ist die Hypothese, dass die Mikroglia aufgrund von Alterungsvorgängen verstärkt zur proinflammatorischen Reaktion neigen und die Phagozytose eingeschränkt ist, was zur Ablagerung von $A \beta$ führt (Luo et al. 2010).

Allerdings zeigt die Tatsache, dass Mikroglia bei der passiven $A \beta$ - Immunisierung Plaques tatsächlich stark in ihrer Größe reduzieren können (Bacskai et al. 2001), dass eine effektive Phagozytose nicht grundsätzlich ausgeschlossen ist, sondern eher von der Art der Aktivierung abhängig ist (Luo et al. 2010).

Wann Mikroglia nun protektive oder schädigende Funktion haben, ist unbekannt. Bei der Erklärung müssen aber verschiedene Arten der Aktivierung und deren zeitlicher Ablauf berücksichtigt werden (Colton 2009).

\subsubsection{Rolle der mononukleären Phagozyten beim Morbus Alzheimer}

In verschiedenen Alzheimertiermodellen konnte gezeigt werden, dass hämatopoietische Zellen ins ZNS rekrutiert werden, zu den Plaques wandern und dort mikrogliaartige Morphologie und Oberflächenmerkmale annehmen (Malm et al. 2005, Simard et al. 2006). Im Rahmen dieser Versuche wurde allerdings immer mit Knochenmarkschimären gearbeitet, wodurch eine Aussage über die physiologische Rolle von hämatopoietischen Zellen in Alzheimertiermodellen nicht möglich ist (Cameron und Landreth 2010). Wie auch bei anderen ZNS - Pathologien, finden sich in den Alzheimertiermodellen eine erhöhte Anzahl hämatopoietischer Zellen im Gehirn (Malm et al. 2005, Stalder et al. 2005). Postuliert wurde, dass diese hämatopoietischen Zellen einen günstigen Einfluss durch die Phagozytose von $A \beta$ 
nehmen (Town et al. 2008, Malm et al. 2008, Boissoneault et al. 2008). Erbracht wurde der direkte Beweis allerdings erst durch die Depletion der mononukleären Phagozyten mit anschließender Zunahme der Plaquezahl und - fläche (Simard et al. 2006). Im direkten in - vitro - Vergleich von Mikroglia und Makrophagen wurde in letzteren ein deutlich niedrigerer lysosomaler $\mathrm{pH}$ - Wert festgestellt, was die Degradierung von fibrillärem $A \beta$ erleichtert (Majumdar et al. 2007). Wenn es diese Makrophagen mit ihrer höheren $A \beta$ - Phagozytosekapazität schaffen, in das Gehirn zu gelangen, könnten sie das $A \beta$ effizienter phagozytieren als die endogenen Mikroglia und dadurch von therapeutischem Nutzen sein. 


\subsection{Zielsetzung}

Im Rahmen dieser Arbeit sollen folgende Fragen beantwortet werden:

1. Aus welchen hämatopoietischen Vorläuferzellen entstehen die postnatal eingewanderten, mononukleären Gewebemakrophagen im Gehirn von APP ${ }^{\text {swe/PS1 }}$ - Tieren?

2. Unter welchen Bedingungen können sie das Blut verlassen und in das zentrale Nervensystem einwandern?

3. Welche Auswirkungen haben die zur Herstellung von Knochenmarks chimären benötigte Bestrahlung und die endogenen Mikroglia auf das Hirnmilieu und die Alzheimerpathologie?

4. Kann eine Hirnbestrahlung allein den $A \beta$ - Gehalt beeinflussen?

5. Wie verändert sich der $A \beta$ - Gehalt in der Abwesenheit rekrutierter hämatogener Zellen? 


\section{Materialien und Methoden}

2.1 Chemikalien, Enzyme, Antibiotika, Reinigungssysteme und Tiere

Herstellung von

Produkt Hersteller

Knochenmarkschimären

$\begin{array}{ll}\text { DMEM } & \text { Invitrogen, Karlsruhe, D } \\ \text { Penicillin } & \text { Biochrom, Berlin, D } \\ \text { Streptomycin } & \text { Biochrom, Berlin, D } \\ \text { Cotrimoxazol } & \text { Biochrom, Berlin, D }\end{array}$

Durchflusszytometrie

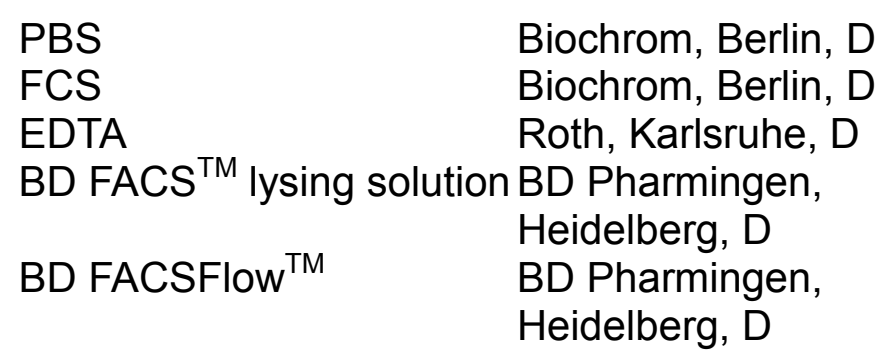

qRT-PCR

RNAlater
RNeasy ${ }^{\circledR}$ Mini Kit
Qiashredder
B-Mercaptoethanol
DNase I
DNase Buffer
RNase Inhibitor RNasin
5x Buffer
dNTP
DTT
Reverse Transkriptase
SuperScript
SYBR ${ }^{\circledR}$ Green
Fluorescein Mix

Gefrierschnitte
PFA

Sucrose

Tissue - Tek, O.C.T.

Compound

FCS

Triton X-100

DAKO Fluorescence

Mounting Medium
Qiagen, Hilden, D

Qiagen, Hilden, D

Qiagen, Hilden, D

Sigma, München, D

Roche Diagnostics,

Mannheim, D

Roche Diagnostics,

Mannheim, D

Promega, Madison, USA

Invitrogen, Karlsruhe, D

Fermentas St. Leon-Rot,

D

Invitrogen, Karlsruhe, D

Invitrogen, Karlsruhe, D

Thermo Scientific, Hamburg, D

Merck, Darmstadt, D

Sigma, München, D

Satura Finetek, Zoeterwoude, NL Biochrom, Berlin, D Sigma, München, D DAKO, Hamburg, D 
Genotypisierung

$\begin{array}{ll}\text { Isopropanol } & \text { Applichem, Darmstadt, } \\ & \text { D } \\ \text { Proteinase K } & \text { Roche Diagnostics, } \\ & \text { Mannheim, D } \\ \text { TrisHCl } & \text { Roth, Karlsruhe, D } \\ \text { EDTA } & \text { Roth, Karlsruhe, D } \\ \mathrm{NaCl} & \text { Merck, Darmstadt, D } \\ \text { SDS } & \text { Sigma, München, D } \\ \text { Ethanol } & \text { Merck, Darmstadt, D } \\ & \\ \text { GoTaq Flexi Buffer } & \text { Promega, Mannheim, D } \\ \text { MgCl } 2 & \text { Promega, Mannheim, D } \\ \text { dNTP } & \text { Fermentas St. Leon-Rot, } \\ & \text { D } \\ \text { GoTaq Polymerase } & \text { Promega, Mannheim, D } \\ \text { Agarose } & \text { Starlab GmbH, } \\ \text { Ethidiumbromid } & \text { Ahrensburg, D } \\ \text { PBS } & \text { Sigma, München, D } \\ & \text { Biochrom, Berlin, D } \\ \text { APPswe/PS1 } & \text { Referenz/Hersteller } \\ & \text { The Jackson Laboratory, } \\ \text { EGFP ACTß } & \text { USA } \\ \text { CCR2-/- } & \text { The Jackson Laboratory, } \\ \text { C57BL/6 } & \text { USA } \\ & \text { Kuziel et al. 1997 } \\ \text { Charles River, USA }\end{array}$

verwendete Mausmodelle B6.Cg-Tg(APPswe,PSEN1dE9) $85 \mathrm{Dbo} / \mathrm{J}$ C57BL/6-Tg(CAG-EGFP)1Osb/J

\subsection{Das APP ${ }^{\text {swe }} /$ PS1-dE9 - Tiermodell des Morbus Alzheimer}

In dieser Arbeit wurden doppeltransgene Mäuse verwendet, die sowohl die humanisierte Form des APP - Gens mit der schwedischen Mutation (APP ${ }^{\text {swe }}$ ) als auch das Gen für humanes Präsenilin mit der Deletion von Exon 9 tragen (PS1-dE9). Bei der schwedischen Mutation handelt es sich um eine 695 - Aminosäuren - lange Form des APP, welche sich durch den Austausch zweier Aminosäuren (Lys ${ }^{595} \rightarrow$ Asn, $\mathrm{Met}^{596} \rightarrow$ Leu) auszeichnet. Diese Mutation bewirkt eine vermehrte Entstehung des $A \beta$ - Spaltprodukts über die Prozessierung durch die $\beta$ - Sekretase (Citron et al. 1994). Die Mutation im Präsenilin - Gen, dessen Protein Bestandteil des Y - Sekretase Komplexes ist, führt zu einer vermehrten Produktion des stärker pathogenen $A \beta_{42}$ (Borchelt et al. 1996, Jankowsky et al. 2004). Diese Mutationen wurden bei Patienten entdeckt, die an seltenen, erblichen Varianten des Morbus Alzheimer erkrankt sind 
und für die ein früher Krankheitsbeginn typisch ist (Mullan et al. 1992). Beide Mutationen sind an einem Locus lokalisiert und stehen jeweils unter Kontrolle des Maus - Prionprotein - Promoterelements, das die Expression von APP ${ }^{\text {swe }} / P S 1-d E 9$ in allen Zellen reguliert, am höchsten jedoch in Neuronen und Astrozyten (Garcia Alloza et al. 2006). Die Kombination dieser beiden Mutationen verstärkt die A $\beta$ Ablagerung im Gehirn und führt zum erstmaligen Auftreten der Plaques bereits nach 4 - 6 Monaten und einer zerebralen Amyloidangiopathie ab dem 6. Monat (Garcia Alloza et al. 2006). Ähnlich wie bei dem Morbus Alzheimer finden sich um die Plaques herum zahlreiche Mikroglia und Astrozyten mit Zeichen reaktiver Veränderungen (Malm et al. 2007, Ruan et al. 2009). An den in der Nähe von Plaques gelegenen Neuronen lassen sich in diesem Alzheimertiermodell zahlreiche morphologische Veränderungen beobachten. Dies betrifft zum einen eine Reduktion der dendritischen Spines und eine veränderte Architektur des Dendritenbaumes, zum anderen auch dystrophe bis hin zu unterbrochenen Neuriten, die in Plaquenähe variköse Auftreibungen zeigen (Tsai et al. 2004, Spires et al. 2005, Knafo et al. 2009a, Knafo et al. 2009b). Zusätzlich findet man in ähnlichen Tiermodellen auch eine Beeinträchtigung synaptischer Signalübertragung (Stern et al. 2004), wie beispielsweise eine neuronale Hyperaktivität selektiv in der Nähe von Plaques (Busche et al. 2008) und eine Veränderung astrozytärer Netzwerke (Kuchibhotla et al. 2009). In dem Morris Water Maze, einem Modell für visuell - räumliches Lernen und Gedächtnis sowie in einem Modell für auditorische Angstkonditionierung konnten auch auf Verhaltensebene kognitive Defizite beobachtet werden, die mit denen von Alzheimerpatienten vergleichbar sind (Savonenko et al. 2005, Knafo et al. 2009a, O'Leary und Brown 2009).

Trotz dieser vielen Ähnlichkeiten spiegelt dieses hier verwendete Tiermodell nicht vollständig die Merkmale des Morbus Alzheimer wider. Die ausgeprägte Atrophie des Temporallappens, bedingt durch ein Zugrundegehen von Nervenzellen, fehlt (Oh et al. 2009), beziehungsweise konnte nur für einige kleine Hirnregionen gezeigt werden (O'Neil et al. 2007). Ein weiterer entscheidender Unterschied ist zudem, dass in diesem Tiermodell keine neurofibrillären Tangles gefunden wurden (Duyckaerts et al. 2008), was (bisher ungeklärte) Fragen hinsichtlich des kausalen Zusammenhangs von $A \beta$ - und Tau - Pathologie aufwirft. Dieses Modell eignet sich folglich nur zur Untersuchung der $\beta$ - Amyloidopathie. 


\subsection{Herstellung von Knochenmarkschimären}

Das Prinzip:

Mit dieser Methode ist es möglich, zwischen dem bestrahlungssensitiven, hämatopoietischen Kompartiment und dem radioresistenten Kompartiment zu unterscheiden. Da es in unserem Fall um das ZNS geht, entspricht das radioresistente Kompartiment den residenten Mikroglia, die aufgrund ihrer geringen Proliferationsrate durch die Bestrahlung nicht betroffen sind. Unter normalen Umständen kann man residente Mikroglia und eingewanderte mononukleäre Phagozyten nicht unterschieden, weil sie sich durch ähnliche Oberflächenmerkmale auszeichnen. Durch den Austausch des hämatopoietischen Kompartiments mit nachverfolgbaren Zellen wird diese Unterscheidung möglich. Voraussetzung für diesen Knochenmarkschimärismus ist, dass man eine Knochenmarkstransplantation durchführt. Die dafür benötigten hämatopoietischen Stammzellen werden aus dem Knochenmark von genetisch markierten Tieren, zusammen mit sämtlichen weiteren Entwicklungsstufen hämatopoietischer Zellen, gewonnen und anschließend dem Empfänger intravenös injiziert. In unserem Falle wurde dafür eine gentechnisch veränderte Mauslinie benutzt, bei der ein EGFP - Protein unter der Kontrolle des $\beta$ Actin (ACT $\beta$ ) - Promoters exprimiert wird (im Folgenden als GFP bezeichnet) (Ballestrem et al. 1998). Da ACT $\beta$ ein Zytoskelettprotein ist, das in fast jeder eukaryotischen Zelle des Organismus exprimiert wird, fluoresziert das transgene Tier unter Anregung von Licht der Wellenlänge $488 \mathrm{~nm}$ grün. Die Donorzellen im Empfängertier lassen sich auf diese Weise unter einem Fluoreszenzmikroskop ohne eine zusätzliche immunhistochemische Färbung beobachten.

Die Konditionierung der Tiere erfolgt mit einer letalen Strahlendosis, welche die endogenen, hämatopoietischen Zellen deletiert und den neu injizierten, genetisch veränderten Stammzellen die Möglichkeit gibt, sich in den entsprechenden Knochenmarksnischen anzusiedeln.

Als Kontrolle werden Mäuse verwendet, die zwar rekonstituiert sind, deren Kopf aber von der Bestrahlung ausgenommen wurde (geschützt bestrahlt) sowie Tiere, die zwar am ganzen Körper bestrahlt wurden, aber dafür Spenderknochenmark von CCR2 - Knockout - Mäusen $\left(\mathrm{CCR} 2^{-/}\right)$, die mit ACT - GFP - Mäusen gekreuzt wurden, erhalten haben (Abb. 2). Bei beiden Varianten findet man eine drastische Reduktion der ramifizierten, eingewanderten GFP ${ }^{+}$- Phagozyten im Gehirn (Mildner et al. 2007). 


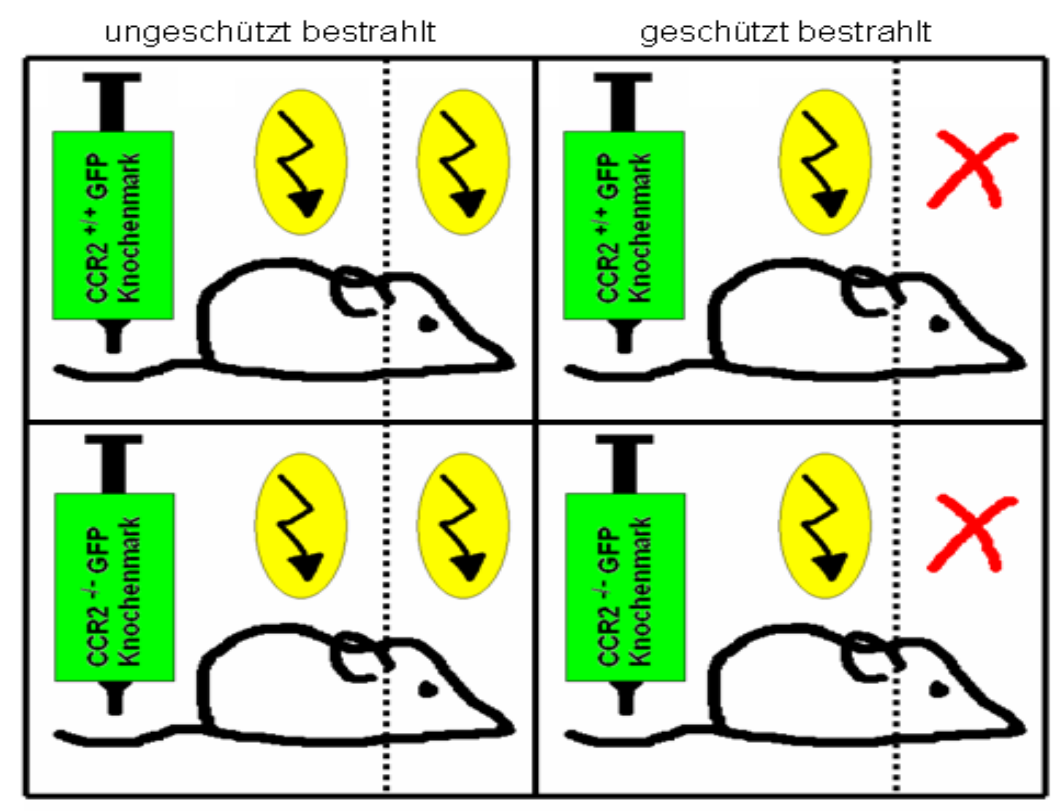

Abbildung 2: Schematische Darstellung der verschiedenen Knochenmarkschimären. Die linke Spalte zeigt die ungeschützt bestrahlten Tiere, die rechte Spalte zeigt die kopfgeschützt bestrahlten Tiere. Die obere Spalte zeigt die Tiere mit Injektion von Wildtyp - CCR2 ${ }^{++}$- GFP Knochenmark, die untere Spalte zeigt die Tiere mit Injektion von CCR2 - Knockout (CCR2 ${ }^{-1}$ ) GFP - Knochenmark.

Da allerdings in den geschützt bestrahlten Tieren aufgrund fehlender Rekonstitution in den blutbildenden Schädelknochen niedrigere Chimärismusraten erreicht würden, muss die Menge des injizierten ACT - GFP - Knochenmarks in den ganzkörperbestrahlten Tieren angepasst werden, um vergleichbare Rekonstitutionslevel zu erhalten. Daher enthält bei den ungeschützt bestrahlten Tieren das Donor Knochenmark nur $60 \%$ ACT $\beta$ - GFP - Knochenmark und $40 \%$ Wildtyp Knochenmark von C57BL/6 - Tieren im Vergleich zu $100 \%$ ACT $\beta$ - GFP Knochenmark in geschützt bestrahlten Tieren. Bei den mit CCR2 - defizientem Knochenmark rekonstituierten Tieren wurde eine Reduktion der inflammatorischen Monozyten beobachtet. Zum Erreichen gleicher Chimärismuslevel wurde kompensatorisch das CCR2 ${ }^{+/+}$- GFP - Knochenmark ebenfalls mit $40 \%$ Wildtyp Knochenmark gemischt.

\section{Die Durchführung:}

Zur Bestrahlung wurden die etwa 3 Monate alten Tiere mit 100 mg/kg Körpergewicht Ketamin und $5 \mathrm{mg} / \mathrm{kg}$ Körpergewicht Rompun narkotisiert. Um eine exakte Bestrahlung zu gewährleisten, wurden die Tiere in einer speziell angefertigten 
Plexiglas - Kammer $(20 \mathrm{~cm}$ x $20 \mathrm{~cm} \times 3 \mathrm{~cm}$ ) fixiert und mit einem 6 - MeV - Röntgen Varian - Linearbeschleuniger mit einer Dosis von 11 Gy und mit parallelen, entgegengesetzten Feldern bestrahlt. Die maximale Dosis wirkte in 1,5 cm Tiefe. Zur geschützten Bestrahlung wurde das Bestrahlungsfeld auf $14 \mathrm{~cm} \times 20 \mathrm{~cm}$ verkleinert, so dass sich der Kopf mit einem Sicherheitsabstand von 0,5 cm der Bestrahlung entzog.

Das Knochenmark wurde unter sterilen Bedingungen gewonnen, indem die Femura und Tibiae der erwachsenen Tiere gleichen Geschlechts freipräpariert und mit einer $27 G$ - Kanüle punktiert wurden, um das Knochenmark mit DMEM herausspülen zu können. Dem Medium war Penicillin und Streptomycin zur Infektionsprophylaxe beigesetzt. Die Zellsuspension wurde mit einem 40 - $\mu \mathrm{m}$ - Sieb filtriert und auf Eis gelagert. Mit Hilfe einer Neubauer - Zählkammer wurde die Zellzahl bestimmt. Nach einer Zentrifugation mit $1100 \mathrm{rpm}$ bei $4{ }^{\circ} \mathrm{C}$ für 7 Minuten wurde der Überstand verworfen und die Zellzahl mit DMEM auf 1,6 x $10^{7}$ Zellen/ml eingestellt. $300 \mu \mathrm{der}$ Knochenmarkszellsuspension wurden 24 Stunden nach der Bestrahlung mit einer $30 G$ - Kanüle intravenös in die laterale Schwanzvene injiziert.

Zur weiteren Infektionsprophylaxe wurde dem Trinkwasser für 10 Tage das Antibiotikum Cotrimoxazol, eine Kombinationspräparat aus Trimethoprim und Sulfamethoxazol beigefügt.

\subsection{Durchflusszytometrie}

\section{Das Prinzip:}

Mit dieser Methode, auch Fluorescence Activated Cell Sorting (FACS) genannt, werden Zellpopulationen in flüssigen Medien auf ihre Größe, Granularität und Oberflächenmerkmale untersucht. Dies geschieht, indem man einzelne Zellen durch eine Kapillare saugt und dabei einen Laserstrahl passieren lässt. Dabei wird das Licht nach vorne hin gebeugt (forward scatter), was eine Beurteilung der Zellgröße erlaubt. Die seitliche Streuung (sideward scatter) hingegen ist ein Maß für die Granularität der Zelle. Zusätzlich können auf den Zellen gebundene fluoreszenzfarbstoffgekoppelte Antikörper mit Licht der entsprechenden Wellenlänge angeregt und das emittierte Licht detektiert werden, was eine Charakterisierung der Zelle nach Oberflächenmerkmalen erlaubt. 


\section{Die Durchführung:}

Das Blut der Mäuse wurde durch eine retroorbitale Punktion gewonnen. Dazu wurden die Tiere mit Ketamin und Rompun betäubt und eine heparinisierte Glaskapillare (Hirschmann Laborgeräte, Eberstadt, Deutschland) seitlich am Augapfel vorbeigeschoben. Etwa 5 Tropfen Blut wurden in einem mit zu einem Viertel mit FACS - Puffer gefüllten Röhrchen (BD Falcon) aufgefangen und auf Eis gelagert. Anschließend wurden die Röhrchen mit FACS - Puffer (2 \% FCS, 2 \% EDTA 0,5 M in PBS) vollständig aufgefüllt und die Zellen bei $6{ }^{\circ} \mathrm{C}$ und $1100 \mathrm{rpm}$ für 7 Minuten abzentrifugiert (Eppendorf). Nach Verwerfen des Überstandes wurden die Zellen mit 0,7 $\mu$ fluoreszenzfarbstoffgekoppeltem Antikörper für 25 Minuten bei $4{ }^{\circ} \mathrm{C}$ in Dunkelheit inkubiert. Nach mehreren Waschschritten wurden die Erythrozyten mit jeweils $0,8 \mathrm{ml} B D$ FACS Lysing Solution für 3 Minuten bei Dunkelheit lysiert. Zum Stop der Lyse wurde das Röhrchen komplett mit FACS - Puffer aufgefüllt. Nach einem weiteren Zentrifugationsschritt wurden der Überstand verworfen, verbleibende Tropfen abgeklopft und die Zellen schließlich mit 0,3 ml FACS - Puffer resuspendiert. Die Messung erfolgte mit dem FACS - Calibur - Zytometer ${ }^{\circledR}$ (Becton Dickinson, Heidelberg, Deutschland). Bei der Benutzung mehrerer Fluoreszenzfarbstoffe war die Kompensation mit einfachmarkierten Kontrollfärbungen notwendig, da sich die Emissionsspektren der Farbstoffe überschneiden. Zusätzlich wurden unmarkierte Proben als Negativkontrollen verwendet. Für die Auswertung der Daten wurde das Programm WinMDI 2.9 (Joe Trotter, TRSI, La Jolla, CA, USA) benutzt.

Zur Beurteilung des Knochenmarkschimärismus war keine Färbung notwendig, da alle Donorzellen das ACT $\beta$ - GFP exprimieren, welches das Zytometer unter der Wellenlänge des Fluoreszenzfarbstoffes FITC erkennt.

\begin{tabular}{|l|l|l|l|}
\hline Antikörper & Klon & Isotyp & Hersteller \\
\hline CD11b & $M 1 / 70$ & Ratte IgG2b $\kappa$ & eBioscience \\
\hline CD3 & $145-2 C 11$ & Arm. Hamster IgG1 & eBioscience \\
\hline Ly-6C & AL21 & Ratte IgM & eBioscience \\
\hline B220 & RA3-6B2 & Ratte IgG2a $\kappa$ & BD Pharmingen \\
\hline Ly-6G & 1A8 & Ratte IgG2b $\kappa$ & BD Pharmingen \\
\hline
\end{tabular}

Tabelle 1: Bei der Durchflusszytometrie verwendete Fluoreszenzantikörper 


\begin{tabular}{|l|l|l|l|}
\hline Fluorochrom & Absorptionsmax. & Emissionsmax. & Anregungswellenlängen \\
\hline FITC & $495 \mathrm{~nm}$ & $519 \mathrm{~nm}$ & $488 \mathrm{~nm}$ \\
\hline PE & $480,565 \mathrm{~nm}$ & $578 \mathrm{~nm}$ & $488,532 \mathrm{~nm}$ \\
\hline PerCP & $482 \mathrm{~nm}$ & $678 \mathrm{~nm}$ & $488,532 \mathrm{~nm}$ \\
\hline APC & $650 \mathrm{~nm}$ & $660 \mathrm{~nm}$ & $595,633,635,647 \mathrm{~nm}$ \\
\hline
\end{tabular}

Tabelle 2: Eigenschaften der verwendeten Fluorochrome

\subsection{Genexpressionsanalyse}

\section{Das Prinzip:}

Eine Möglichkeit zur Beurteilung der Aktivität von Genen in einzelnen Zellen oder Zellverbänden ist die Quantifizierung der mRNA. Da die mRNA intrazellulär vorliegt, bedarf es zunächst der Zelllyse. Anschließend muss die mRNA mit speziellen Filtersäulen aus dem Lysat isoliert werden, wobei sie vor den allgegenwärtigen Enzymen mit RNase - Aktivität geschützt werden muss. Da die mRNA sehr instabil ist, wird von ihr eine komplementäre Kopie auf DNA - Basis (cDNA) angefertigt. Dazu wird das Enzym Reverse Transkriptase benutzt. Anschließend kann mit 2 verschiedenen, kurzen DNA - Fragmenten (Primer), die komplementär an die Sequenz des zu untersuchenden Gens binden und von der Taq - Polymerase als Matrize zur Synthese eines neuen DNA - Strangs genutzt werden, das zu untersuchende Gen vervielfältigt werden. In den entstandenen Doppelstrang kann ein Fluoreszenzfarbstoff interkalieren. Mit jedem Synthesezyklus entstehen mehr Kopien, bis das Fluoreszenzsignal so stark ist, dass es sich vom Hintergrundsignal abhebt und einen exponentiellen Verlauf nimmt. Abhängig von der Ausgangsmenge der cDNA geschieht dies früher oder später. Diese Anzahl an Zyklen wird mit cycle threshold (ct - Wert) angegeben. Diese Methode wird als quantitative Reverse Transcription Polymerase Chain Reaction (qRT - PCR) bezeichnet. Um verschiedene Proben miteinander vergleichen zu können, muss man alle gemessenen Werte auf ein Gen beziehen, das in Zellen aus allen Proben gleich stark exprimiert wird, wie zum Beispiel das an der Glykolyse beteiligte Enzym Glycerinaldehyd - 3 - phosphat Dehydrogenase (GAPDH). Um auch die Expression verschiedener Gene quantitativ miteinander vergleichen zu können, muss zusätzlich noch die Primereffizienz durch Verdünnungsreihen von cDNA bestimmt werden (Pfaffl et al. 2001). 


\section{Die Durchführung:}

Die RNA - Isolierung wurde mittels des RNeasy Kits von der Firma Qiagen durchgeführt. Zunächst wurde das zu untersuchende Gewebe in 0,5 ml RNAlater (Qiagen) für mindestens 24 Stunden gelagert. Anschließend wog man davon $30 \mathrm{mg}$ ab und überführte es zur Lyse in $600 \mu \mathrm{l} \mathrm{RLT}$ - Puffer und $6 \mu \mathrm{l} \beta$ - Mercaptoethanol und homogenisierte es mit dem Ultra Turrax® (IKA - Group), gefolgt von Qiashredder - Säulen (Qiagen). Nach Zentrifugation des Lysats für 3 Minuten bei 10000 rpm wurde der Überstand in ein neues Reaktionsgefäß gegeben und mit $600 \mu \mathrm{l} 70 \%$ Ethanol die DNA ausgefällt. Dann gab man die Probe in 2 Schritten in die RNeasy spin column und zentrifugierte bei 10000 rpm wobei der Durchfluss jeweils verworfen wurde. Nun wurde die Säule noch mit $700 \mu \mathrm{l}$ RW1 - Puffer und 2 mal mit $500 \mu \mathrm{l} \mathrm{RPE}$ - Puffer gewaschen und schließlich ohne Flüssigkeit „trocken“ zentrifugiert. Die Eluation der in der Säule gebundenen mRNA erfolgte in 2 Schritten mit jeweils $20 \mu \mathrm{l}$ RNase - freiem Wasser. Das Eluat wurde wegen der Instabilität der mRNA auf Eis gelagert und sofort die Reinheit und Konzentration auf spektrophotometrische Weise bestimmt. Die Reinheit ergab sich aus dem Absorptionskoeffizienten von A260 zu A280 und die Konzentration wurde mit folgender Formel berechnet: Konzentration $\mathrm{RNA}=44 \mu \mathrm{g} / \mathrm{ml} \times \mathrm{A} 260 \times$ Verdünnung. Die in Wasser gelöste RNA wurde bei $-20{ }^{\circ} \mathrm{C}$ gelagert.

Anschließend an die RNA - Isolierung folgte der DNase - Verdau zur Beseitigung von Kontaminationen chromosomaler DNA im Eluat. $1 \mu \mathrm{g}$ RNA wurde hierzu mit $1 \mu \mathrm{l}$ DNase, 1,4 $\mu \mathrm{l}$ DNase - Puffer und $1 \mu \mathrm{l}$ RNasin dem Reaktionsansatz zugeführt und mit Wasser auf $14 \mu \mathrm{l}$ aufgefüllt und $30 \mathrm{~min}$ bei $36^{\circ} \mathrm{C}$ inkubiert. Zur Inaktivierung der DNase wurde der Ansatz für $10 \mathrm{~min}$ bei $70^{\circ} \mathrm{C}$ gelagert.

Jetzt konnte der Schritt der reversen Transkription begonnen werden. Zusätzlich zu den $14 \mu \mathrm{l}$ RNA - Ansatz aus dem DNase - Verdau wurden $8 \mu \mathrm{d}$ dT Primer, $8 \mu \mathrm{l} 5 \mathrm{x}$ Puffer, $4 \mu \mathrm{l}$ dNTP, $4 \mu \mathrm{l}$ 0,1 M DTT und $2 \mu \mathrm{l}$ Superscript - Reverse - Transkriptase hinzugefügt und dieser Ansatz $1 \mathrm{~h}$ bei $36^{\circ} \mathrm{C}$ und anschließend zur Hitzeinaktivierung der Reversen Transkriptase 15 min bei $95{ }^{\circ} \mathrm{C}$ inkubiert. Letzendlich wurde die neusynthetisierte cDNA mit $50 \mu$ doppelt destilliertem Wasser $\left(\mathrm{ddH}_{2} \mathrm{O}\right)$ verdünnt und bei $-20^{\circ} \mathrm{C}$ aufbewahrt.

Der Reaktionsansatz für die qRT - PCR bestand aus folgenden Komponenten:

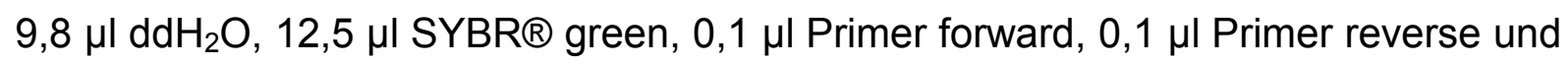
2,5 $\mu \mathrm{l} \mathrm{cDNA}$. Für jede Probe wurden jeweils 3 Ansätze und Negativkontrollen in eine 
96 - Well - Platte pipettiert, mit einer durchsichtigen Klebefolie verschlossen und in den ICycler $^{\circledR}$ (Bio-Rad, München, Deutschland) eingelegt. Nach einem zuvor programmierten Ablauf von Temperaturerhöhungen und - absenkungen wurde die PCR durchgeführt und am Ende jedes Zyklus die Fluoreszenzintensität gemessen. Die Auswertung der ct - Werte erfolgte mit Excel (Microsoft, Redmond, WA, USA).

\begin{tabular}{|lc|c|c|}
\hline Gen & Primersequenz & $\begin{array}{c}\text { Hybridisierungs- } \\
\text { temp. [ }\end{array}$ \\
\hline GAPDH & -
\end{tabular}

Tabelle 3: Primersequenzen und Hybridisierungstemperaturen für die quantitative Reverse Transkriptase - Polymerase - Kettenreaktion

\subsection{Enzyme - linked immunosorbent assay (ELISA)}

\section{Das Prinzip:}

Diese Methode dient dem immunologischen Nachweis von Proteinen, aber auch anderen niedermolekularen Verbindungen, wie Hormonen. In dieser Arbeit wurde der sogenannte Sandwich - ELISA genutzt. Dazu wird eine Platte mit Antikörpern beschichtet, die die nachzuweisende Verbindung aus der Probe binden. Nach dem Auswaschen der ungebundenen Bestandteile wird ein weiterer Antikörper hinzugegeben, der ebenfalls an der nachzuweisenden Verbindung, jedoch an einem anderen Epitop bindet. Dieser ist enzymkonjugiert und bewirkt nach Zugabe des Substrats eine Farbreaktion, die nach einem Waschschritt photometrisch durch Verdünnungsreihen quantifiziert wird.

\section{Die Durchführung:}

Der ELISA wurde in Kooperation mit Dr. Markus Kummer, Abteilung für Neurologie, Rheinische Friedrich - Wilhelms - Universität Bonn, durchgeführt. 


\subsection{Western Blot}

\section{Das Prinzip:}

Diese Methode dient dem immunologischen Nachweis von Proteinen und wird deswegen auch Immunoblot genannt. Sie hat gegenüber dem ELISA den Vorteil, dass gleichzeitig eine Vielzahl von Proteinen nachgewiesen werden kann. Mittels einer Gelelektrophorese wird das Proteinhomogenat gemäß seiner Größe bzw. Ladung aufgetrennt. Anschließend werden die Proteinbanden durch ein senkrecht zum Gel angelegtes, elektrisches Feld auf eine Nitrocellulosemembran übertragen. Dadurch werden die Proteine, nach vorherigem Blocken der unspezifischen Bindungsstellen, dem Nachweis durch spezifische Antikörper zugänglich. Dann erfolgt die Bindung von Sekundärantikörpern, die enzymgekoppelt sind und durch eine Farbreaktion die gewünschte Proteinbande sichtbar machen.

\section{Die Durchführung:}

Der Western Blot wurde in Kooperation mit Dr. Markus Kummer, Abteilung für Neurologie, Rheinische Friedrich - Wilhelms - Universität Bonn, durchgeführt.

\subsection{Immunfluoreszenz auf Gefrierschnitten}

\section{Das Prinzip:}

Die histologische Aufbereitung von Hirngewebe dient der Anfärbung bestimmter Proteine, die vielfältige Aussagen über die Identität und Funktion von Zellen, aber auch über extrazelluläre Proteinablagerungen erlaubt. Zunächst wird dazu das nachzuweisende Protein mit einem Primärantikörper selektiv gebunden und dann mit einem Sekundärantikörper, der Fluorochrom - gekoppelt ist und gegen den Primärantikörper gerichtet ist, detektierbar gemacht. Unter Vermeidung von Kreuzreaktion mehrerer Sekundärantikörper mit Primärantikörpern sind somit auch Doppel - und Dreifachfärbungen möglich. Unter Anregung der Fluorochrome mit einem Fluoreszenzmikroskop emittieren diese Licht in den Wellenlängenbereichen der Farben Rot, Blau und Grün. 


\section{Die Durchführung:}

Zu Beginn wurde das Tier mit Ketamin und Rompun narkotisiert, fixiert und das Herz freipräpariert. In den linken Ventrikel wurde eine Kanüle eingeführt und mit einer Rollenpumpe zunächst mit PBS perfundiert. Mit einer Schere wurde dazu der rechte Vorhof inzidiert, sodass das Blut aus dem Kreislauf herausgespült werden konnte. Anschließend wurde mit gekühlter 4 \% PFA - Lösung zur Gewebefixierung perfundiert. Dann wurden Schädel und Wirbelsäule freipräpariert und in 4 \% PFA in einem 50 - ml - Sarstedtröhrchen zur weiteren Fixierung aufbewahrt. Nach 3 Tagen wurde das ZNS aus Schädel und Wirbelsäule freipräpariert und zur Entwässerung für 3 weitere Tage in $30 \%$ Sucrose in bidestilliertem Wasser überführt und bei $4{ }^{\circ} \mathrm{C}$ gelagert. Anschließend wurde das Gewebe in Abschnitte geteilt, so dass die zu untersuchenden Bereiche des ZNS zugänglich wurden. Die Gewebestücke wurden nun mit dem Fixierungsgel Tissue - Tek in Plastikdöschen eingebettet und bei $-20^{\circ} \mathrm{C}$ eingefroren. Am Kryostat wurden $20 \mu \mathrm{m}$ dicke Koronarschnitte angefertigt und auf Objektträgern aufgetragen.

Für die Färbung wurden die Schnitte zunächst mit $10 \%$ FCS und 0,5 \% Triton geblockt und permeabilisiert. Dann wurde mit dem Primärantikörper (Iba-1 für Mikroglia und Makrophagen oder dem A $\beta$ - spezifischen Antikörper 6E10, jeweils 1:100) bei $4{ }^{\circ} \mathrm{C}$ über Nacht inkubiert. Mit dem Cy3 - direktgekoppelten Sekundärantikörper (1:200) wurde für 1 Stunde bei Raumtemperatur und abschließend noch mit DAPI (1:10000) für 15 Minuten zur Färbung der Zellkerne inkubiert. Für eine Iba-1/A $\beta$ - Doppelfärbung wurde der $A \beta$ - Antikörper 6E10 mit einem Cy3 - gekoppelten Sekundärantikörper und lba-1 mit einem biotinyliertem Sekundärantikörper und Pacific - Blue - gekoppeltem Streptavidin inkubiert. Eingedeckelt wurde der Schnitt mit dem DAKO Fluorescence Mounting Medium und einem Deckgläschen.

Untersucht wurden die Schnitte mit dem Fluoreszenzmikroskop Olympus BX-51. Aufnahmen wurden mit der Kamera Olympus DP71 und dem Bildanalysesoftware analySIS (Soft Imaging System GmbH, Münster, Deutschland) bei 200 - und 400 facher Vergrößerung gemacht. Die Quantifizierung der verschiedenen Zellen erfolgte manuell und geblindet an mindestens 3 Schnitten/Tier. Bei einigen entscheidenden Auszählungen wurden die erhobenen Daten durch einen zusätzlichen, unabhängigen Wissenschaftler bestätigt. 


\subsection{Genotypisierung}

\section{Das Prinzip:}

Diese Methode dient dem Nachweis von spezifischen Gensequenzen, wie er bei der Zucht von gentechnisch veränderten Tieren zur Bestimmung des Genotyps gebraucht wird. Zunächst wird aus einer Gewebebiopsie die DNA isoliert und es werden 2 komplementäre Oligonukleotide (Primer), die vor und hinter der DNA Zielsequenz binden, hinzugegeben. An die Bindungsstellen zwischen Primern und homologer, chromosomaler DNA beginnt die Taq - Polymerase unter Zugabe von Nukleotiden, einen neuen, zur Zielsequenz komplementären DNA - Strang zu synthetisieren. Dadurch ist eine exponentielle Vervielfältigung der DNA - Zielsequenz möglich (Polymerasekettenreaktion). Nach gelelektrophoretischer Auftrennung der DNA erfolgt die bildliche Darstellung des mit Ethidiumbromid gefärbten DNA Amplifikats unter UV - Licht.

\section{Die Durchführung:}

Zunächst wurde ein $2 \mathrm{~mm}$ langes Ende eines Mäuseschwanzes über Nacht in $500 \mu \mathrm{l}$ Lysepuffer (100 mM TrisHCl, $5 \mathrm{mM}$ EDTA, $200 \mathrm{mM} \mathrm{NaCl}, 0,2 \%$ SDS) und $12 \mu \mathrm{l}$ Proteinase $\mathrm{K}$ zum Proteinverdau bei $56{ }^{\circ} \mathrm{C}$ inkubiert. Nach einem Zentrifugationsschritt wurde der Überstand in ein neues Reaktionsgefäß überführt und die DNA durch Zugabe von $500 \mu \mathrm{l} 100 \%$ Isopropanol ausgefällt. Nach weiterem Zentrifugieren wurde der Überstand verworfen und die im Pellet enthaltene DNA mit $500 \mu \mathrm{l} 70 \%$ Ethanol gewaschen. Nach einem letzten Zentrifugationsschritt wurde der

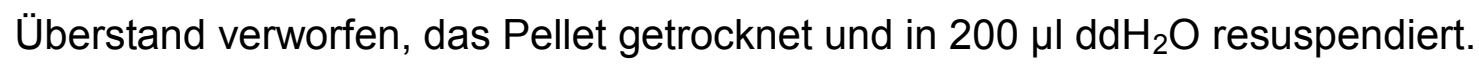

Der Reaktionsansatz setzte sich aus $2 \mu \mathrm{l}$ der isolierten DNA, der DNA - Polymerase GoTaq $0,2 \mu \mathrm{l}$, den beiden Primern mit jeweils $0,5 \mu \mathrm{l}$ (Konzentration $50 \mathrm{pmol} / \mu \mathrm{l}$ ), dNTP $5 \mu \mathrm{l}, \mathrm{MgCl}_{2} 1,5 \mu \mathrm{l}$, GoTaq Flexi Buffer $5 \mu$ und $\mathrm{H}_{2} \mathrm{O}$ 10,3 $\mu \mathrm{l}$ zusammen. Das Amplifikat wurde auf ein Gel, gegossen aus $120 \mathrm{ml}$ TAE - Puffer, 1,5 g Agarose und $6 \mu \mathrm{l}$ Ethidiumbromid aufgetragen und für 40 Minuten bei $110 \mathrm{~V}$ laufen gelassen. Die UV Belichtung und Dokumentation der Gelelektrophorese erfolgte mit ChemiDoc (Bio Rad, München, Deutschland). 


\begin{tabular}{|c|c|c|c|}
\hline Gen & & Primersequenz & $\begin{array}{l}\text { Hybridisierungs- } \\
\text { temp. }\left[{ }^{\circ} \mathrm{C}\right]\end{array}$ \\
\hline $\begin{array}{l}\mathrm{CCR}^{-/-} \\
\text {Neomycinkassette }\end{array}$ & $\begin{array}{l}\text { for } \\
\text { rev }\end{array}$ & $\begin{array}{l}\text { 5'- TTG TCA AGA CCG ACC TGT CCG GT -3، } \\
\text { 5- GAC GAG ATC ATC GCC GTC GGG CA -3‘ }\end{array}$ & 60 \\
\hline
\end{tabular}

Tabelle 4: Primersequenzen und Hybridisierungstemperaturen für die Genotypisierungs Polymerase - Kettenreaktion

\subsection{Statistische Auswertung}

Die statistische Auswertung der Daten erfolgte mit Microsoft $($ Office Excel 2002 (Microsoft Corporation, Redmond, USA). Statistische Unterschiede wurden durch einen ungepaarten Student T - Test geprüft. Ein Signifikanzniveau von $p<0,05$ wurde mit einem Sternsymbol $\left(^{*}\right)$ gekennzeichnet. 


\section{Experimente und Ergebnisse}

\subsection{Versuchsdesign}

Für die vorliegende Arbeit wurden folgende Knochenmarkschimären hergestellt (vgl. Abb. 2):

$$
\begin{aligned}
& \mathrm{CCR}^{-/-} \text {- GFP - Knochenmark } \rightarrow \text { ungeschützt bestrahlt, APP }{ }^{\text {swe/PS1 }}(\mathrm{n}=4) \\
& \mathrm{CCR}^{+/+} \text {- GFP - Knochenmark } \rightarrow \text { ungeschützt bestrahlt, APP swe/PS1 }(\mathrm{n}=3) \\
& \mathrm{CCR}^{+/+} \text {- GFP - Knochenmark } \rightarrow \text { ungeschützt bestrahlt, } \operatorname{APP}^{\text {swe/PS1 }}(\mathrm{n}=6) \\
& \mathrm{CCR}^{+/+} \text {- GFP - Knochenmark } \rightarrow \text { geschützt bestrahlt, APP }{ }^{\text {swe/PS1 }}(\mathrm{n}=6)
\end{aligned}
$$

Die Knochenmarksrekonstitution erfolgte im Alter von 3 Monaten und die Analyse der Gehirne nach 10 Monaten (Abb. 3).

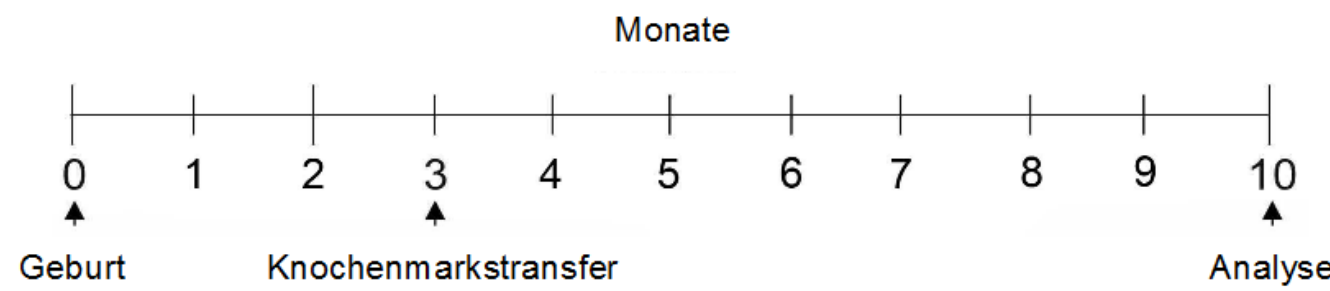

Abbildung 3: Zeitlicher Ablauf der Knochenmarksrekonstitution der APP ${ }^{\text {swe/PS1 }}$ - Tiere mit Zeitpunkt von Geburt, Knochenmarksrekonstitution und Analyse.

Das Gehirn wurde durch Koronarschnitte zerteilt, um Gewebe für die Immunfluoreszenz, qRT - PCR, ELISA und Western Blot zu gewinnen (Abb. 4).

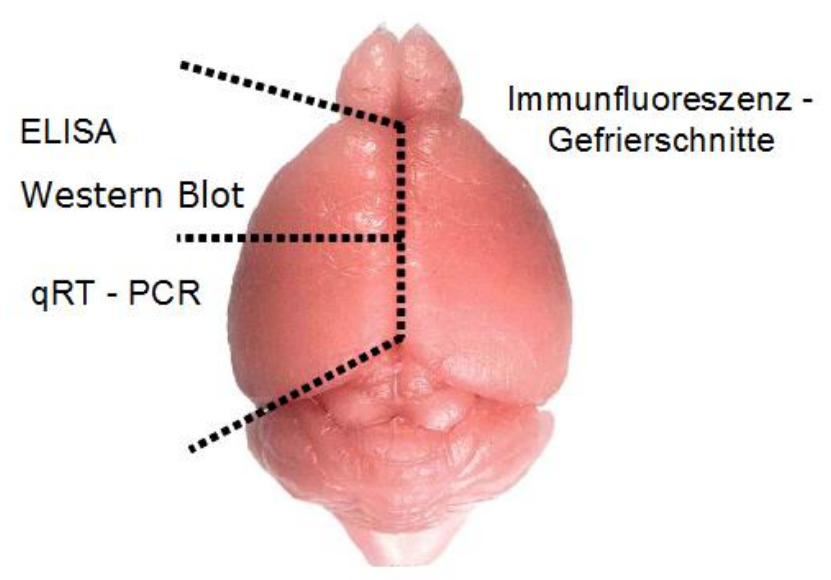

Abbildung 4: Aufteilung des Hirngewebes von 10 Monate alten APP swe/PS1 - Chimären für Immunfluoreszenz - Gefrierschnitte, qRT - PCR, ELISA und Western Blot. 
3.2 Ly-6C $\mathrm{C}^{\text {hi }}$ - Monozyten sind die Vorläuferzellen der mononukleären Phagozyten im APP ${ }^{\text {swe/PS1 }}$ - Gehirn

\subsubsection{Massive Reduktion der Ly-6C $\mathrm{C}^{\text {hi }}$ - Monozyten bei CCR2 - defizientem Knochenmark}

Der Chemokinrezeptor CCR2 wird auf Knochenmarkszellen benötigt, damit die inflammatorischen Monozyten das Knochenmark verlassen und in die Blutzirkulation eintreten können (Serbina und Pamer 2006). Aus diesem Grund sind CCR2 defiziente Tiere durch eine starke Reduktion von im Blut zirkulierenden Ly-6C ${ }^{\text {hi }}$ Monozyten gekennzeichnet (Serbina und Pamer 2006). Wie erwartet, ließ sich in unseren mit $\mathrm{CCR}^{-{ }^{--}}$- GFP - Knochenmark rekonstituierten APP ${ }^{\text {swe/PS1 }}$ - Tieren eine selektive und signifikante Reduktion der Ly- $6 C^{\text {hi }}$ - Monozyten feststellen, während die Tiere mit $\mathrm{CCR}^{+/+}$- GFP - Knochenmark keine Erniedrigung dieser Zellen aufwiesen (Abb. 5). Im Gegensatz zu CCR2 - exprimierenden Ly-6C ${ }^{\text {hi }}$ - Monozyten migrieren die Ly-6Clow - Monozyten CCR2 - unabhängig aus dem Knochenmark. Diese Zellpopulation kann daher als Referenzpopulation verwendet werden, um den Gesamtchimärismus zu beurteilen. Wie in Abbildung 5 gezeigt, konnten in den mit $\mathrm{CCR}^{+/+}$- oder $\mathrm{CCR}^{-/-}$- Knochenmark transplantierten Tieren keine signifikanten Unterschiede in der Anzahl dieser Zellen beobachtet werden.
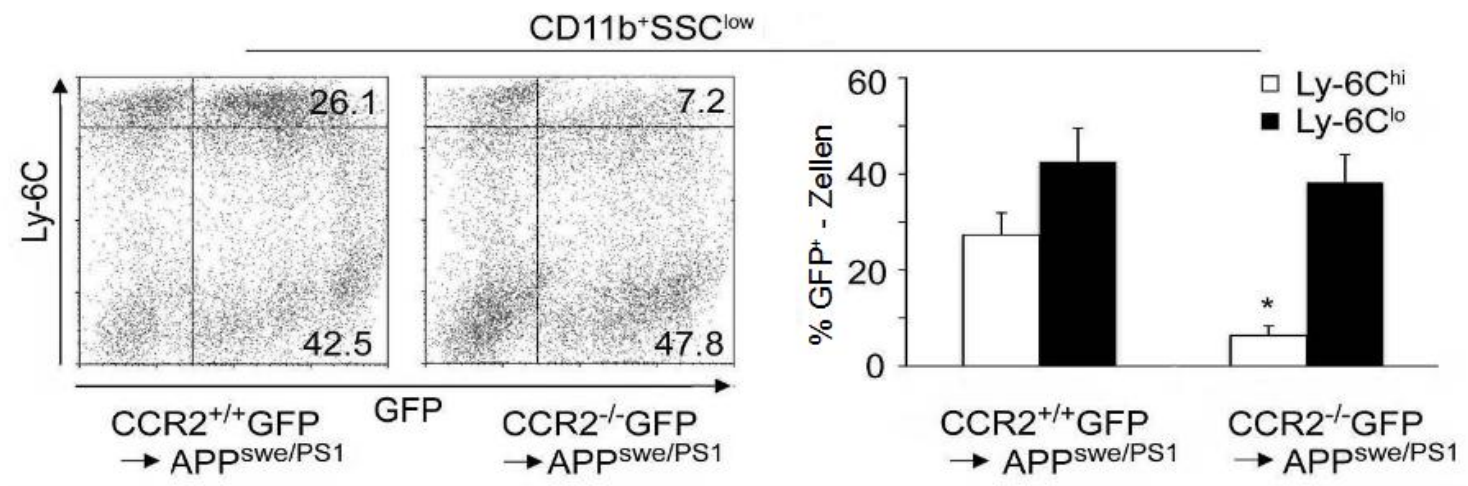

Abbildung 5: Die Blut - FACS - Analyse 7 Monate nach Knochenmarkstransfer bei $A P P^{\text {swe/PS1 }}$ - Tieren zeigte eine signifikante Reduktion der Ly-6C $C^{\text {hi }}-C^{2} 11 b^{+}-S_{S C}{ }^{\text {low }}-$ Monozyten in $\mathrm{CCR}^{-/-}$- GFP $\rightarrow \mathrm{APP}^{\text {swe/PS1 }}$ - Chimären verglichen mit $\mathrm{CCR}^{+/+}-\mathrm{GFP} \rightarrow$ APP ${ }^{\text {swe/PS1 }}$ - Chimären. Repräsentative Dot Blots beider Gruppen (links). Prozentuale Anteile der $\mathrm{GFP}^{+}-\mathrm{CD}_{11 \mathrm{~b}^{+}}-\mathrm{Ly}_{-6 C^{\text {hi }}}$ - Monozyten beider Gruppen (rechts). SSC: side scatter, Mittelwerte \pm Standardabweichung, ${ }^{*}$ : statistische Signifikanz $p<0,05$ 


\subsubsection{Ly-6C hi $^{\text {h }}$ Monozyten migrieren in APP ${ }^{\text {swe/PS1 }}$ - Gehirne}

Durch eine Knochenmarksrekonstitution mit genetisch unterschiedlichem Donor wird die Unterscheidung zwischen residenten Mikroglia und eingewanderten, aus dem transplantierten Knochenmark stammenden, mononukleären Phagozyten möglich. 7 Monate nach dem Knochmarkstransfer untersuchten wir das Gehirn der APP ${ }^{\text {swe/PS1 }}$ Tiere histologisch. In einer Doppelfärbung für $A \beta$, einem Indikator für pathologische $A \beta$ - Plaque - Ablagerungen und Iba-1, einem Marker für Mikroglia und Makrophagen, fanden wir zahlreiche parenchymale Zellen mit mikrogliaartiger Ramifizierung, die positiv für Iba-1 und GFP waren. Diese Zellen befanden sich teils in unmittelbarer Nähe der, bei 10 Monate alten Tieren, deutlich sichtbaren Amyloidplaques, teils aber auch im Gewebe zwischen den Plaques (Abb. 6).

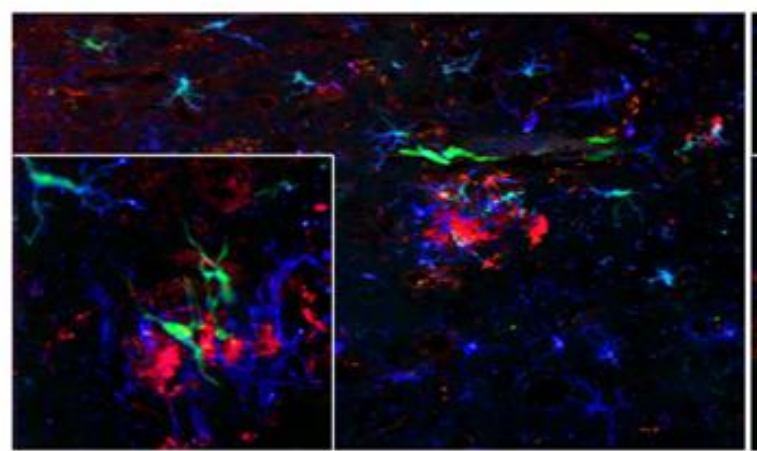

$\mathrm{CCR}^{+/+} \mathrm{GFP} \rightarrow \mathrm{APP}^{\mathrm{swe} / \mathrm{PS} 1}$

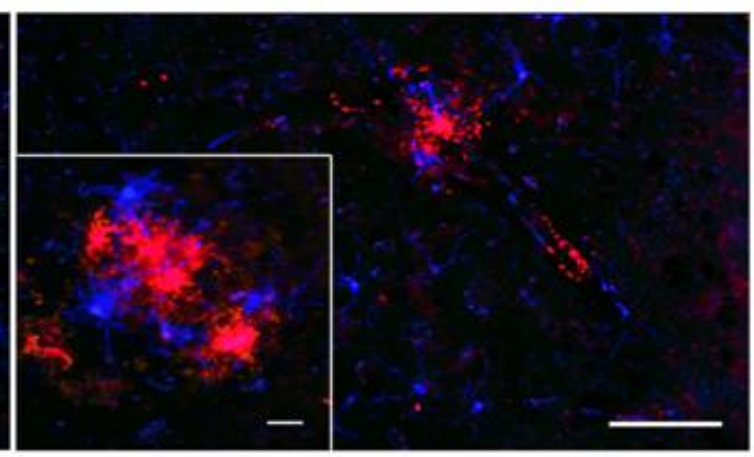

$\mathrm{CCR}^{-/-\mathrm{GFP}} \rightarrow \mathrm{APP}^{\mathrm{swe} / \mathrm{PS} 1}$

Abbildung 6: Immunhistochemische Untersuchung von Gehirnen der APP ${ }^{\text {swe/PS1 }}$ - Chimären. In der Fluoreszenzmikroskopie zeigten sich in den $\mathrm{CCR}^{+/+}-$GFP $\rightarrow \mathrm{APP}^{\text {swe/PS1 }}$ - Chimären im Hippocampus zahlreiche ramifizierte $\mathrm{GFP}^{+}$- Zellen (links), welche drastisch reduziert in den $\mathrm{CCR}^{-/-}$- GFP $\rightarrow$ APP $^{\text {swe/PS1 }}$-Gehirnen waren (rechts). Iba-1 (blau). A $\beta$ (rot). Einige Iba-1 reaktive Phagozyten stammten vom Donor (GFP, grün), die übrigen stellten residente Mikroglia (Iba- $\left.1^{+}, \mathrm{GFP}^{-}\right)$dar. Das Detailbild zeigt Amyloidplaques sowie plaqueassoziierte Mikroglia und mononukleäre GFP ${ }^{+}$- Phagozyten. Übersichtsbild Balken: $100 \mu \mathrm{m}$. Detailbild Balken: $50 \mu \mathrm{m}$.

Im Gegensatz dazu waren diese Zellen in der mit CCR2 ${ }^{-/}$- Knochenmark rekonstituierten Gruppe im Kortex und Hippocampus drastisch reduziert (Kortex: 2,3 \pm 1,6 GFP ${ }^{+}$- Zellen $/ \mathrm{mm}^{2}$, Hippocampus 6,2 $\pm 11,5 \mathrm{GFP}^{+}$- Zellen $/ \mathrm{mm}^{2}$ versus Kortex $53,2 \pm 7,9 \mathrm{GFP}^{+}-$Zellen $/ \mathrm{mm}^{2}$, Hippocampus 45,8 $\pm 9,1 \mathrm{GFP}^{+}-$Zellen $/ \mathrm{mm}^{2}$ in $\mathrm{CCR}^{+/+}$- Chimären, Kortex: $p=0,00005$, Hippocampus $\left.p=0,0045\right)$ (Abb. 7A). Dies zeigt, dass die Anwesenheit von Ly-6C $C^{\text {hi }}$ - Monozyten im Blut für die Einwanderung der mononukleären Phagozyten in das Gehirn von APP ${ }^{\text {swe/PS1 }}$ - Tieren nötig ist. In 
der mit CCR2 ${ }^{+/+}$- Knochenmark rekonstituierten Gruppe waren $50 \pm 6 \%$ der Plaques im Kortex und $46 \pm 8 \%$ im Hippocampus mit mononukleären Phagozyten assoziiert. In den Tieren mit CCR2 - defizientem Knochenmark waren es dagegen nur $5 \pm 4 \%$ im Kortex und $17 \pm 10 \%$ im Hippocampus (Abb. 7B).
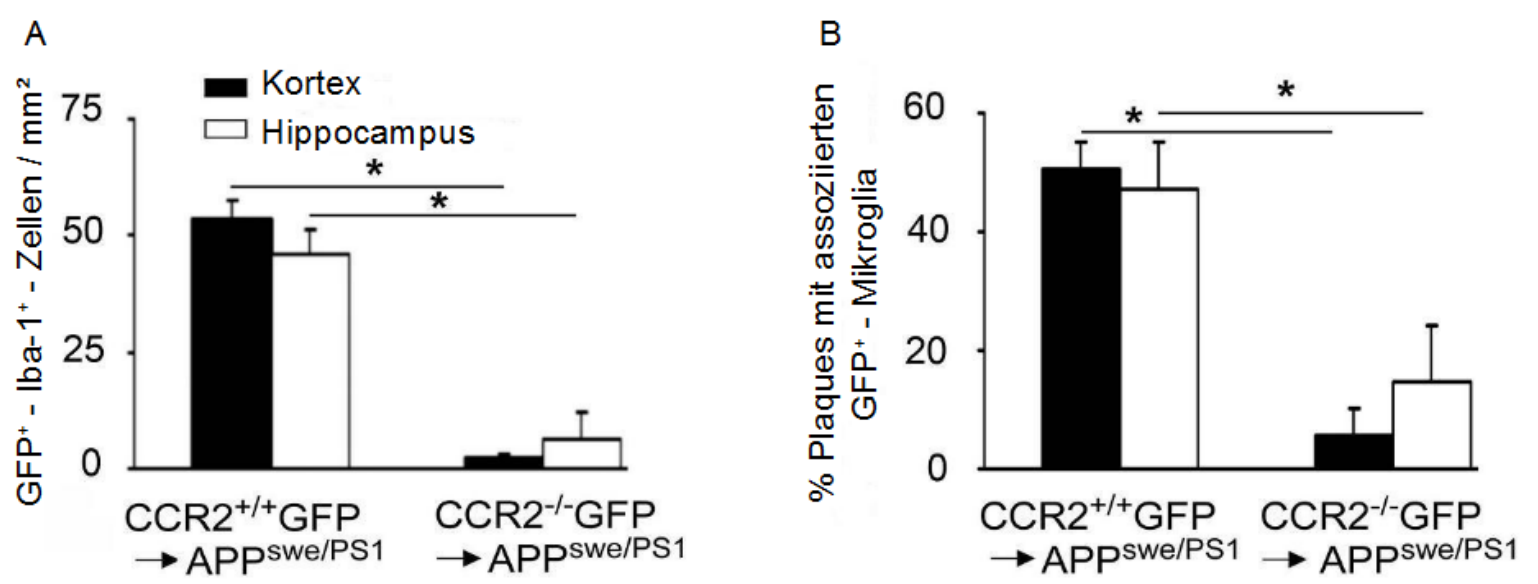

Abbildung 7: Semiquantitative Analyse der in den Kortex und Hippocampus rekrutierten mononukleären Phagozyten (GFP+ - Iba-1+ - Zellen). A: Reduktion der mononukleären Phagozyten $/ \mathrm{mm}^{2}$ in CCR2 ${ }^{-/-}$- GFP $\rightarrow$ APP $^{\text {swe/PS1 }}$ - Chimären verglichen mit CCR2 ${ }^{+/+}-$GFP $\rightarrow$ APP ${ }^{\text {swe/PS1 }}$ - Chimären. Mittelwerte \pm Standardabweichung, ${ }^{*}:$ statistische Signifikanz $p<$ 0,05. B: Prozentualer Anteil der Amyloidplaques mit assoziierten mononukleären Phagozyten in APP ${ }^{\text {swe/PS1 }}$ - Chimären.

\subsection{Die Einwanderung von Ly-6C ${ }^{\text {hi }}$ - Monozyten ins ZNS ist abhängig von der Gewebekonditionierung}

\subsubsection{Stabiler Chimärismus in den Chimären}

Nachdem die Ly-6C hi $^{\text {- }}$ CCR2 $^{+}$- Monozyten als Vorläuferpopulation der mononukleären Phagozyten im APP ${ }^{\text {swe/PS1 }}$ - Gehirn identifiziert wurden, wurde mit ganzkörperbestrahlten (ungeschützt) und kopfgeschützt bestrahlten Knochenmarkschimären überprüft, ob die Gewebekonditionierung durch Bestrahlung eine notwendige Bedingung für die Rekrutierung mononukleärer Phagozyten in das Gehirn von APP ${ }^{\text {swe/PS1 }}$ - Tieren ist. Wie Mildner und Kollegen zeigen konnten, bedarf es unter physiologischen Bedingungen der Bestrahlung, damit mononukleäre Phagozyten in das Gehirn einwandern können (Mildner et al. 2007). Ob dies auch unter pathologischen Bedingungen in einem Tiermodell einer neurodegenerativen Erkrankung ähnlich ist, wurde bislang nicht untersucht. Möglich wäre auch, dass eine Störung der Bluthirnschranke, wie sie bei Alzheimerpatienten beschrieben wurde 
(Algotsson und Winblad 2007), ausreicht, um mononukleäre Phagozyten in das Gehirn einwandern zu lassen. Um die geschützt und ungeschützt bestrahlten Tiere vergleichen zu können, ist ein ähnlich hoher Chimärismus in beiden Gruppen Voraussetzung. In der Durchflusszytometrie wurde Blut 1 und 7 Monate nach der Knochenmarkstransplantation untersucht. Hier zeigte sich nach 1 Monat in der geschützt bestrahlten Gruppe lediglich eine geringe Verminderung sowohl der Ly$6 C^{\text {hi }}$ - als auch der Ly-6C low - Monozyten, die keine Signifikanz aufwies (Abb. 8).

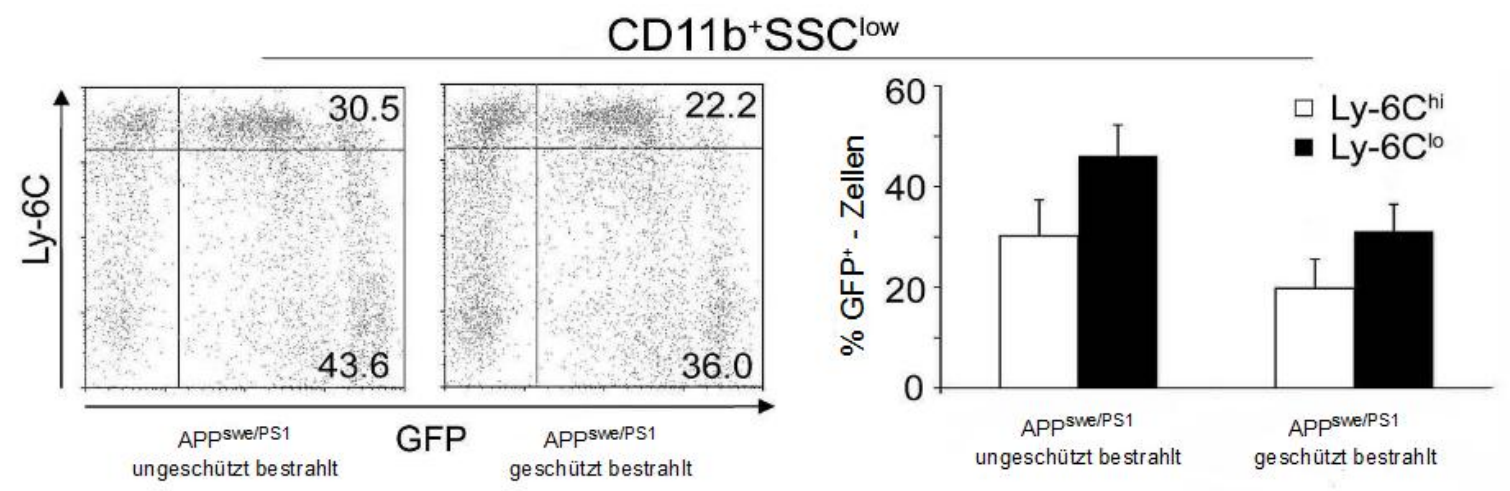

Abbildung 8: Die FACS - Analyse von Blut 1 Monat nach Knochenmarkstransfer bei APP ${ }^{\text {swe/PS1 }}$ - Tieren zeigte keine signifikanten Unterschiede der Ly-6C ${ }^{\text {hi }}-C^{2} 11 b^{+}-S_{S C}{ }^{\text {low }}$ und $L y-6 C^{\text {low }}-C^{2} 11 b^{+}-S S C^{\text {low }}-$ Monozyten in ungeschützt und geschützt bestrahlten APP swe/PS1 - Chimären. Repräsentative Dot Blots beider Gruppen (links). Prozentuale Anteile der GFP ${ }^{+}-$CD11b $^{+}-$Ly-6C $\mathrm{C}^{\text {hi }}$ - und Ly-6C ${ }^{\text {low }}$ - Monozyten beider Gruppen (rechts). SSC: side scatter, Mittelwerte \pm Standardabweichung, ${ }^{*}$ : statistische Signifikanz $p<0,05$.

Nach 7 Monaten, kurz vor der Analyse der Mäuse, wurde der Gesamtchimärismus, sowie der Anteil der vom Donor stammenden CD4 ${ }^{+}-$T-Helferzellen, der B220 - B-

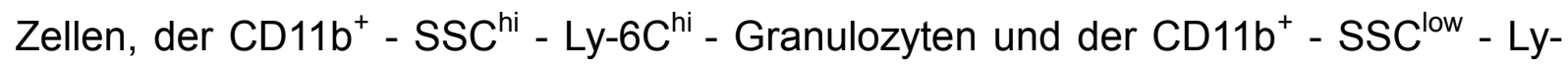
$6 \mathrm{C}^{\text {hi }}$ inflammatorischen Monozyten bestimmt, um einen stabilen Chimärismus aller Blutzellen zu überprüfen. Dabei wurde bei den 4 genannten Blutzellpopulationen eine signifikante Reduktion der $\mathrm{GFP}^{+}$- Zellen festgestellt; die Unterschiede im Chimärismus sämtlicher Blutzellen waren mit $p=0,057$ jedoch nicht signifikant (Abb. 9). Dies erklärt sich durch den fehlenden Austausch des im Schädelknochen lokalisierten Knochenmarks im Zuge der geschützen Bestrahlung. 


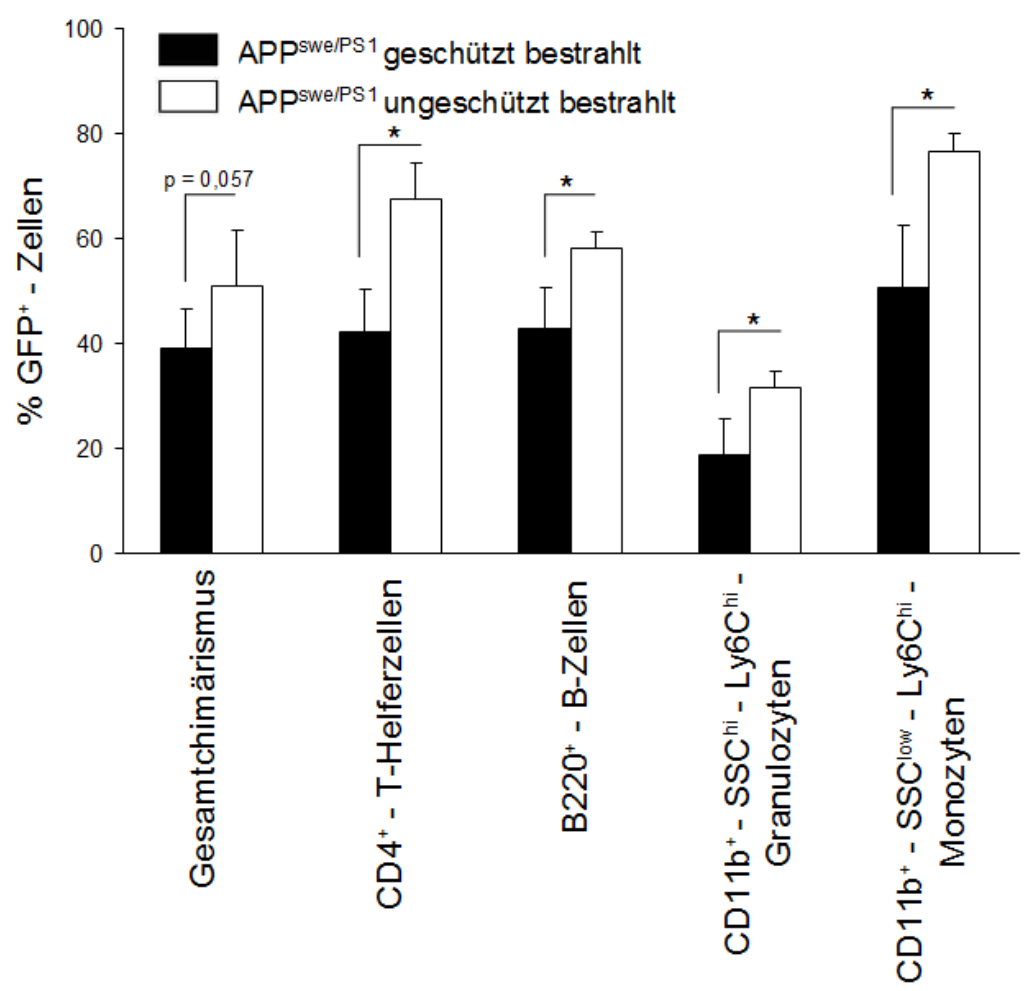

Abbildung 9: Die Blut - FACS - Analyse 7 Monate nach Knochenmarkstransfer bei ungeschützt und geschützt bestrahlten APP ${ }^{\text {swe/PS1 }}$ - Tieren zeigte signifikante Unterschiede im Chimärismus von verschiedenen Blutzellen, jedoch nicht im Gesamtchimärismus sämtlicher Blutzellen.

\subsubsection{Die Einwanderung von Ly-6C ${ }^{\text {hi }}$ - Monozyten ins ZNS bedarf vorheriger Bestrahlung}

Im Alter von 10 Monaten, also 7 Monate nach der Knochenmarkstransplantation, wurden die Mäuse getötet und das ZNS anschließend histologisch untersucht. In einer Färbung für Iba-1, $A \beta$ und Zellkerne (DAPI) wurde festgestellt, dass sich nur im Kortex und Hippocampus von ungeschützt bestrahlten Tieren ramifizierte $\mathrm{GFP}^{+}$- Iba$1^{+}$- Zellen befanden. Diese Zellen waren teilweise in unmittelbarer Nähe der Amyloidplaques im Kortex und Hippocampus lokalisiert. Die GFP ${ }^{+}-\mathrm{Iba}-1^{+}$- Zellen wiesen dabei eine reaktive Morphologie auf, wobei die zur Plaqueseite der Zelle gelegenen Fortsätze auf das Zentrum der Plaque gerichtet waren, ohne dieses jedoch zu erreichen (Abb. 10A). Im Gegensatz dazu waren die entsprechenden Hirnregionen der geschützt bestrahlten Tiere komplett frei von parenchymalen, aus dem Knochenmark stammenden GFP ${ }^{+}$- Zellen (Abb. 10B). Das Rückenmark in den gleichen Tieren war als einzige Region des ZNS in beiden Gruppen der Bestrahlung ausgesetzt und diente daher als interne Kontrolle. Die histologische Quantifizierung 
der ramifizierten $\mathrm{GFP}^{+}-\mathrm{Iba}-1^{+}$- Zellen in Rückenmarksquerschnitten ergab keine signifikanten Unterschiede zwischen den verschiedenen Chimärengruppen hinsichtlich der Zellzahl (Abb. 10C). Dies zeigt, dass eine Rekrutierung mononukleärer Phagozyten nur in den Regionen erfolgte, die einer vorherigen Bestrahlung unterlaufen waren. Des Weiteren beweisen diese Experimente, dass die Schädigung der Bluthirnschranke durch die Alzheimerpathologie nicht ausreichte, um die Translokation von peripheren Monozyten aus dem Blut ins ZNS zu bewirken.

A
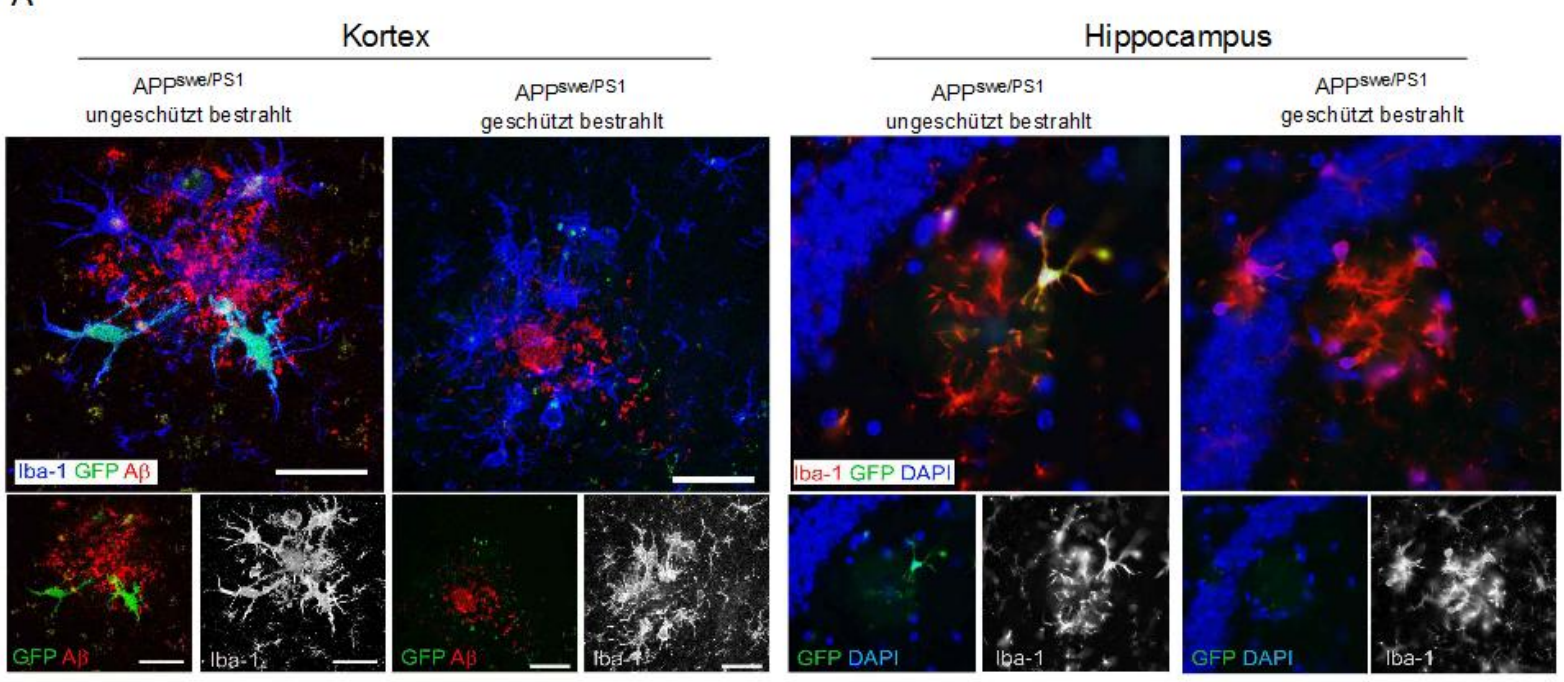

B
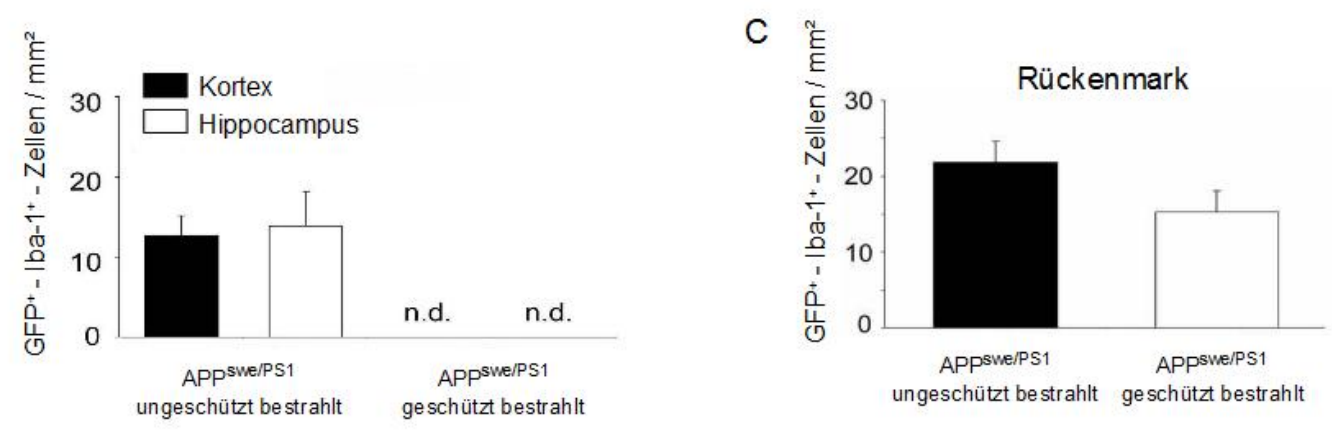

Abbildung 10: Mononukleäre Phagozyten wurden nur nach vorheriger Bestrahlung in Kortex und Hippocampus der APP ${ }^{\text {swe/PS1 }}$ - Chimären rekrutiert. A: Die Immunhistochemische Untersuchung zeigte plaqueassoziierte mononukleäre Phagozyten (GFP ${ }^{+}-$Iba- $1^{+}$- Zellen) nur in ungeschützt bestrahlten APP ${ }^{\text {swe/PS1 }}$ - Chimären. Kortex (links): residente Mikroglia $\left(\mathrm{GFP}^{-} \mathrm{Iba}^{+} \mathrm{1}^{+}\right.$) (blau), A (rot), mononukleäre $\mathrm{GFP}^{+}$- Phagozyten (grün). Hippocampus (rechts): residente Mikroglia (rot), DAPI - Zellkernfärbung (blau), mononukleäre $\mathrm{GFP}^{+}$Phagozyten (grün). Balken: $30 \mu \mathrm{m}$. B: Semiquantitative Analyse der mononukleären Phagozyten (GFP ${ }^{+}-\mathrm{Iba}-1^{+}$- Zellen) pro $\mathrm{mm}^{2}$ in Kortex und Hippocampus von ungeschützt und geschützt bestrahlten APP ${ }^{\text {swelPS1 }}$ - Chimären. Die geschützt bestrahlten Tiere waren völlig frei von mononukleären $\mathrm{GFP}^{+}$- Phagozyten, n.d.: nicht detektierbar. C: Die Quantifizierung von mononukleären $\mathrm{GFP}^{+}$- Phagozyten pro $\mathrm{mm}^{2}$ im Rückenmark von geschützt und ungeschützt bestrahlten APP ${ }^{\text {swelPS1 }}$ - Chimären zeigte keine signifikanten Unterschiede. Mittelwerte \pm Standardabweichung. 


\subsubsection{Schwache Assoziation von mononukleären Phagozyten mit}

\section{Amyloidplaques}

In der histologischen Quantifizierung zeigte sich, dass im Kortex nur $24 \pm 4 \%$ aller Plaques mit mononukleären $\mathrm{GFP}^{+}$- Phagozyten assoziiert waren (Abb. 11A). Im Hippocampus war dieser Anteil mit $17 \pm 10 \%$ geringer und variabler (Abb. 11A). Um beurteilen zu können, ob die mononukleären Phagozyten gezielt zu den Plaques rekrutiert werden, wurde weiterhin der Prozentsatz der $\mathrm{GFP}^{+}$- Zellen mit Plaqueassoziation bestimmt. Demnach waren im Kortex nur $28 \pm 7 \%$ und im Hippocampus $10 \pm 9 \%$ der GFP ${ }^{+}$- Zellen plaqueassoziiert (Abb. 11B). Ein Großteil der mononukleären Phagozyten war demnach parenchymal lokalisiert und wurde nicht durch die $A \beta$ - Ablagerungen beeinflusst. Auffällig war zudem, dass die mononukleären Phagozyten nicht gleichmäßig über das Gehirngewebe verteilt waren, sondern immer in Gruppen auftraten, zwischen denen es Bereiche gab, die völlig frei von diesen Zellen waren. Zusammenfassend lässt sich festhalten, dass nur ein geringer Anteil der mononukleären $\mathrm{GFP}^{+}$- Phagozyten an die Plaques rekrutiert wurde.
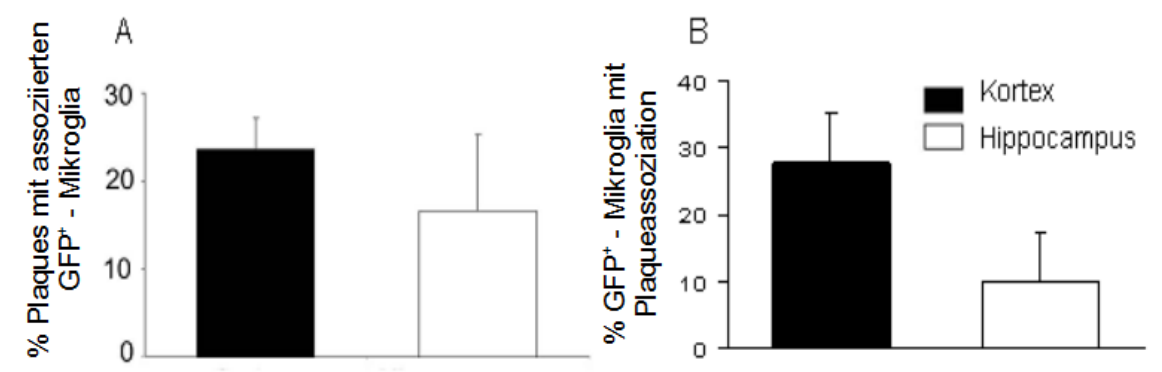

Abbildung 11: Schwache Plaqueassoziation von mononukleären $\mathrm{GFP}^{+}$- Phagozyten in ungeschützt bestrahlten APP ${ }^{\text {swelPS1 }}$ - Chimären. A: Prozentualer Anteil der Amyloidplaques mit assoziierten mononukleären Phagozyten in Kortex und Hippocampus. B: Prozentualer Anteil der mononukleären GFP ${ }^{+}$- Phagozyten in Kortex und Hippocampus mit Plaqueassoziation. 
3.4 Die Gewebekonditionierung verändert das Hirnmilieu

\subsubsection{Veränderungen des zellulären Netzwerks und Reduktion der Mikroglia infolge der Bestrahlung}

Wie bereits gezeigt werden konnte, hat die Bestrahlung vielfältige Auswirkungen auf das ZNS (Kalm et al. 2009a, Kalm et al. 2009b). So kann es durch die Bestrahlung zu einer Aktivierung von Mikroglia kommen (Mildner et al. 2007), was bei der Untersuchung der Rolle mononukleärer Phagozyten im Rahmen der Alzheimerpathologie berücksichtigt werden muss.
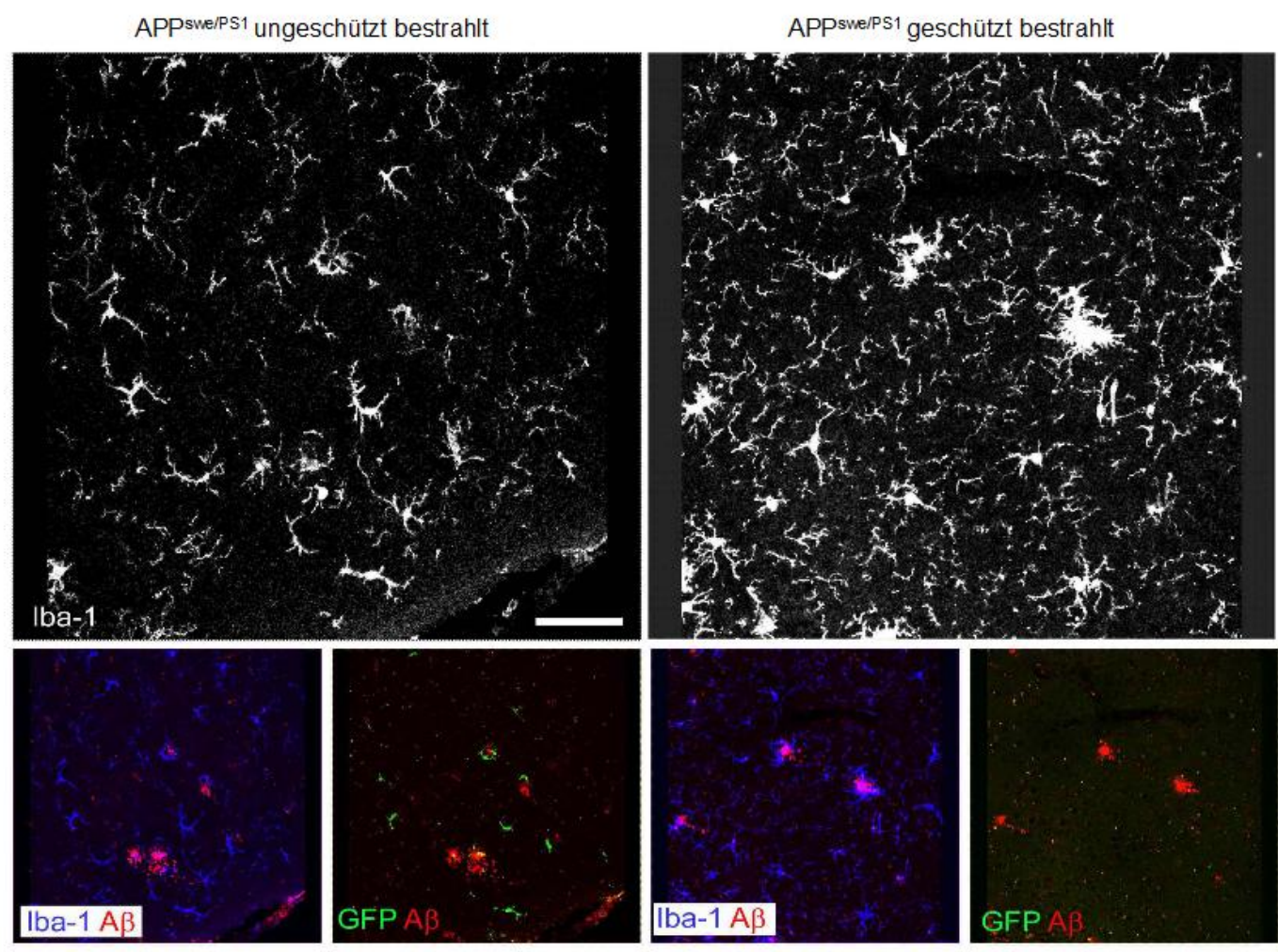

Abbildung 12: Morphologische Veränderungen des Mikroglianetzwerks in ungeschützt bestrahlten APP ${ }^{\text {swe/PS1 }}$ - Chimären. A: Die Immunhistochemische Untersuchung von Iba- $1^{+}$Mikroglia im Kortex von ungeschützt (links) und geschützt bestrahlten APP swe/PS1 - Chimären (rechts). Obere Reihe: Iba-1 (weiß), untere Reihe: Iba-1 (blau), GFP (grün), A $\beta$ (rot). Eingewanderte, mononukleäre $\mathrm{GFP}^{+}$- Phagozyten, die zum Teil mit Amyloidplaques assoziiert waren, fanden sich nur in ungeschützt bestrahlten APP ${ }^{\text {swe/PS1 }}$ - Chimären (links). Balken: $50 \mu \mathrm{m}$.

Deswegen wurde zunächst anhand einer Doppelfärbung für lba-1 und $A \beta$ das zelluläre, Iba- $1^{+}$- Netzwerk in den ungeschützt und geschützt bestrahlten APP ${ }^{\text {swe/PS1 }}$ Chimären verglichen. Hierunter fielen in den geschützt bestrahlten Tieren lediglich 
residente Iba- $1^{+}$- Mikroglia, in den ungeschützt bestrahlten Tieren kamen zudem die mononukleären Iba- $1^{+}-\mathrm{GFP}^{+}$- Phagozyten hinzu. In den geschützt bestrahlten Tieren waren die endogenen Iba- $1^{+}$- Zellen gleichmäßig im Hirnparenchym verteilt. Sie zeigten eine enge Assoziation mit den Plaques, was mit einer massiven reaktiven Veränderung verbunden war (Abb. 12 rechts). In den ungeschützt bestrahlten Tieren hingegen war das Netz der Fortsätze deutlich weniger dicht. Zudem zeigten die plaqueassoziierten Zellen eine amöboide Morphologie und nur wenige in das Plaquezentrum reichende Fortsätze (Abb. 12 links). Um die Unterschiede im zellulären Netzwerk besser verstehen zu können, wurden die Iba- $1^{+}$- Mikroglia quantifiziert. Dies ergab eine signifikante Reduktion der Mikroglia in den ungeschützt bestrahlten Tieren von $94 \pm 7 \mathrm{lba}-1^{+}-$Zellen $/ \mathrm{mm}^{2}$ (Kortex) und $110 \pm 9 \mathrm{lba}-1^{+}$Zellen/mm $\mathrm{mm}^{2}$ (Hippocampus) versus $205 \pm 21 \mathrm{lba}-1^{+}-$Zellen $/ \mathrm{mm}^{2}$ (Kortex) und $219 \pm$ $20 \mathrm{lba}-1^{+}$- Zellen/mm² (Hippocampus) in geschützt bestrahlten Tieren (Abb. 13).

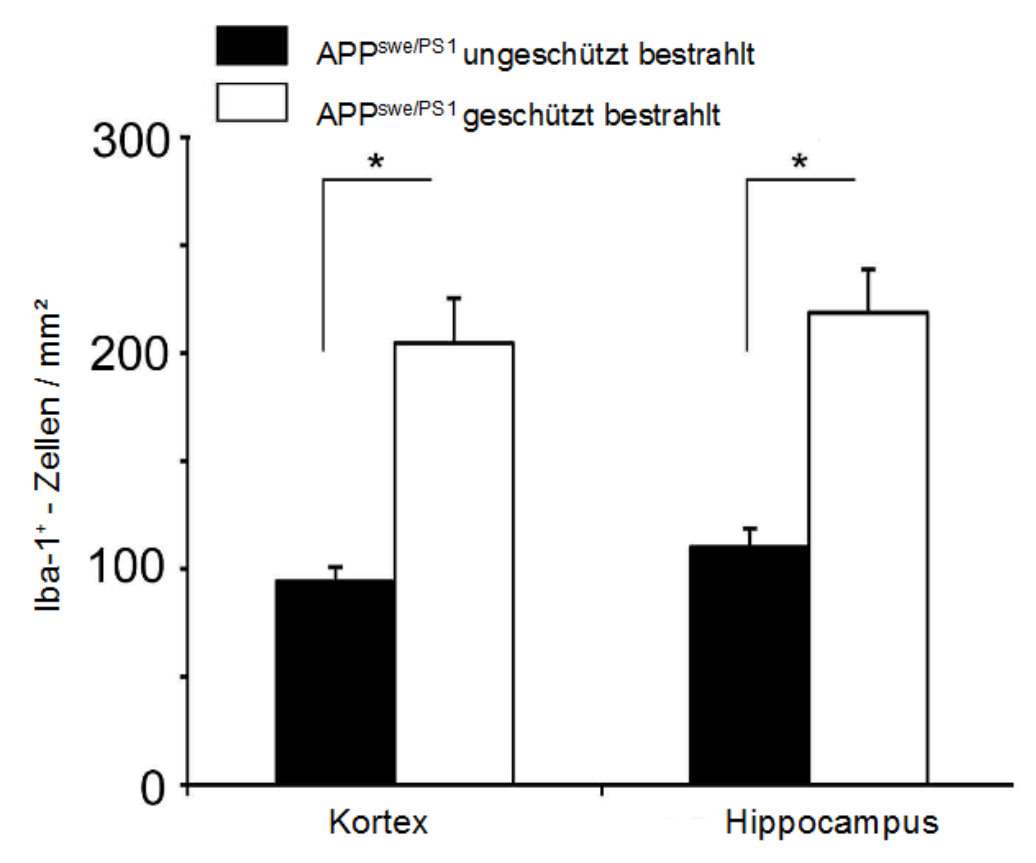

Abbildung 13: Reduktion der $\mathrm{Iba}-1^{+}-$Mikroglia in ungeschützt bestrahlten APPswe/PS1 Chimären. Iba- $1^{+}$- Mikroglia/mm $/ \mathrm{mm}^{2}$ im Kortex und Hippocampus von ungeschützt und geschützt bestrahlten APPswe/PS1 - Chimären. Mittelwerte \pm Standardabweichung, ${ }^{*}$ : statistische Signifikanz $\mathrm{p}<0,05$. 


\subsubsection{Unterschiede in der Reaktion der Mikroglia auf Amyloidplaques}

Um die zelluläre Reaktion an den Amyloidplaques näher zu untersuchen, wurde in beiden Gruppen die Anzahl der plaqueassoziierten Iba- $1^{+}$- Zellen in Abhängigkeit zur Plaquegröße $\left(0-999 \mu \mathrm{m}^{2}, 1000-2999 \mu \mathrm{m}^{2}\right.$, > $\left.2999 \mu \mathrm{m}^{2}\right)$ erhoben. In allen 3 Gruppen zeigte sich in den geschützt bestrahlten Tieren eine signifikant erhöhte Anzahl plaqueassoziierter Zellen im Kortex (0 - $999 \mu \mathrm{m}^{2}: 3,5 \pm 0,6 \mathrm{lba}-1^{+}$- Mikroglia/ Plaque in geschützt bestrahlten Tieren, $1,5 \pm 0,1 \mathrm{lba}-1^{+}-$Mikroglia/Plaque in ungeschützt bestrahlten Tieren, $1000-2999 \mu \mathrm{m}^{2}: 6,5 \pm 1,9 \mathrm{lba}-1^{+}$- Mikroglia/ Plaque in geschützt bestrahlten Tieren, 2,1 $\pm 0,7 \mathrm{Iba}_{-1}^{+}$- Mikroglia/Plaque in ungeschützt bestrahlten Tieren, $>2999 \mu \mathrm{m}^{2}: 7,3 \pm 1,5 \mathrm{lba}-1^{+}$- Mikroglia/Plaque in geschützt bestrahlten Tieren, 2,6 $\pm 0,4 \mathrm{Iba}-1^{+}-$Mikroglia/Plaque in ungeschützt bestrahlten Tieren) (Abb. 14).

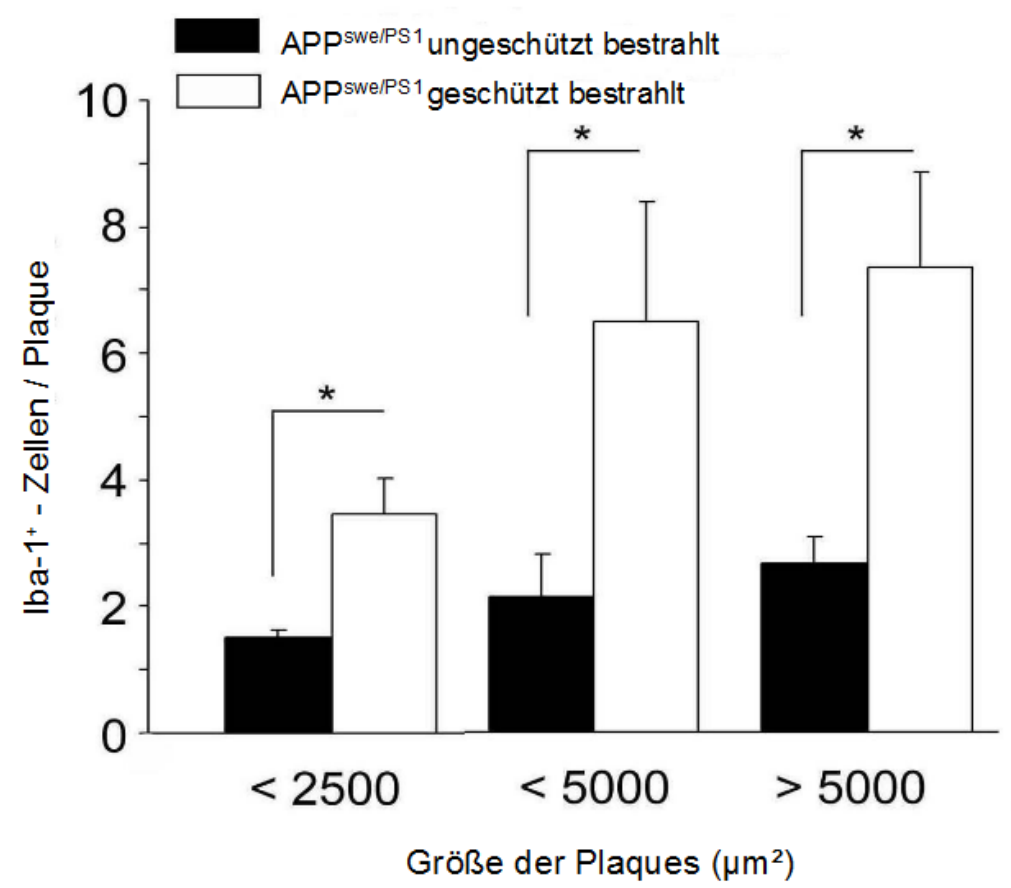

Abbildung 14: Reduktion der plaqueassoziierten Mikroglia in ungeschützt bestrahlten APP ${ }^{\text {swe/PS1 }}$ - Chimären. Quantifizierung der Iba- $1^{+}$- Zellen/Amyloidplaque in Abhängigkeit von verschiedenen Plaquegrößen in ungeschützt bestrahlten verglichen mit geschützt bestrahlten APPswe/PS1 - Chimären. Mittelwerte \pm Standardabweichung, * : statistische Signifikanz $p<0,05$. 

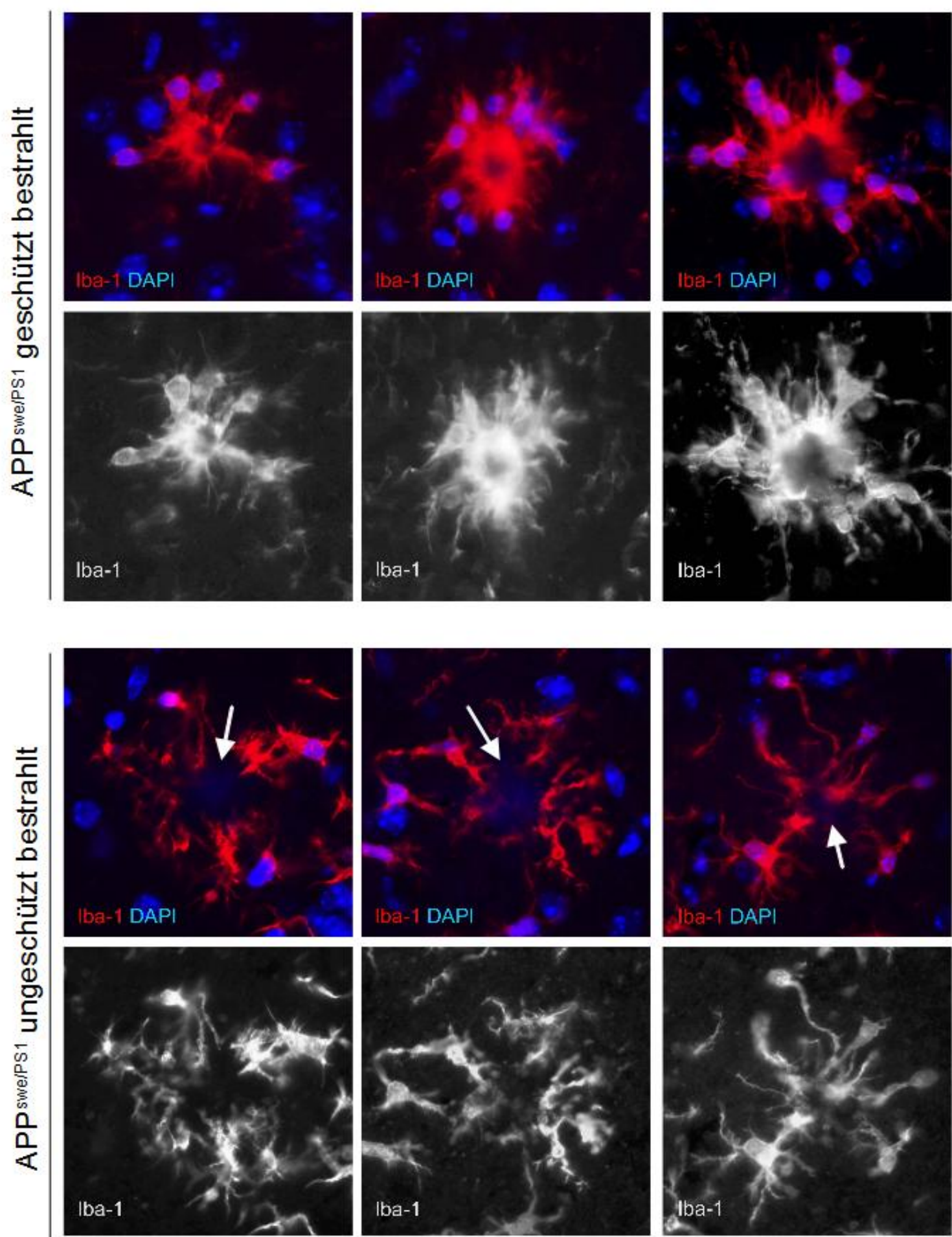

Abbildung 15: Morphologische Veränderungen der plaqueassoziierten Mikroglia in ungeschützt bestrahlten APP ${ }^{\text {swe/PS1 }}$ - Chimären. Im Vergleich zu plaqueassoziierten Mikroglia in geschützt bestrahlten APP ${ }^{\text {swe/PS1 }}$ - Chimären (oben) sind die Mikroglia in ungeschützt bestrahlten Tieren von amöboider Morphologie und weniger eng um den Plaque angeordnet (unten). Iba-1 (rot), DAPI - Kernfärbung (blau), Schwarz - Weiß - Aufnahme: Iba-1 (weiß). Pfeile zeigen das Plaquezentrum. 
Die Untersuchung der plaqueassoziierten Zellen im Detail bestätigte die zu Abbildung 12 formulierte Aussage. Im geschützt bestrahlten Gehirn waren die mikroglialen Fortsätze auf das Zentrum gerichtet, wo sie miteinander verschmolzen, sodass keine einzelnen Fortsätze mehr erkennbar waren. In dem ungeschützt bestrahlten Gehirn hingegen war die Ausrichtung der Fortsätze auf das Plaquezentrum deutlich schwächer ausgeprägt und die Zellen waren eher von amöboider Morphologie (Abb. 15).

\subsubsection{Veränderungen der Mikrogliamorphologie}

Um festzustellen, ob die morphologischen Veränderungen der $\mathrm{lba}-1^{+}$- Zellen in den ungeschützt bestrahlten Tieren nur auf die plaqueassoziierten Zellen beschränkt

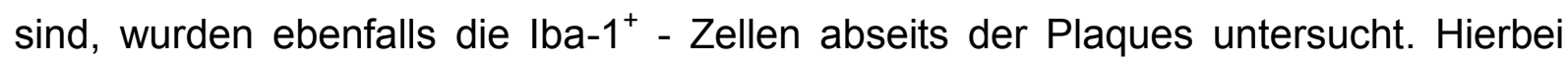
zeigten sich morphologische Unterschiede im Sinne einer Aktivierung. 18,9 $\pm 2,4$ \%

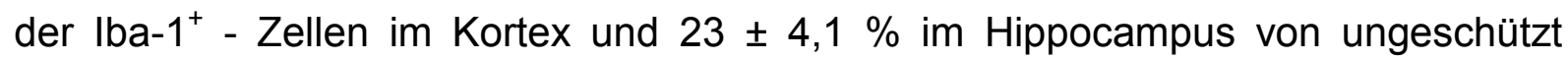
bestrahlten Tieren wiesen einen polygonalen Zellkern mit verdickten Fortsätzen auf, die entlang einer Längsachse ausgerichtet waren (Abb. 16, Abb. 17). Außerdem hatten diese Zellen auf ihren Fortsätzen zahlreiche feine Ausläufer, die in den geschützt bestrahlten Tieren nicht beobachtbar waren (Abb. 17 unten). Demgegenüber standen in beiden Gruppen die normalen, nicht - aktivierten Mikroglia mit ihren runden bis ovalen Zellkernen und den radiär angeordneten, fein verzweigten Fortsätzen (Abb. 17 oben).

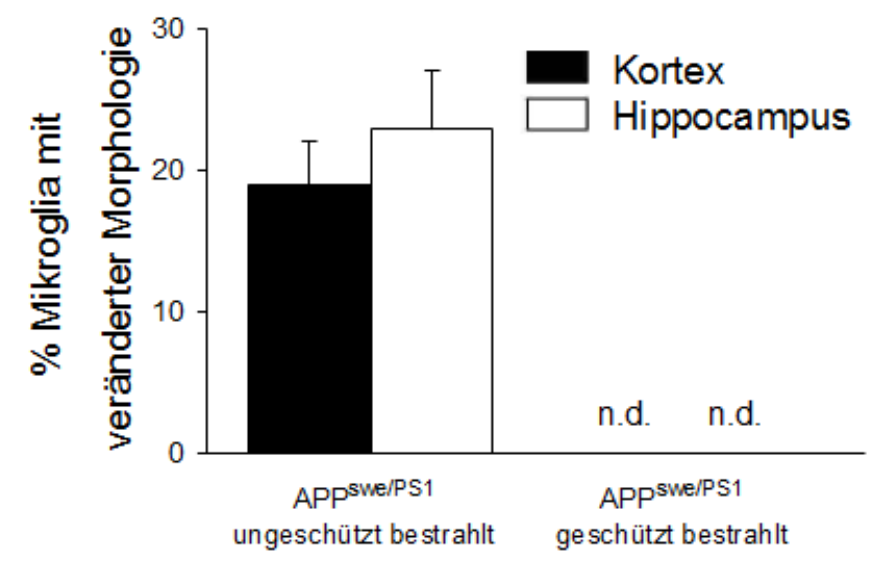

Abbildung 16: Prozentualer Anteil der nicht - plaqueassoziierten Mikroglia in Kortex und Hippocampus mit morphologischen Veränderungen in APP ${ }^{\text {swe/PS1 }}$ - Chimären. Im Gegensatz zu ungeschützt bestrahlten Tieren traten in geschützt bestrahlten Tieren keine Mikroglia mit morphologischen Veränderungen auf. Mittelwerte \pm Standardabweichung, n.d.: nicht detektierbar. 

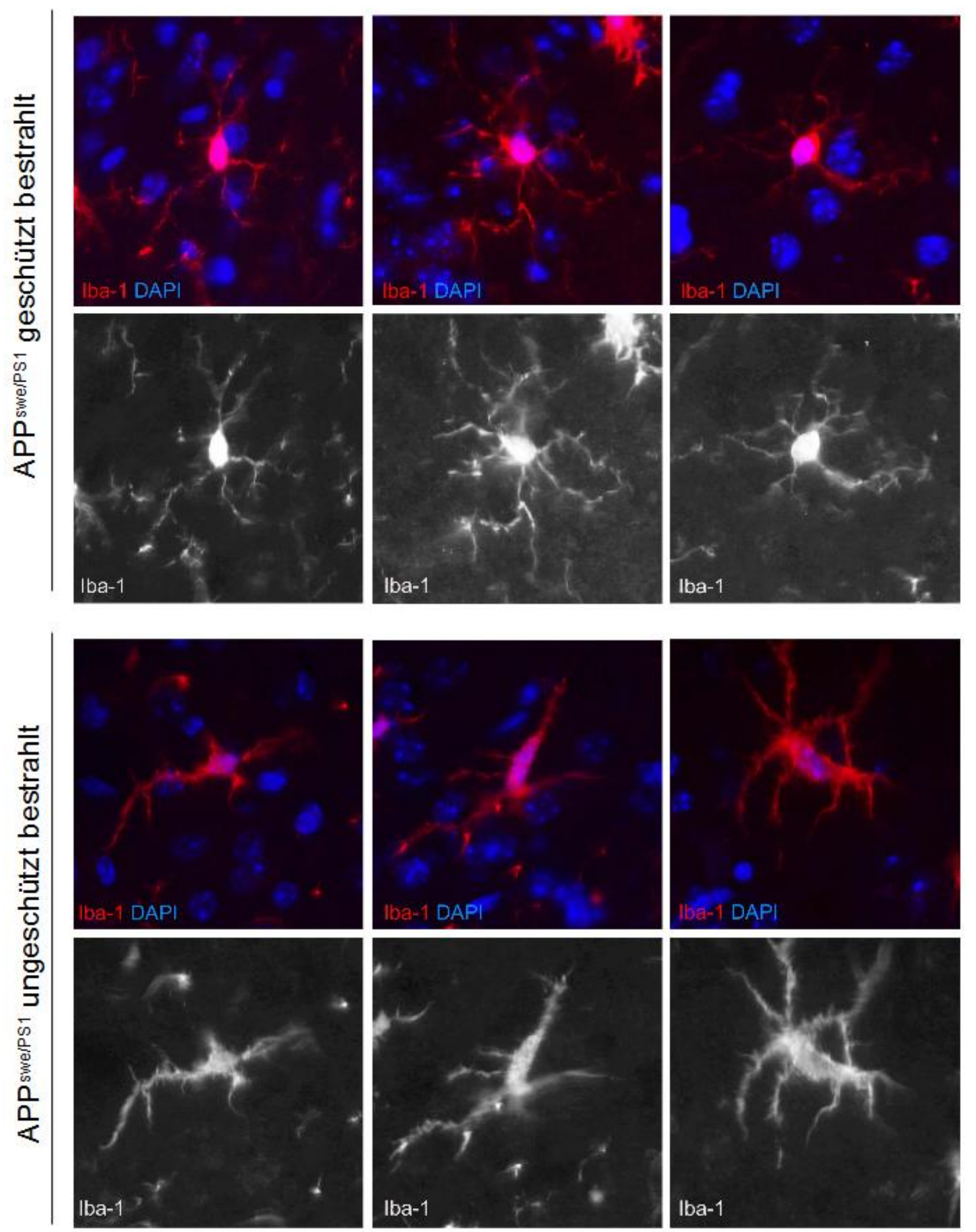

Abbildung 17: Morphologische Veränderungen der nicht - plaqueassoziierten Mikroglia in ungeschützt bestrahlten APP swe/PS1 - Chimären. Im Vergleich zu Mikroglia in geschützt bestrahlten APP ${ }^{\text {swe/PS1 }}$ - Chimären (oben) hatten die Mikroglia in ungeschützt bestrahlten Tieren teilweise größere Zellkörper sowie weniger und dickere Fortsätze, die durch feine Ausläufer charakterisiert sind (unten). Iba-1 (rot), DAPI - Kernfärbung (blau), Schwarz - Weiß - Aufnahme: Iba-1 (weiß). 
Um die Ursache und den Zeitpunkt der morphologischen Veränderungen näher zu ergründen, wurden die mononukleären $\mathrm{GFP}^{+}$- Phagozyten im Kortex auf dieselben morphologischen Veränderungen wie bei den residenten Mikroglia untersucht. $52 \pm$ $7,5 \%$ der mononukleären $\mathrm{GFP}^{+}$- Phagozyten wiesen ebenfalls die weiter oben in diesem Absatz beschriebenen morphologischen Veränderungen auf (Abb. 18).
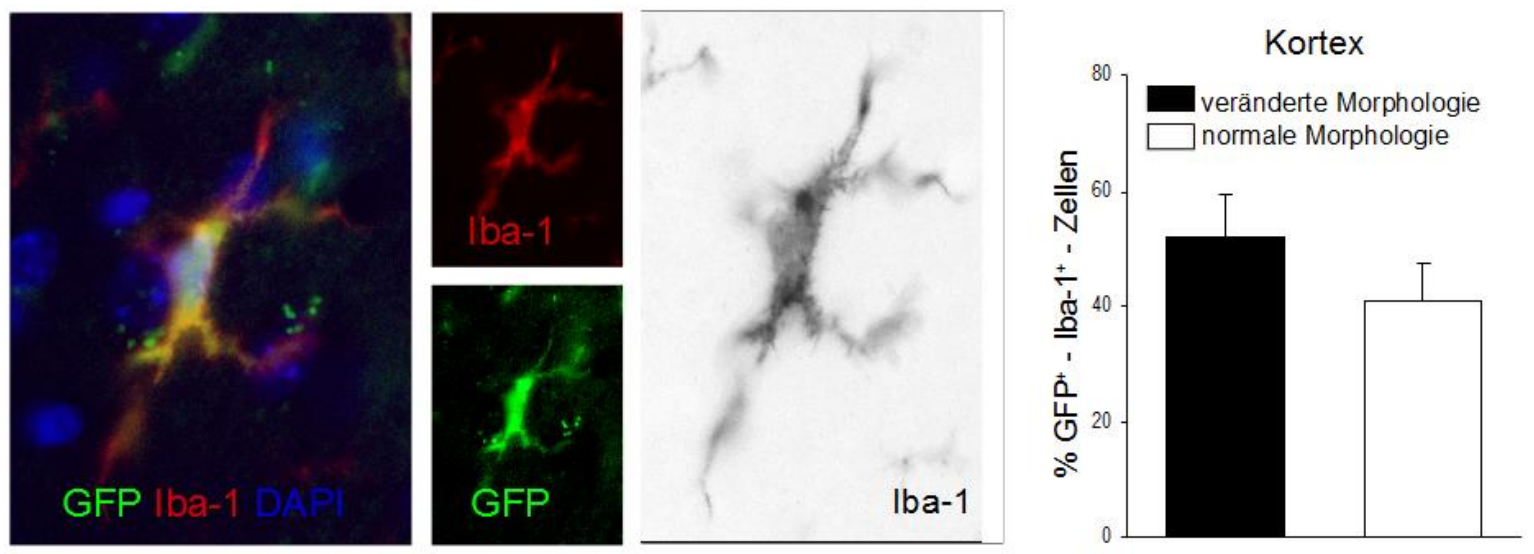

Abbildung 18: Die mononukleären $\mathrm{GFP}^{+}$- Phagozyten in ungeschützt bestrahlten APP ${ }^{\text {swe/PS1 }}$ - Chimären zeigten die gleichen morphologischen Veränderungen wie die residenten Mikroglia (s. Abb. 17). Immunhistochemische Darstellung der mononukleären $\mathrm{GFP}^{+}$Phagozyten mit veränderter Morphologie (links). Iba-1 (rot), DAPI - Kernfärbung (blau), GFP (grün). Die feinen Ausläufer auf den Fortsätzen werden besonders deutlich in der invertierten Schwarz - Weiß - Darstellung der lba-1 - Färbung (Mitte). Prozentualer Anteil der mononukleären $\mathrm{GFP}^{+}$- Phagozyten mit veränderter Morphologie (rechts).

\subsubsection{Veränderungen der Genexpression}

Es ist bekannt, dass die Bestrahlung des ZNS eine starke Regulation der Genexpression nach sich zieht (Mahmoud - Ahmed et al. 2006). Zur Untersuchung solcher Veränderungen in unseren Knochenmarkschimären führten wir quantitative Reverse - Transkriptase - PCRs mit Hirnhomogenaten von ungeschützt und

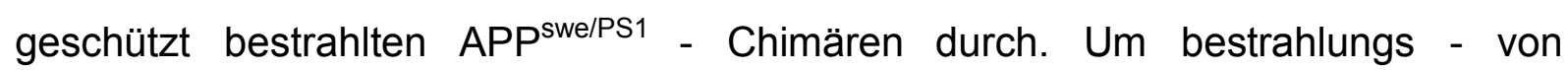
alzheimerbedingten Veränderungen abgrenzen zu können, wurden auch nicht rekonstituierte und rekonstituierte (= ungeschützt bestrahlte) Wildtypkontrollen hinzugenommen.

Chemokine spielen eine wichtige Rolle bei der Rekrutierung myeloischer Zellen zu ZNS - Pathologien und sind beim Morbus Alzheimer und seinen Tiermodellen in erhöhter Konzentration im Hirn nachweisbar (Akiyama et al. 2000). Die untersuchten 
Chemokine CCL3 und CXCL10 wiesen in den geschützt bestrahlten Tieren eine signifikant erhöhte Induktion der entsprechenden mRNA gegenüber der ungeschützt bestrahlten Tiere auf (CCL3: APP ${ }^{\text {swe/PS1 }}$ geschützt versus ungeschützt bestrahlt: 5,33 $\pm 0,19$ vs. $3,02 \pm 0,1$. CXCL10: APP ${ }^{\text {swe/PS1 }}$ geschützt vs. ungeschützt bestrahlt: $3,29 \pm$ 0,32 vs. 1,66 $\pm 0,2$ ) (Abb. 19 A, B). In bestrahlten Wildtyptieren sowie in transgenen Alzheimertiermodellen konnte keine Induktion der CXCL10 - mRNA nachgewiesen werden. Beim CCL3 führte die Bestrahlung der Wildtypen nicht zu einer Hochregulation der entsprechenden mRNA, jedoch war das Vorliegen der Alzheimerpathologie mit einer Induktion der mRNA verbunden (APP ${ }^{\text {swe/PS1 }}$ ungeschützt bestrahlt vs. Wildtyp ungeschützt bestrahlt: CCL3: $3,02 \pm 0,1$ vs. $1,17 \pm$ $0,07)$.

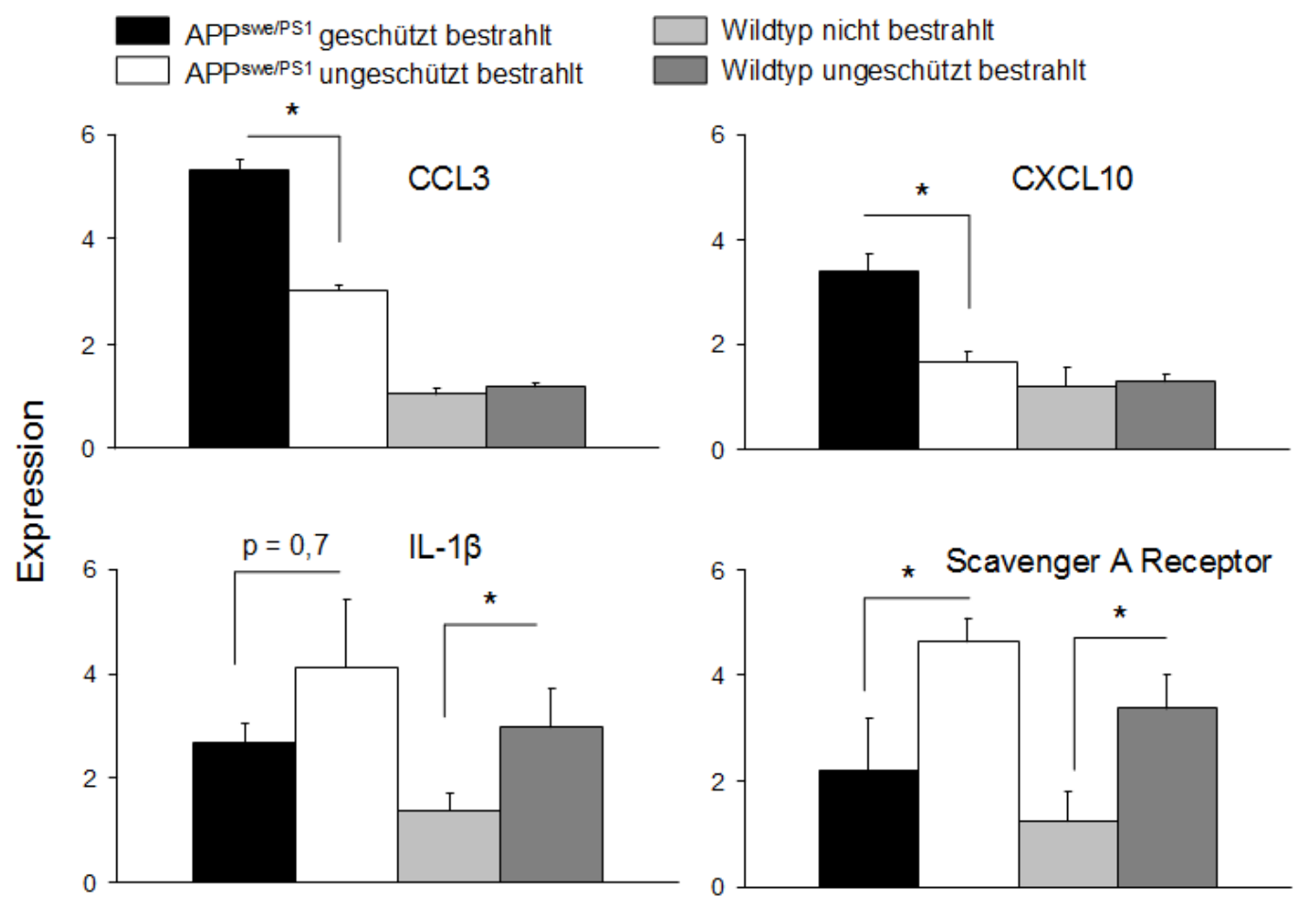

Abbildung 19: Veränderte Genexpression von Zytokinen und Chemokinen in ungeschützt bestrahlten APPswe/PS1 - Chimären. Quantitative Reverse - Transkriptase - PCR von CCL3 -, CXCL10 -, IL-1 $\beta$ - und Scavenger Receptor $A$ - mRNA - Expression in ungeschützt und geschützt bestrahlten APP ${ }^{\text {swe/PS1 }}$ - Chimären und Wildtypkontrollen. Relative Erhöhung der Expression verglichen mit der Expression von GAPDH. Mittelwerte \pm Standardabweichung, * : statistische Signifikanz $p<0,05$.

Der vorwiegend auf Mikroglia exprimierte Scavenger Receptor $A$ spielt eine wichtige Rolle bei der Phagozytose von A $\beta$ (Paresce et al. 1996). Die mRNA des Scavenger Receptors $A$ war in den ungeschützt bestrahlten Tieren im Bezug auf die geschützt 
bestrahlten Tiere signifikant erhöht (APP ${ }^{\text {swe/PS1 }}$ ungeschützt vs. geschützt bestrahlt: 4,64 $\pm 0,46$ vs. $2,22 \pm 0,97$ ) (Abb. 19 D). Es handelte sich dabei um einen reinen Bestrahlungseffekt, weil sich eine ähnliche Erhöhung der mRNA auch in ungeschützt bestrahlten gegenüber nicht - bestrahlten Wildtypen zeigte (Wildtyp ungeschützt vs. nicht - bestrahlt: $3,38 \pm 0,63$ vs. $1,25 \pm 0,56)$.

IL-1 $\beta$ ist ein zentrales proinflammatorisches Zytokin, das die Neuroinflammation beim Morbus Alzheimer vermittelt (Shaftel et al. 2007). Um herauszufinden, ob durch die Bestrahlung des ZNS dort eine proinflammatorische Reaktion verursacht wird, wurde die Expression der IL-1 $\beta$ - mRNA in ungeschützt und geschützt bestrahlten Tieren untersucht. In den ungeschützt bestrahlten Tieren war die IL-1 - mRNA stärker exprimiert, als in den geschützt bestrahlten Tieren (APP ${ }^{\text {swe/PS1 }}$ ungeschützt vs. geschützt bestrahlt: $4,14 \pm 1,29$ vs. $2,67 \pm 0,36$ ) (Abb. 19 C). Allerdings war dieser Unterschied mit $p=0,7$ nicht signifikant und kann so lediglich als Trend interpretiert werden.

3.5 Reduktion des A - Gehalts im APP ${ }^{\text {swe/PS1 }}$ - Gehirn durch Bestrahlung Aufgrund der beschriebenen Veränderungen im Expressionsprofil im ZNS und der beobachteten, morphologischen Veränderungen der Mikroglia durch Bestrahlung schließt sich die Frage an, ob die Bestrahlung auch Auswirkungen auf den $A \beta$ Gehalt des Gehirns hat. Dazu wurde dieser aus Hirnlysaten mittels ELISA und Western Blot in geschützt und ungeschützt bestrahlten APP ${ }^{\text {swe/PS1 }}$ - Chimären bestimmt. Wie zuvor gezeigt wurde, kommt es nur zu einer Infiltration des ZNS durch mononukleäre, GFP - exprimierende Phagozyten, wenn das Gehirn durch eine Bestrahlung konditioniert worden ist (Abb. 10). Des Weiteren konnten wir zeigen, dass es zu bestrahlungsbedingten morphologischen Veränderungen der residenten, endogenen Mikroglia kommt (Abb. 17). Zur Beurteilung des $A \beta$ - Gehalts wurde mittels ELISA lösliches und unlösliches $A \beta_{40}$ und $A \beta_{42}$ aus Hirnlysaten bestimmt. Während das lösliche $A \beta_{40}$ und $A \beta_{42}$ in beiden Gruppen vergleichbare Mengen erreichte, war das unlösliche $A \beta_{40}$ und $A \beta_{42}$ in den ungeschützt bestrahlten Tieren signifikant erniedrigt (Abb. 20 A). Um festzustellen, ob die Reduktion des unlöslichen $A \beta$ auf eine veränderte Expression oder Prozessierung zurückzuführen ist, wurde ein Western Blot für APP und $\beta$-CTF durchgeführt. Die Quantifizierung des APP wies keine Unterschiede zwischen ungeschützt und geschützt bestrahlten APP ${ }^{\text {swe/PS1 - }}$ Chimären auf. Gleiches galt für das $\beta$-CTF, welches als Spaltprodukt der $\beta$ - 
Sekretase die Aktivität dieses Enzyms angibt. Zusätzlich konnte im Western Blot eine signifikante Reduktion des Gesamt - $A \beta$ in den ungeschützt bestrahlten Tieren gezeigt werden (Abb. 20 B), was die Ergebnisse des ELISA bestätigt. Als Ursachen für die Reduktion des unlöslichen $A \beta$ können also eine bestrahlungsbedingt unterschiedlich starke Expression des APP sowie eine veränderte Prozessierung durch die $\beta$ - Sekretase ausgeschlossen werden, was auf eine verstärkte Elimination des unlöslichen $A \beta$ in den ungeschützt bestrahlten Tieren schließen lässt.

A
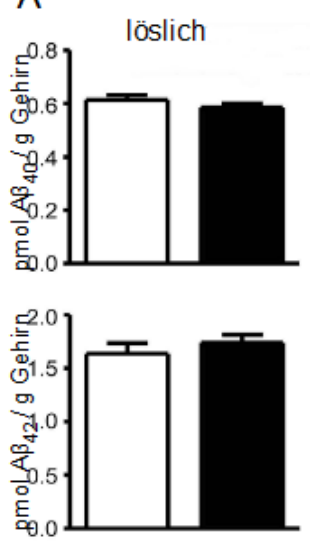

$\square \mathrm{APP}^{\text {swe/PS1}}$ ge schützt bestrahlt
$\mathrm{APP}^{\text {swe/PS1 }}$ ungeschützt be strah
B
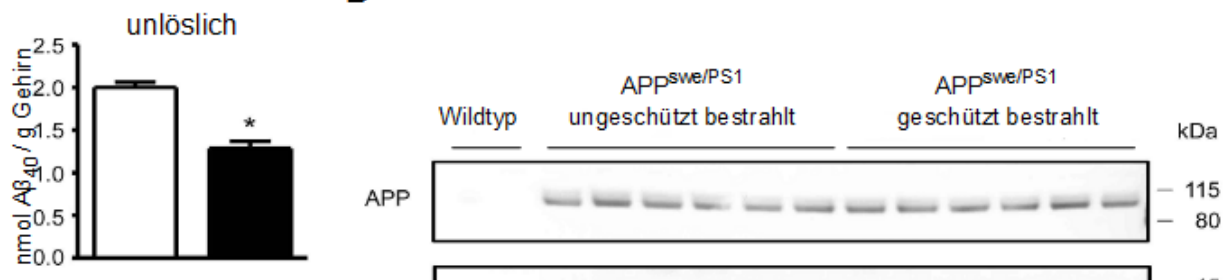

$\beta-\mathrm{CTF}$

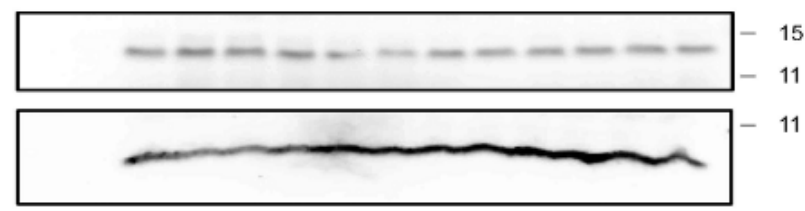

Abbildung 20: Reduzierte unlösliche $A \beta$ - Level, aber unveränderte APP - Expression und Prozessierung in ungeschützt bestrahlten APP swe/PS1 - Chimären. A: Quantifizierung von löslichem und unlöslichem $A \beta_{40}$ und $A \beta_{42}$ aus Hirnlysaten in ungeschützt und geschützt bestrahlten APP ${ }^{\text {swelPS1 }}$ - Chimären mittels ELISA. * : statistische Signifikanz $p<0,05$. B: Quantifizierung der Proteine APP, A $\beta$ und $\beta-C T F$ in ungeschützt und geschützt bestrahlten APP ${ }^{\text {swe/PS1 }}$ - Chimären mittels Western Blot. Wildtypen dienten als Negativkontrolle.

Bedeutendster Bestandteil der Amyloidplaques ist das unlösliche A $\beta$ (Shankar et al. 2008). Aus diesem Grund versuchten wir, die biochemisch nachgewiesene Reduktion des unlöslichen $A \beta$ auch histologisch zu bestätigen. Dazu bestimmten wir den Prozentsatz der $A \beta^{+}$- Fläche aller Plaques in Bezug auf die Gesamtfläche des Schnittes. Sowohl im Kortex als auch im Hippocampus konnten in den ungeschützt bestrahlten Tieren gegenüber den geschützt bestrahlten keine signifikanten Unterschiede festgestellt werden (Abb. 21). Dies stellt jedoch keinen grundsätzlichen Widerspruch zu den ELISA - Daten dar, weil die histologische Quantifizierung deutlich unpräziser als die biochemische ist und deshalb nur sehr starke Unterschiede in der Plaquefläche aufzeigen kann (Haass und Selkoe 2007). 


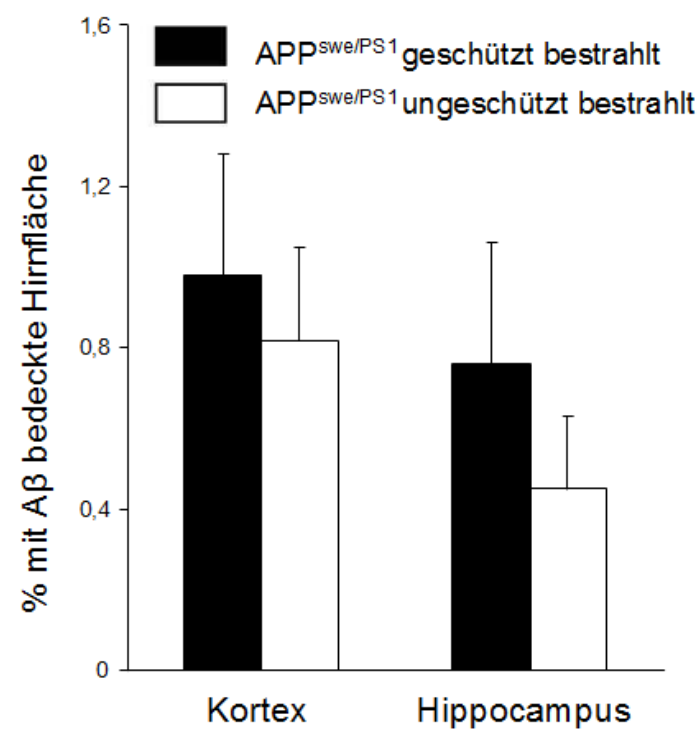

Abbildung 21: Kein signifikanter Unterschied der $A \beta$ - immunreaktiven Fläche in Kortex und Hippocampus von ungeschützt und geschützt bestrahlten APP ${ }^{\text {swe/PS1 }}$ - Chimären. Histologische Quantifizierung des prozentualen Anteils der mit $A \beta$ bedeckten Hirnfläche in ungeschützt und geschützt bestrahlten APP ${ }^{\text {swe/PS1 }}$ - Chimären.

\subsection{Mononukleäre Phagozyten sind nicht ursächlich für die Reduktion}

$\operatorname{des} A \beta$ - Gehalts im APP swe/PS1 - Gehirn

Nachdem gezeigt wurde, dass in ungeschützt bestrahlten APP ${ }^{\text {swe/PS1 }}$ - Gehirnen der $A \beta$ - Gehalt reduziert ist, wurde nach der Ursache gesucht. Es wurde postuliert, dass die eingewanderten mononukleären Phagozyten, im Vergleich zu den residenten Mikroglia, eine erhöhte Effizienz bei der A $\beta$ - Phagozytose aufweisen (Simard et al. 2006). Um die Rolle der mononukleären Phagozyten im Rahmen der Alzheimerpathologie eingehender zu untersuchen, wurden Knochenmarkschimären als Kontrollen benötigt, die zwar ungeschützt bestrahlt wurden, aber trotzdem keine eingewanderten mononukleären Phagozyten im Gehirn aufwiesen und so die Abgrenzung gegenüber unspezifischen Bestrahlungsfolgen ermöglichten. Diese Bedingungen erfüllten die mit $\mathrm{CCR}^{-/-}$- GFP - Knochenmark rekonstituierten, ungeschützt bestrahlten APP ${ }^{\text {swe/PS1 }}$ - Mäuse in idealer Weise, die mit Chimären verglichen wurden, die ebenfalls ungeschützt bestrahlt wurden, jedoch $\mathrm{CCR}^{+/+}$GFP - Knochenmark erhalten hatten (s. Abb. 6 und 7). Unerwarteterweise zeigte der ELISA für das lösliche $A \beta_{40}$ und das unlösliche $A \beta_{40}$ und $A \beta_{42}$ zwischen beiden Gruppen keine signifikanten Unterschiede (Abb. 22 A). Auch im Western Blot für das Gesamt - A $\beta$ wurde dies bestätigt (Abb. 22 B). Die Quantifizierung der Proteine APP 
und $\beta$-CTF ergab ebenfalls keine signifikanten Unterschiede, sodass eine veränderte APP - Expression und Aktivität der $\beta$ - Sekretase durch die Anwesenheit mononukleärer Phagozyten im ZNS ausgeschlossen werden konnte (Abb. 22 B). Damit wurde gezeigt, dass die Reduktion des $A \beta$ - Gehalts in ungeschützt bestrahlten APP ${ }^{\text {swe/PS1 }}$ - Chimären (Abb. 20) keine Folge der Einwanderung mononukleärer Phagozyten ist, sondern durch bestrahlungsbedingte Veränderungen im ZNS verursacht wird.
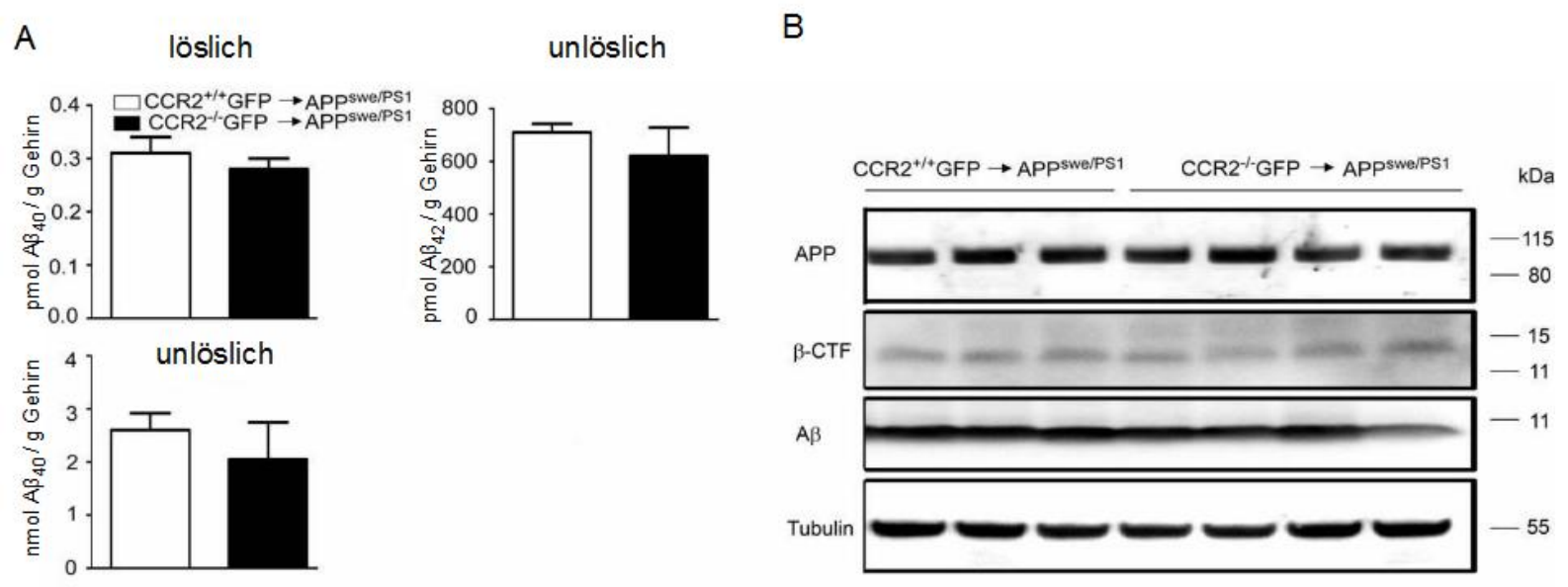

Abbildung 22: Kein signifikanter Unterschied im $A \beta$ - Level sowie unveränderte APP Expression und - Prozessierung in ungeschützt bestrahlten CCR2 ${ }^{-/-}-$GFP $\rightarrow$ APP $^{\text {swe/PS1 }}$ Chimären verglichen mit $C C R 2^{+/+}-$GFP $\rightarrow$ APP ${ }^{\text {swe/PS1 }}$ - Chimären. A: Quantifizierung von löslichem und unlöslichem $A \beta_{40}$ und $A \beta_{42}$ aus Hirnlysaten in ungeschützt bestrahlten $C C R 2^{-1-}$ GFP $\rightarrow$ APP ${ }^{\text {swe/PS1 }}$ - Chimären und CCR2 ${ }^{+/+}$- GFP $\rightarrow$ APP ${ }^{\text {swe/PS1 }}$ - Chimären mittels ELISA. B: Quantifizierung der Proteine APP, $\beta-C T F, A \beta$ und Tubulin in ungeschützt bestrahlten CCR2 ${ }^{-\alpha_{-}}$GFP $\rightarrow$ APP ${ }^{\text {swe/PS1 }}$ - Chimären und $\mathrm{CCR}^{+/+}-$GFP $\rightarrow$ APP $^{\text {swelPS1 }}$ - Chimären mittels Western Blot. Wildtypen als Negativkontrolle. 


\section{Diskussion}

Hämatogene mononukleäre Phagozyten im ZNS wurden bisher in einer Vielzahl neurologischer Erkrankungen beschrieben (Yong und Rivest 2009). Allgemein akzeptiert ist die Ansicht, dass diese Phagozyten myeloischen Ursprungs sind (Ransohoff und Perry 2009). Allerdings war die exakte Subpopulation der monozytären Vorläuferzellen beim Morbus Alzheimer bisher unbekannt. Um diese Frage zu beantworten, wurde in der vorliegenden Arbeit auf eine genetisch veränderte Maus zurückgegriffen, die sich durch einen phänotypischen Defekt in der Zusammensetzung der Monozytenpopulationen auszeichnet. Aufgrund der CCR2 Defizienz können die inflammatorischen Monozyten ( $\left.L y-6 C^{\text {hi }}, C C R 2^{+}\right)$nicht aus dem Knochenmark migrieren, so dass es zu einer selektiven Reduktion dieser Zellpopulation im Blut kommt, wohingegen die residenten Monozyten (Ly-6C ${ }^{\text {low }}$, CCR2') davon nicht betroffen sind (Serbina und Pamer 2006). Auch bei der Transplantation von CCR2 - defizienten, hämatogenen Knochenmarkszellen in bestrahlten APP ${ }^{\text {swe/PS1 }}$ - Mäusen konnte eine selektive Reduktion der peripheren, inflammatorischen Monozyten ( $\mathrm{Ly}-6 \mathrm{C}^{\mathrm{hi}}, \mathrm{CCR} 2^{+}$) erreicht werden. Interessanterweise war in diesen APP ${ }^{\text {swe/PS1 }}$ - Tieren mit der peripheren Reduktion der inflammatorischen Monozyten auch eine drastische Reduktion der mononukleären Phagozyten im ZNS verbunden. In Anbetracht des allseits etablierten Konzepts, dass Monozyten unter bestimmten Bedingungen zu Gewebemakrophagen differenzieren können (Geissmann et al. 2010), ist es damit wahrscheinlich, dass in diesem Alzheimertiermodell die $\mathrm{Ly}_{-} 6 \mathrm{C}^{\mathrm{hi}}-\mathrm{CCR}^{+}$- Monozyten die Vorläuferzellen der mononukleären Phagozyten im Gehirn sind.

Allerdings haben neueste Untersuchungen gezeigt, dass CCR2 nicht nur von Ly- $6 C^{\text {hi }}$

- Monozyten exprimiert wird, sondern auch von einem kleinen Anteil myeloischer Vorläuferstammzellen, die bei entzündlichen Prozessen CCR2 - abhängig in die peripheren Organe rekrutiert werden ( $\mathrm{Si}$ et al. 2010). Da bei der Injektion von Knochenmark im Rahmen der Knochenmarkstransplantation myeloische Stammzellen unphysiologischerweise ins Blut gelangen (Ajami et al. 2007), ist es daher alternativ möglich, dass diese myeloischen $\mathrm{CCR}^{+}$- Stammzellen Vorläuferzellen der mononukleären Phagozyten im Gehirn darstellen und bei Ausschaltung des CCR2 - Gens nicht mehr ins Gehirn einwandern können. Diese Möglichkeit ist zur Zeit noch nicht geklärt und bedarf weiterer Forschung. 
Die verbreitete Methode zur Untersuchung mononukleärer Phagozyten im ZNS ist der Knochenmarkschimärismus, der sich zur Konditionierung des Empfängers der Bestrahlung bedient. Es wurden jedoch Zweifel geäußert, dass diese Methode physiologische Verhältnisse abbildet, weil die Bestrahlung im Verdacht steht, die Bluthirnschranke zu öffnen und den Eintritt mononukleärer Phagozyten zu ermöglichen (Ransohoff und Perry 2009). Unter physiologischen Bedingungen findet keine Rekrutierung mononukleärer Phagozyten statt (Mildner et al. 2007). Zusätzlich besteht aber auch im Rahmen des Morbus Alzheimer eine Störung der Bluthirnschranke (Algotsson und Winblad 2007, Bowmann et al. 2007).

Die Frage, ob es beim Morbus Alzheimer zu einer Infiltration von myeloischen Zellen kommt, nimmt eine zentrale Position bei möglichen Therapiekonzepten ein. So wird von einigen Wissenschaftlern eine zelluläre Immuntherapie vorgeschlagen, bei der genetisch veränderte oder alternativ aktivierte, mikrogliale Vorläuferzellen injiziert werden sollen, die zu einer Reduktion oder gar zu einer Inhibierung der Erkrankung führen könnten (Lebson et al. 2010, Malm et al. 2010). Allerdings ist eine durchlässige Bluthirnschranke eine Grundvoraussetzung für eine solche Therapie, die es den Vorläuferzellen ermöglicht, in das ZNS zu migrieren. Mit den in der vorliegenden Arbeit hergestellten, experimentellen Gruppen von geschützt bzw. ungeschützt bestrahlten transgenen APP ${ }^{\text {swe/PS1 }}$ - Tieren wurde ein experimentelles Design gewählt, welches die Unterscheidung zwischen einer strahlungsbedingten und einer alzheimerpathologiebedingten Bluthirnschrankenstörung erlaubt und so entscheidend zum Verständnis des Morbus Alzheimer beitragen kann.

Im ZNS 10 - Monate - alter APP'swe/PS1 - Chimären fanden sich bei ungeschützter Bestrahlung zahlreiche mononukleäre $\mathrm{GFP}^{+}$- Phagozyten, die allerdings keine

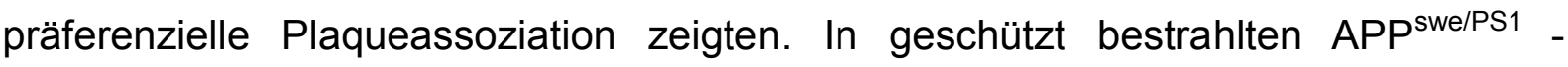
Chimären hingegen blieb eine Migration von peripheren Monozyten ins ZNS vollständig aus. Die signifikante Reduktion im Blutchimärismus von T- und B-Zellen, Granulozyten sowie inflammatorischer Monozyten 7 Monate nach Rekonstitution in geschützt bestrahlten Chimären reduziert die Aussagekraft dieser Daten nicht. Wenn die Höhe des Blutchimärismus mit der Zahl der rekrutierten mononukleären Phagozyten im ZNS korrelieren würde, müsste man in den geschützt bestrahlten

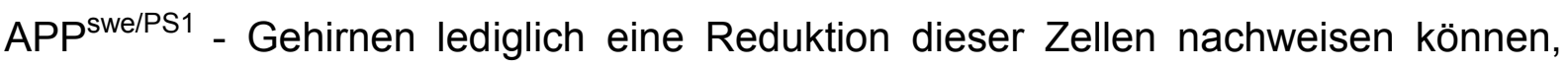
aber kein vollständiges Fehlen, wie es in dieser Arbeit gezeigt wurde. 
Diese Ergebnisse belegen, dass die pathologischen ZNS - Bedingungen in diesem Tiermodell allein, ohne die Bestrahlung, nicht ausreichen, um die Einwanderung mononukleärer Phagozyten zu bewirken. Eine Störung der Bluthirnschranke liegt also in diesem APP ${ }^{\text {swe/PS1 }}$ - Mausmodell nicht vor. Daher lassen die vorliegenden Daten Zweifel an einer potentiellen, therapeutischen Verwendung von Monozyten als "Trojanische Pferde“ aufkommen, da die Rekrutierung dieser Zellen nur bestrahlungsbedingt zu sein scheint.

Allerdings stehen diese Ergebnisse im Gegensatz zu einer kürzlich veröffentlichten Studie, in der durch die andauernde Infusion in die Halsgefäße von gentechnisch veränderten, myeloischen $\mathrm{CD}_{11 \mathrm{~b}^{+}}$- Zellen aus dem Knochenmark die Amyloidablagerung in einem Alzheimertiermodell gestoppt werden konnte und zahlreiche Donorzellen an den Plaques nachweisbar waren (Lebson et al. 2010). Warum es in dieser Publikation zu einer Rekrutierung peripherer, myeloischer Zellen ins ZNS ohne Gewebekonditionierung kommt, ist nicht bekannt, könnte aber durch Verwendung eines anderen Alzheimertiermodells erklärt werden. Ein weiterer Grund könnte die unphysiologisch hohe Anzahl transferierter myeloischer Zellen sein, die mit $5 \times 10^{6}$ Zellen etwa dem 10 - fachen der zirkulierenden Monozyten in der Maus entspricht (Mildner et al. 2007).

Weiterhin ist kritisch anzumerken, dass das in der vorliegenden Arbeit verwendete

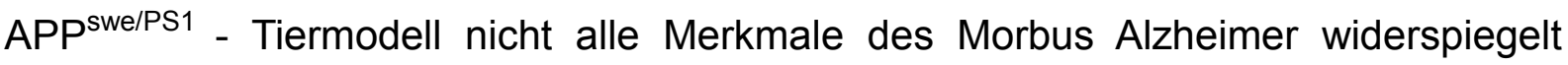
(s.Absatz 2.2), sodass eine Rekrutierung mononukleärer Phagozyten beim Alzheimerpatienten nicht mit letzter Sicherheit ausgeschlossen werden kann. Bei einer Subpopulation von Alzheimerpatienten wurde über den Nachweis von im Liquor cerebrospinalis physiologischerweise nicht vorkommendem, aus dem Blut filtriertem Albumin, eine pathologische Durchlässigkeit der Bluthirnschranke, zumindest für Proteine, beschrieben (Algotsson und Winblad 2007, Bowmann et al. 2007).

Auch wenn die Einwanderung mononukleärer Phagozyten unter anderen Bedingungen (späteres Krankheitsstadium, dem Vollbild des Morbus Alzheimer) nicht ausgeschlossen erscheint, ist besonders eine Therapie in der Frühphase des Morbus Alzheimer zur Prävention kognitiver Defizite notwendig und eine weitere Erforschung der Mechanismen, unter denen die Öffnung der Bluthirnschranke stattfindet, sinnvoll, um mit dem Einsatz dieses Wissens eine zelluläre Gentherapie möglichst effizient zu gestalten. Ein Beispiel dafür ist die osmotische Öffnung der Bluthirnschranke mit Mannitol (Marchi et al. 2010). 
Nachdem gezeigt wurde, dass die Alzheimerpathologie des APP ${ }^{\text {swe/PS1 }}$ - Tiermodells allein nicht hinreichend für die Rekrutierung mononukleärer Phagozyten ist, konnte hier gezeigt werden, dass dagegen die Bestrahlung des Gehirns eine notwendige Voraussetzung dafür ist. Dies ist bereits für gesunde Mäusegehirne belegt (Mildner et al. 2007), bislang jedoch nicht für ein Tiermodell einer neurodegenerativen Erkrankung.

Diese neuen Erkenntnisse haben, wie bereits erwähnt, weitreichende Folgen für eine mögliche Therapie beim Morbus Alzheimer. Die eingewanderten, mononukleären Phagozyten werden als Vehikel für den Transfer nutzbringender Gene ins ZNS diskutiert (Priller et al. 2001, Lebson et al. 2010). Um gezielt die mononukleären Phagozyten genetisch zu manipulieren und damit die Wahrscheinlichkeit von unerwünschten Nebenwirkungen zu minimieren, ist die Kenntnis der entsprechenden Vorläuferzellen im Blut, also der Ly-6Chi - CCR2 ${ }^{+}$- Monozyten, eine notwendige Voraussetzung. Außerdem wurde in dieser Arbeit gezeigt, dass die Einwanderung mononukleärer Phagozyten ins ZNS von APP ${ }^{\text {swe/PS1 }}$ - Tieren physiologischerweise nicht stattfindet und erst der vorherigen Bestrahlung des Gehirns als Konditionierung bedarf. Es gibt jedoch auch ZNS - Erkrankungen, bei denen eine Rekrutierung mononukleärer Phagozyten ohne Bestrahlung möglich ist. So wurde zum Beispiel bei Patienten mit X - gekoppelter Adrenoleukodystrophie eine Therapie mit gentechnisch veränderten Stammzellen und Konditionierung durch Cyclophosphamid und Busulfan durchgeführt und ein positiver Effekt beobachtet, der auf den Gentransfer durch mononukleäre Phagozyten ins ZNS zurückgeführt wurde (Cartier et al. 2009). Die Krankheit weist allerdings per se eine massive Störung der Bluthirnschranke auf, erkennbar an den kernspintomographischen Anreicherungen von Gadolinium in den Entmarkungsherden. Außerdem ist unklar, ob die Chemotherapie Einfluss auf die Integrität der Bluthirnschranke hat. Zur Untersuchung der Rekrutierung mononukleärer Phagozyten sind deswegen schonendere Methoden zur Konditionierung nötig.

In zahlreichen Untersuchungen wurden mononukleäre Phagozyten in der Nähe von Amyloidplaques beschrieben und es wurde postuliert, dass diese Zellen die Ablagerung von Amyloidplaques beschränken können (Simard et al. 2006). Auch wenn nach unseren Ergebnissen ebenfalls eingewanderte mononukleäre Phagozyten an den Plaques beobachtet wurden, finden sich diese Zellen nur an 25 
\% aller Plaques im Kortex. Im APP23 - Tiermodell waren nach 16 Monaten nur an 20 \% aller Plaques vom Donor abstammende mononukleäre Phagozyten gefunden worden und keine statistisch signifikante Korrelation zwischen der gesamten Plaquefläche und der Zahl der eingewanderten mononukleären Phagozyten (Stalder et al. 2005). Ein weiteres Indiz dafür, dass die mononukleären Phagozyten nicht gezielt zu den Plaques bzw. allenfalls zu einer Subpopulation von Plaques rekrutiert werden, ist die Tatsache, dass von allen mononukleären Phagozyten nur knapp 30 \% plaqueassoziiert sind. In der Literatur finden sich diesbezüglich noch niedrigere Zahlen. So waren im APP ${ }^{\text {swe/PS1 }}$ - Tiermodell 9 Monate nach Rekonstitution nur 6 \% der mononukleären Phagozyten plaqueassoziiert (Malm et al. 2005). Bei einer so geringen Assoziation mononukleärer Phagozyten mit Amyloidplaques ist ein entscheidender Einfluß auf die Plaquegröße sowie die gezielte Rekrutierung aus dem Blut zu den Plaques unwahrscheinlich.

Die Bestrahlung des Kopfes hat weitreichende Auswirkungen auf das menschliche Gehirn. Entscheidend ist, dass sich bei bis zu 50 \% der Langzeitüberlebenden nach Schädelbestrahlung kognitive Defizite entwickeln (Crossen et al. 1994), die besonders ausgeprägt nach der pädiatrischen Radiotherapie sind (Spiegler et al. 2004). Auch in Mäusen und Ratten ließen sich diese Ergebnisse reproduzieren (Raber et al. 2004, Hodges et al. 1998). Neurone sind postmitotische Zellen und als solche bestrahlungsresistent; allerdings werden die kognitiven Defizite unter anderem auf eine bestrahlungsbedingte Störung der adulten Neurogenese zurückgeführt (Zhu et al. 2009, Andres - Mach et al. 2008). Wichtig ist die Unterscheidung von akut vorübergehenden und chronischen Bestrahlungsfolgen.

Auswirkungen der Bestrahlung auf die Bluthirnschranke sind schon länger bekannt. Bei Bestrahlung des Gehirns ist das Zytokin TNF-a im Sinne einer entzündlichen Reaktion im Serum erhöht (Kaya et al. 2004). Hinzu kommen eine erhöhte Durchlässigkeit der Bluthirnschranke für Proteine, was sich durch eine verminderte Expression von Proteinen erklärt, aus denen die tight junctions zusammengesetzt sind (Occludin, ZO-1). Weiterhin konnte eine verminderte Reaktivität für GFAP als Indiz einer Astrozytendysfunktion beobachtet werden (Kaya et al. 2004). Interessant ist, dass alle diese Veränderungen nur maximal einige Tage andauern und sich anschließend wieder zurückbilden. Möglicherweise gibt es nur ein kurzes Zeitfenster innerhalb dessen die Bluthirnschranke geöffnet ist und die Infiltration mononukleärer 
Phagozyten möglich ist. Danach erhält sich diese Zellpopulation offenbar durch Proliferation, was auch die mitotischen Aktivität dieser Zellen erklären würde (Longo et al. 2010).

Bestrahlungsbedingt kommt es weiterhin zu einer akuten Entzündungsreaktion (Kalm et al. 2009b), wobei auch von einigen Autoren der Übergang in eine chronische Entzündung beschrieben wurde. 2 bzw. 3 Monate nach Bestrahlung wurde eine persistierende Aktivierung von Mikroglia beschrieben, quantifiziert durch den zellulären Marker CD68 (Monje et al. 2003, Rola et al. 2004). In der vorliegenden Arbeit wurde 7 Monate nach Bestrahlung die chronische Aktivierung anhand morphologischer Kriterien sowie einer veränderten, proinflammatorischen Genexpression festgestellt. Dass die chronische Entzündung über einen solchen Zeitrahmen persistiert, war bisher nicht bekannt. Die Bestrahlung bewirkt u.a. DNA Doppelstrangbrüche, die über eine Aktivierung des NF-kB - Signalwegs zu einer proinflammatorischen Reaktion der Mikroglia führen können (Dong et al. 2010).

Durch die Bestrahlung kann es auch zu einer verstärkten mikroglialen Apoptose kommen, die in einer verminderten Zahl der residenten Mikroglia resultiert (Kalm et al. 2009a, Wirenfeldt et al. 2007). Kalm und Kollegen beschreiben 6 Stunden bzw. 7 Tage nach Bestrahlung ausschließlich akute Veränderungen. Wirenfeldt und Kollegen haben Mikroglia in Knochenmarkschimären quantifiziert und eine Reduktion auf etwa 25 - 30 \% festgestellt. Leider wird dort keine Angabe zum Zeitpunkt der Analyse gemacht. In der vorliegenden Arbeit waren die Mikroglia 7 Monate nach Bestrahlung um $50 \%$ reduziert, woraus sich folgern lässt, dass die Mikroglia infolge der Bestrahlung ihr Potential zur Regeneration verlieren beziehungsweise anhaltend einer erhöhten Apoptoserate unterliegen.

Für die geschilderten, morphologischen Veränderungen (feine Ausläufer auf allen Fortsätzen), die ausschließlich bei Mikroglia aus ungeschützt bestrahlten Gehirnen auftraten, gibt es bisher keine Literaturreferenz. Ihre Rolle ist unklar und bedarf weiterer Untersuchung. Interessant ist, dass die eingewanderten mononukleären Phagozyten die gleichen morphologischen Veränderungen aufweisen. Damit ist die Bestrahlung als direkte Ursache für die Morphologieveränderung ausgeschlossen, weil die mononukleären Phagozyten erst nach Bestrahlung in den Rezipienten gelangen und nie einer direkten Bestrahlung ausgesetzt waren. Die Bestrahlung setzt offenbar einen Prozess in Gang, der dann sekundär zu den morphologischen Veränderungen führt. Dieser Prozess könnte zum einen durch die chronische 
Entzündung des Hirnparenchyms oder durch die eingewanderten mononukleären Phagozyten angetrieben werden.

Die Tatsache, dass der morphologieveränderte Anteil der mononukleären $\mathrm{GFP}^{+}$Phagozyten mit 50 \% etwa doppelt so hoch ist, wie bei den residenten Mikroglia zeigt, dass die ersteren empfindlicher auf den zur Morphologieveränderung führenden Reiz reagieren, als die residenten Mikroglia.

Die Reduktion und veränderte Morphologie der Mikroglia geht einher mit einem bisher nicht beschriebenen veränderten Verhalten an den Amyloidplaques. In der ungeschützt bestrahlten Gruppe wurden deutlich weniger Mikroglia am Plaque festgestellt, was zum großen Teil durch die reduzierte Mikrogliazahl erklärt werden kann. Andererseits müssen die Mikroglia in der ungeschützt bestrahlten Gruppe auch funktionelle Veränderungen aufweisen, weil die Morphologie der Mikroglia am Plaque im Gegensatz zu der geschützt bestrahlten Gruppe deutlich amöboider ist.

Zusätzlich ließen sich in der qRT - PCR der ungeschützt bestrahlten Gruppe eine erniedrigte Expression der Chemokine CCL3 und CXCL10 nachweisen, was auf eine Dysregulation der Chemotaxis hindeutet. Die Bestrahlung allein ist dafür nicht ursächlich, weil die verminderte Expression erst in Kombination der Bestrahlung mit der Alzheimerpathologie auftritt. Die adäquate Reaktion des ZNS auf Noxen wie Amyloidplaques ist infolge der Bestrahlung langfristig gestört. Dabei sind nicht nur die Mikroglia als Quelle der Chemokine denkbar, sondern auch Neurone und Astrozyten (Harrison et al. 2003). In der ungeschützt bestrahlten Gruppe wurde der Scavenger Receptor $A$ verstärkt exprimiert. Dieser Rezeptor ist an der Phagozytose von fibrillärem $A \beta$ beteiligt und wird nur bei Aktivierung von Mikroglia und peripheren Makrophagen exprimiert (Husemann et al. 2002, Frenkel et al. 2008). Immunhistochemisch wurde der SRA auf plaqueassoziierten Mikroglia nachgewiesen (Frenkel et al. 2008). Das Zytokin IL-1 $\beta$ ist ein zentrales Signalmolekül der klassischen Neuroinflammation (Herber et al. 2006, Halle et al. 2008). In der vorliegenden Arbeit war die Expression dieses Gens in ungeschützt bestrahlten gegenüber geschützt bestrahlten Wildtypen signifikant erhöht. Folglich ist die Ursache allein die Bestrahlung. Die Tatsache, dass im Rahmen der Alzheimerpathologie das IL-1 $\beta$ ebenfalls erhöht ist, maskiert die verstärkte Expression in den ungeschützt bestrahlten Alzheimertieren gegenüber den geschützt bestrahlten und erklärt, wieso lediglich eine nicht - signifikante Erhöhung des IL-1 $\beta$ in dieser Arbeit gezeigt wurde. Zudem wurden Hirnhomogenisate untersucht, die die 
Zytokinkombination aus sämtlichen Zelltypen des ZNS beinhaltet. Für ein klareres Ergebnis wäre die Analyse der einzelnen Zelltypen nötig. Im Rahmen der Bestrahlung ist also von einer verstärkten Expression des IL-1 $1 \beta$ auszugehen, was Ausdruck der chronischen Entzündung ist und ein morphologisches Korrelat hat. Bei der klassischen Neuroinflammation sind jedoch die Chemokine meist erhöht (Frank Cannon et al. 2009), weswegen in unserem Fall eine atypischen Entzündung, verbunden mit einer verstärkten Phagozytose vermittelt durch den Scavenger Receptor $A$, vorliegt. Eine denkbare Erklärung wäre, dass sich die Chemokin produzierende Zellpopulation im Laufe der chronischen Entzündung erschöpft und die Ausschüttung von Chemokinen reduziert wird.

Insgesamt wird deutlich, dass die neuropathologischen Langzeitfolgen einer Gehirnbestrahlung weitaus langanhaltender und umfangreicher sind, als bisher angenommen wurde. Die nur sehr spärlichen Berichte von Langzeitveränderungen stehen im Gegensatz zu den kognitiven Defiziten, die auch noch Jahre nach der Bestrahlung auftreten können. 180 Tage nach Bestrahlung und Knochenmarkstransplantation wurden weitere Langzeitveränderungen, wie eine geringere Zelldichte, eine veränderte Architektur des Bulbus olfaktorius sowie ein reduziertes Gewicht desselben beschrieben (Diaz et al. 2010). Außerdem bekommen Mäuse mit schwarzem Fell nach Bestrahlung in der entsprechenden Körperregion dauerhaft ein helles Fell (Mildner et al. 2007), was auf eine Zerstörung der Melanozytenvorläufer zurückzuführen ist (Inomata et al. 2009). Schließlich ist auch noch zu klären, inwieweit Strahlendosen nach Durchtritt durch die menschliche Kalotte biologisch äquivalent zu den Verhältnissen bei Mäusen sind.

Im Anschluss an die beschriebenen, vielfältigen Auswirkungen der Schädelbestrahlung auf das Hirnparenchym stellt sich die Frage, inwieweit diese die Amyloidpathologie beeinflussen. Die biochemische Quantifizierung des unlöslichen $A \beta$ ergab eine Reduktion in den ungeschützt bestrahlten, mit Wildtypknochenmark rekonstituierten APP ${ }^{\text {swe/PS1 }}$ - Tieren. Die Messung der APP - Expression und des APP - Spaltprodukts $\beta$-CTF ergaben keine signifikanten Unterschiede, sodass der Grund für die Reduktion des unlöslichen $A \beta$ in einer gesteigerten Degradation liegen muss. Von zahlreichen Autoren wurde postuliert, dass mononukleäre Phagozyten im Gegensatz zu den residenten Mikroglia die Fähigkeit zur Degradierung von $A \beta$ besitzen (El Khoury et al. 2006, Town et al. 2008, Simard et al. 2006). Um dies 
nachzuweisen, wurde $A \beta$ von Knochenmarkschimären quantifiziert, die mit $C C R 2^{-{ }^{-}}$GFP - Knochenmark rekonstituiert wurden und trotz ungeschützter Bestrahlung eine drastisch reduzierte Zahl eingewanderter mononukleärer Phagozyten im Hirn aufwiesen. Überraschenderweise fanden sich keine signifikanten Unterschiede in der $A \beta$ - Menge im Vergleich zu ungeschützt bestrahlten Tieren, die mit CCR2 ${ }^{+/+}$- GFP Knochenmark rekonstituiert worden waren. Die mononukleären Phagozyten sind also in dieser Studie nicht kritisch beteiligt an dem A - Abbau, was im Gegensatz zu einer bisherigen Untersuchung steht, in der nach Ablation der mononukleären Phagozyten ein verstärktes Auftreten von Amyloidplaques beobachtet wurde (Simard et al. 2006). Es müssen also residente Zellpopulationen des ZNS für die Erniedrigung der A $\beta$ Level verantwortlich sein. Aufgrund der engen Assoziation mit den Plaques sind die Mikroglia die wahrscheinlichsten Kandidaten. Ein möglicher Einfluss von Astrozyten oder perivaskulären Makrophagen auf den $A \beta$ - Gehalt in den Knochenmarkschimären wurde nicht untersucht (Wyss - Coray et al. 2003, Hawkes und McLaurin 2009).

Zusammengefasst finden sich in der ungeschützt bestrahlten Gruppe einerseits eine Aktivierung der Mikroglia, eine erhöhte Expression des proinflammatorischen Zytokins IL-1 $\beta$ und des A $\beta$ - Phagozytose - Rezeptors SRA; andererseits bestehen eine Dysregulation der Chemotaxis sowie eine signifikante Reduktion der Mikroglia insgesamt und in Plaqueassoziation. Dass diese Konstellation zu einem erhöhten unlöslichen $A \beta$ - Gehalt führt, scheint zunächst paradox, verdeutlicht aber, dass nicht die Zahl der Mikroglia am Plaque entscheidend für den $A \beta$ - Abbau ist, sondern die Art der Aktivierung. So resultierte in einem Alzheimertiermodell die CCL2 Überexpression zwar in einer erhöhten Zahl von Mikroglia am Plaque, jedoch wurde kein verstärkter $A \beta$ - Abbau beobachtet (Yamamoto et al. 2005). Die Überexpression von IL-1ß führt zu einer chronischen Neuroinflammation, die interessanterweise ebenfalls mit einer selektiven Erniedrigung des unlöslichen $A \beta$ einher geht (Shaftel et al. 2007). Allerdings wurden hier erhöhte Chemokinlevel gemessen, was sich in einer erhöhten Zahl der plaqueassoziierten Mikroglia äußerte. In einer weiteren Publikation kam es infolge einer intrazerebralen Injektion von LPS zu einer morphologisch und immunhistochemisch beobachteten Aktivierung von Mikroglia und einer Abnahme der Plaquefläche (Malm et al. 2005, DiCarlo et al. 2001). Die klassische Aktivierung ist gekennzeichnet durch Zytokine wie IL-1 $\beta$ oder IFN-y. Typisch für die alternative Aktivierung sind Scavenger - Rezeptoren und Zytokine wie IL-4 oder IL-10 (Colton et 
al. 2009). Diese Konstellation ist in den ungeschützt bestrahlten APP swe/PS1 Chimären gegeben. Demgegenüber stehen Untersuchungen, in denen reaktive, plaqueassoziierte Mikroglia in einem kurzen, experimentellen Beobachtungszeitraum in älteren Alzheimermäusen keinen Einfluß auf den $A \beta$ - Gehalt oder Amyloidplaques haben (Grathwohl et al. 2010, Meyer - Luehmann et al. 2008). Es sind weitere Untersuchungen nötig, um die vielfältigen Arten der Aktivierung von Mikroglia zu verstehen und mit therapeutischer Absicht zur Reduktion des $A \beta$ einzusetzen. 


\section{Zusammenfassung}

Reaktive myeloische Zellen im zentralen Nervensystem (ZNS) sind ein zentrales Element in der Pathologie des Morbus Alzheimer, doch die Rolle dieser myeloischen Zellen für die Pathogenese wird derzeit kontrovers diskutiert. Aufgrund ihres Aktivierungszustandes können sie zur neuronalen Toxizität beitragen. Es sind jedoch auch Reparaturfunktionen sowie $A \beta$ - Phagozytose für diese Zellpopulationen beschrieben worden. Die Ursache der funktionellen Divergenz kann darin bestehen, dass sich die myeloischen Zellen des ZNS aus vermutlich zwei Populationen zusammensetzen: den residenten ZNS - spezifischen Mikroglia und den unter pathologischen Bedingungen ins ZNS rekrutierten, myeloischen Knochenmarkszellen. Daher ist die Erforschung der myeloischen Zellen beim Morbus Alzheimer und die Bedingungen, die die Rekrutierung ins Gehirn ermöglichen, entscheidend im Hinblick auf eine mögliche therapeutische Anwendung in Form einer zellulären Immuntherapie.

In der vorliegenden Arbeit konnten durch Knochenmarkstransplantationsexperimente mit CCR2 - defizientem Knochenmark die inflammatorischen Monozyten $\left(\mathrm{Ly}-6 \mathrm{C}^{\text {hi }} \mathrm{CCR}^{+}\right)$erstmals als Vorläuferpopulation der ins ZNS rekrutierten myeloischen Zellen in APP ${ }^{\text {swe/PS1 }}$ - Tieren identifiziert werden. Allerdings gelangten diese mononukleären Phagozyten nicht physiologischerweise ins Gehirn, sondern nur nach vorheriger, zur Herstellung der Knochenmarkschimären nötigen, Bestrahlung. Die Alzheimerpathologie war damit allein nicht ausreichend, um die Migration von Zellen aus dem Blut ins Gehirn zu ermöglichen. Zwischen den Amyloidplaques und den mononukleären Phagozyten wurde nur eine schwache Assoziation beobachtet und es konnte gezeigt werden, dass die Anwesenheit dieser Zellen im APP ${ }^{\text {swe/PS1 }}$ - Gehirn den A $\beta$ - Gehalt nicht kritisch beeinflusst. Dahingegen wurden erstmals weitreichende Langzeitfolgen der Bestrahlung auf das Gehirnmilieu festgestellt, was sich in einem veränderten Zyto- und Chemokinprofil, einer Reduktion der residenten Mikrogliaanzahl sowie einer morphologischen Veränderung der Mikroglia äußerte. Im Rahmen dieser Veränderungen wurde eine Reduktion des unlöslichen $A \beta$ festgestellt.

Die Ergebnisse verdeutlichen, dass nur inflammatorische Monozyten die peripheren Vorläuferzellen darstellen, die während einer ZNS - Pathologie ins Gehirn migrieren können. Allerdings sind die durch den Morbus Alzheimer hervorgerufenen pathologischen Veränderungen allein nicht ausreichend, um die Rekrutierung von 
myeloischen Knochenmarkszellen ins erkrankte ZNS zu bewirken. Aufgrund dieser Daten erscheint eine zelluläre Immuntherapie daher nur mit dem Transfer von inflammatorischen Monozyten und einer vorhergehenden Öffnung der Bluthirnschranke möglich zu sein. Des Weiteren belegen die vorliegenden Daten, dass die entsprechende Regulierung des Aktivierungsmusters entscheidend für die $A \beta$ - Degradation der myeloischen Zellen im Gehirn ist. 


\section{Literaturverzeichnis}

Ajami B, Bennett JL, Krieger C, Tetzlaff W, Rossi FMV (2007): Local self-renewal can sustain CNS microglia maintenance and function throughout adult life. Nat Neurosci 10 1538-1543

Akiyama H, Barger S, Barnum S, Bradt B, Bauer J, Cole GM, Cooper NR, Eikelenboom P, Emmerling M, Fiebich BL, Finch CE, Frautschy S, Griffin WST, Hampel H, Hull M, Landreth G, Lue LF, Mrak R, Mackenzie IR, Mcgeer PL, O'Banion MK, Pachter J, Pasinetti G, Plata-Salaman C, Rogers J, Rydel R, Shen Y, Streit W, Strohmeyer R, Tooyoma I, Van Muiswinkel FL, Veerhuis R, Walker D, Webster S, Wegrzyniak B, Wenk G, Wyss-Coray T (2000): Inflammation and Alzheimer's disease. Neurobiol Aging 21, 383-421

Algotsson A, Winblad B (2007): The integrity of the blood-brain barrier in Alzheimer's disease. Acta Neurol Scand 115, 403-408

Alzheimer's Association (2009): Alzheimer's Disease Facts and Figures. Alzheimer \& Dementia (www.alz.org)

Andres - Mach M, Rola R, Fike JR (2008): Radiation effects on neural precursor cells in the dentate gyrus. Cell Tissue Res $\underline{311}, 251-262$

Backskai BJ, Kajdasz ST, Christie RH, Carter C, Games D, Seubert P, Schenk D, Hyman BT (2001): Imaging of amyloid-beta deposits in brains of living mice permits direct observation of clearance of plaques with immunotherapy. Nat Med $\underline{7}, 369-372$

Ballestrem C, Wehrle-Haller B, Imhof BA (1998): Actin dynamics in living mammalian cells. J Cell Sci 111, 1649-1658

Bell RD, Zlokovic BV (2009): Neurovascular mechanisms and blood-brain barrier disorder in Alzheimer's disease. Acta Neuropathol 118, 103-113

Boissonneault V, Lessard M, Filali M, Relton J, Wong G, Rivest S (2008): Macrophage colony-stimulating factor prevents beta-amyloid deposition and cognitive impairment in APPSwe/PS1 transgenic mice. J Neuroimmunol 203, 187

Borchelt DR, Thinakaran G, Eckman CB, Lee MK, Davenport F, Ratovitsky T, Prada CM, Kim G, Seekins S, Yager D, Slunt HH, Wang R, Seeger M, Levey Al, Gandy SE, Copeland NG, Jenkins NA, Price DL, Younkin SG (1996): Familial Alzheimer's disease-linked presenilin 1 variants elevate $A$ beta 1-42/1-40 ratio in vitro and in vivo. Neuron $\underline{17}, 1005-1013$

Bowman GL, Kaye JA, Moore M, Waichunas D, Carlson NE, Quinn JF (2007): Bloodbrain barrier impairment in Alzheimer disease - Stability and functional significance. Neurology $\underline{68}, 1809-1814$

Braak H, Braak E (1991): Neuropathological Staging of Alzheimer-Related Changes. Acta Neuropathol $\underline{82}, 239-259$

Busche MA, Eichhoff $\mathrm{G}$, Adelsberger $\mathrm{H}$, Abramowski D, Wiederhold $\mathrm{KH}$, Haass $\mathrm{C}$, Staufenbiel M, Konnerth A, Garaschuk O (2008): Clusters of hyperactive neurons 
near amyloid plaques in a mouse model of Alzheimer's disease. Science $\underline{321}, 1686-$ 1689

Cameron B, Landreth GE (2010): Inflammation, microglia, and alzheimer's disease. Neurobiol Dis $\underline{37}, 503-509$

Cartier N, Hacein - Bey - Abina S, Bartholomae CC, Veres G, Schmidt M, Kutschera I, Vidaud M, Abel U, Dal Cortivo L, Caccavelli L, Mahlaoui N, Kiermer V, Mittelstaedt D, Bellesme C, Lahlou N, Lefrere F, Blanche S, Audit M, Payen E, Leboulch P, I'Homme B, Bougneres P, von Kalle C, Fischer A, Cavazzana-Calvo M, Aubourg P (2009): Hematopoietic Stem Cell Gene Therapy with a Lentiviral Vector in X-Linked Adrenoleukodystrophy. Science $\underline{326}, 818-823$

Chinnery HR, Ruitenberg MJ, McMenamin PG (2010): Novel Characterization of Monocyte-Derived Cell Populations in the Meninges and Choroid Plexus and Their Rates of Replenishment in Bone Marrow Chimeric Mice. J Neuropathol Exp Neurol $\underline{69}, 896-909$

Citron M, Vigopelfrey C, Teplow DB, Miller C, Schenk D, Johnston J, Winblad B, Venizelos N, Lannfelt L, Selkoe DJ (1994): Excessive Production of Amyloid BetaProtein by Peripheral Cells of Symptomatic and Presymptomatic Patients Carrying the Swedish Familial Alzheimer-Disease Mutation. Proc Natl Acad Sci U S A $\underline{91}$, 11993-11997

Colton CA (2009): Heterogeneity of Microglial Activation in the Innate Immune Response in the Brain. J Neuroimmune Pharmacol 4, 399-418

Combs CK, Karlo JC, Kao SC, Landreth GE (2001): beta-Amyloid stimulation of microglia and monocytes results in TNF alpha-dependent expression of inducible nitric oxide synthase and neuronal apoptosis. J Neurosci 21, 1179-1188

Corder EH, Saunders AM, Strittmatter WJ, Schmechel DE, Gaskell PC, Small GW, Roses AD, Haines JL, Pericakvance MA (1993): Gene Dose of Apolipoprotein-e Type-4 Allele and the Risk of Alzheimers-Disease in Late-Onset Families. Science $\underline{261}, 921-923$

Crossen JR, Garwood D, Glatstein E, Neuwelt EA (1994): Neurobehavioral Sequelae of Cranial Irradiation in Adults - A Review of Radiation-Induced Encephalopathy. J Clin Oncol $\underline{12}$, 627-642

Davalos D, Grutzendler J, Yang G, Kim JV, Zuo Y, Jung S, Littman DR, Dustin ML, Gan WB (2005): ATP mediates rapid microglial response to local brain injury in vivo. Nat Neurosci $\underline{6}, 752-758$

Deane R, Bell RD, Sagare A, Zlokovic BV (2009): Clearance of Amyloid-beta Peptide Across the Blood-Brain Barrier: Implication for Therapies in Alzheimer's Disease. CNS Neurol Disord Drug Targets $\underline{8}, 16-30$ 
Díaz D, Recio JS, Baltanás FC, Gómez C, Weruaga E, Alonso JR (2011): Longlasting changes in the anatomy of the olfactory bulb after ionizing irradiation and bone marrow transplantation. Neuroscience $\underline{173}, 190-205$

DiCarlo G, Wilcock D, Henderson D, Gordon M, Morgan D (2001): Intrahippocampal LPS injections reduce A beta load in APP+PS1 transgenic mice. Neurobiol Aging $\underline{22}$, 1007-1012

Dong XR, Luo M, Fan L, Zhang T, Liu L, Dong JH, Wu G (2010): Corilagin inhibits the double strand break-triggered NF-kappa B pathway in irradiated microglial cells. Int J Mol Med 25, 531-536

Duyckaerts C, Potier MC, Delatour B (2008): Alzheimer disease models and human neuropathology: similarities and differences. Acta Neuropathol $\underline{115}, 5-38$

Duyckaerts C, Delatour B, Potier MC (2009): Classification and basic pathology of Alzheimer disease. Acta Neuropathol 118, 5-36

Einat H, Yuan PX, Gould TD, Li JL, Du JH, Zhang L, Manji HK, Chen G (2003): The role of the extracellular signal-regulated kinase signaling pathway in mood modulation. J Neurosci $\underline{23}, 7311-7316$

El Khoury J, Toft M, Hickman SE, Means TK, Terada K, Geula C, Luster AD (2007): Ccr2 deficiency impairs microglial accumulation and accelerates progression of Alzheimer-like disease. Nat Med $\underline{13}, 432-438$

Frank - Cannon TC, Alto LT, McAlpine FE, Tansey MG (2009): Does neuroinflammation fan the flame in neurodegenerative diseases? Mol Neurodegener $\underline{4}$

Frenkel D, Puckett L, Petrovic S, Xia WM, Chen GQ, Vega J, Dembinsky-Vaknin A, Shen J, Plante M, Burt DS, Weiner HL (2008): A nasal proteosome adjuvant activates microglia and prevents amyloid deposition. Ann Neurol $\underline{63}, 591-601$

Garcia - Alloza M, Robbins EM, Zhang-Nunes SX, Purcell SM, Betensky RA, Raju S, Prada C, Greenberg SM, Bacskai BJ, Frosch MP (2006): Characterization of amyloid deposition in the APPswe/PS1dE9 mouse model of Alzheimer disease. Neurobiol Dis $\underline{24}, 516-524$

Geissmann F, Manz MG, Jung S, Sieweke MH, Merad M, Ley K (2010): Development of Monocytes, Macrophages, and Dendritic Cells. Science 327, 656-661

Ginhoux F, Greter M, Leboeuf M, Nandi S, See P, Gokhan S, Mehler MF, Conway SJ, $\mathrm{Ng}$ LG, Stanley ER, Samokhvalov IM, Merad M (2010): Fate mapping analysis reveals that adult microglia derive from primitive macrophages. Science $\underline{330}, 841-$ 845

Götz J, Ittner LM (2008): Animal models of Alzheimer's disease and frontotemporal dementia. Nat Rev Neurosci $\underline{9}$, 532-544

Graeber MB, Streit WJ (2010): Microglia: biology and pathology. Acta Neuropathol $\underline{119}, 89-105$ 
Grathwohl SA, Kalin RE, Bolmont T, Prokop S, Winkelmann G, Kaeser SA, Odenthal J, Radde R, Eldh T, Gandy S, Aguzzi A, Staufenbiel M, Mathews PM, Wolburg H, Heppner FL, Jucker M (2009): Formation and maintenance of Alzheimer's disease beta-amyloid plaques in the absence of microglia. Nat Neurosci $\underline{12}, 1361-1363$

Haass C, Selkoe DJ (2007): Soluble protein oligomers in neurodegeneration: lessons from the Alzheimer's amyloid beta-peptide. Nat Rev Mol Cell Biol $\underline{8}, 101-112$

Halle A, Hornung V, Petzold GC, Stewart CR, Monks BG, Reinheckel T, Fitzgerald KA, Latz E, Moore KJ, Golenbock DT (2008): The NALP3 inflammasome is involved in the innate immune response to amyloid-beta. Nat Immunol $\underline{9}, 857-865$

Hanisch UK, Kettenmann H (2007): Microglia: active sensor and versatile effector cells in the normal and pathologic brain. Nat Neurosci 10, 1387-1394

Hardy J, Selkoe DJ (2002): Medicine - The amyloid hypothesis of Alzheimer's disease: Progress and problems on the road to therapeutics. Science 297, 353-356

Harrison JK (2003): Chemokines and chemokine receptors in the central nervous system. Methods 29, 311

Hawkes CA, McLaurin J (2009): Selective targeting of perivascular macrophages for clearance of beta-amyloid in cerebral amyloid angiopathy. Proc Natl Acad Sci U S A $\underline{106}, 1261-1266$

Herber DL, Maloney JL, Roth LM, Freeman MJ, Morgan D, Gordon MN (2006): Diverse microglial responses after intrahippocampal administration of lipopolysaccharide. Glia $\underline{53}, 382-391$

Hodges $\mathrm{H}$, Katzung N, Sowinski P, Hopewell JW, Wilkinson JH, Bywaters T, Rezvani M (1998): Late behavioural and neuropathological effects of local brain irradiation in the rat. Behav Brain Res 91, 99-114

Husemann J, Loike JD, Anankov R, Febbraio M, Silverstein SC (2002): Scavenger receptors in neurobiology and neuropathology: Their role on microglia and other cells of the nervous system. Glia $\underline{40}, 195-205$

Inomata K, Aoto T, Binh NT, Okamoto N, Tanimura S, Wakayama T, Iseki S, Hara E, Masunaga T, Shimizu H, Nishimura EK (2009): Genotoxic stress abrogates renewal of melanocyte stem cells by triggering their differentiation. Cell 137, 1088-1099

Irvine GB, El Agnaf OM, Shankar GM, Walsh DM (2008): Protein aggregation in the brain: The molecular basis for Alzheimer's and Parkinson's diseases. Mol Med $\underline{14}$, 451-464

Jankowsky JL, Fadale DJ, Anderson J, Xu GM, Gonzales V, Jenkins NA, Copeland NG, Lee MK, Younkin LH, Wagner SL, Younkin SG, Borchelt DR (2004): Mutant presenilins specifically elevate the levels of the 42 residue beta-amyloid peptide in vivo: evidence for augmentation of a 42-specific gamma secretase. Hum Mol Genet $\underline{13}, 159-170$ 
Jarrett JT, Berger EP, Lansbury PT (1993): The Carboxy Terminus of the BetaAmyloid Protein Is Critical for the Seeding of Amyloid Formation - Implications for the Pathogenesis of Alzheimers-Disease. Biochemistry $\underline{32}$, 4693-4697

Jellinger KA (2001): Neuropathologie der Demenzen. Journal für Neurologie, Neurochirurgie, Psychiatrie 1, 7-31

Kalm M, Fukuda A, Fukuda H, Ohrfelt A, Lannering B, Bjork-Eriksson T, Blennow K, Marky I, Blomgren K (2009a): Transient Inflammation in Neurogenic Regions after Irradiation of the Developing Brain. Radiat Res 171, 66-76

Kalm M, Lannering B, Bjork-Eriksson T, Blomgren K (2009b): Irradiation-induced loss of microglia in the young brain. J Neuroimmunol 206, 70-75

Kaya M, Palanduz A, Kalayci R, Kemikler G, Simsek G, Bilgic B, Ahishali B, Arican N, Kocyildiz ZC, Elmas L, Kucuk M, Karadeniz A (2004): Effects of lipopolysaccharide on the radiation-induced changes in the blood-brain barrier and the astrocytes. Brain $\operatorname{Res} \underline{1019}, 105-112$

Kim D, Tsai LH (2009): Bridging Physiology and Pathology in AD. Cell 137, 997-1000

Knafo S, Venero C, Merino-Serrais P, Fernaud-Espinosa I, Gonzalez-Soriano J, Ferrer I, Santpere G, DeFelipe J (2009a): Morphological alterations to neurons of the amygdala and impaired fear conditioning in a transgenic mouse model of Alzheimer's disease. J Pathol 219, 41-51

Knafo S, Alonso-Nanclares L, Gonzalez-Soriano J, Merino-Serrais P, FernaudEspinosa I, Ferrer I, DeFelipe J (2009b): Widespread Changes in Dendritic Spines in a Model of Alzheimer's Disease. Cereb Cortex $\underline{19}, 586-592$

Koenigsknecht - Talboo J, Landreth GE (2005): Microglial phagocytosis induced by fibrillar beta-amyloid and IgGs are differentially regulated by proinflammatory cytokines. J Neurosci $\underline{25}$, 8240-8249

Kril JJ, Hodges J, Halliday G (2004): Relationship between hippocampal volume and CA1 neuron loss in brains of humans with and without Alzheimer's disease. Neurosci Lett $\underline{361}, 9-12$

Kuchibhotla KV, Lattarulo CR, Hyman BT, Bacskai BJ (2009): Synchronous Hyperactivity and Intercellular Calcium Waves in Astrocytes in Alzheimer Mice. Science $\underline{323}, 1211-1215$

Kumar VB, Franko M, Banks WA, Kasinadhuni P, Farr SA, Vyas K, Choudhuri V, Morley JE (2009): Increase in Presenilin 1 (PS1) levels in senescence-accelerated mice (SAMP8) may indirectly impair memory by affecting amyloid precursor protein (APP) processing. J Exp Biol 212, 494-498

Kuziel WA, Morgan SJ, Dawson TC, Griffin S, Smithies O, Ley K, Maeda N (1997): Severe reduction in leukocyte adhesion and monocyte extravasation in mice deficient in CC chemokine receptor 2. Proc Natl Acad Sci U S A 22 , 12053-12058 
Landsman L, Jung S (2007): Lung macrophages serve as obligatory intermediate between blood monocytes and alveolar macrophages. J Immunol $\underline{179}$, 3488-3494

Laurén J, Gimbel DA, Nygaard HB, Gilbert JW, Strittmatter SM (2009): Cellular prion protein mediates impairment of synaptic plasticity by amyloid-beta oligomers. Nature $\underline{457}, 1128-1 \mathrm{U} 84$

Lebson L, Nash K, Kamath S, Herber D, Carty N, Lee DC, Li QY, Szekeres K, Jinwal U, Koren J, Dickey CA, Gottschall PE, Morgan D, Gordon MN (2010): Trafficking CD11b-Positive Blood Cells Deliver Therapeutic Genes to the Brain of AmyloidDepositing Transgenic Mice. J Neurosci 30, 9651-9658

Longo B, Romariz S, Blanco MM, Vasconcelos JF, Bahia L, Soares MBP, Mello LE, Ribeiro-dos-Santos R (2010): Distribution and proliferation of bone marrow cells in the brain after pilocarpine-induced status epilepticus in mice. Epilepsia 51, 16281632

Luo XG, Ding JQ, Chen SD (2010): Microglia in the aging brain: relevance to neurodegeneration. Mol Neurodegener $\underline{5}$

Mahmoud - Ahmed AS, Atkinson S, Wong CS (2006): Early gene expression profile in mouse brain after exposure to ionizing radiation. Radiat Res $\underline{2}, 142-154$

Majumdar A, Cruz D, Asamoah N, Buxbaum A, Sohar I, Lobel P, Maxfield FR (2007): Activation of microglia acidifies lysosomes and leads to degradation of Alzheimer amyloid fibrils. Mol Biol Cell $\underline{18}, 1490-1496$

Malm TM, Koistinaho M, Parepalo M, Vatanen T, Ooka A, Karlsson S, Koistinahoa J (2005): Bone-marrow-derived cells contribute to the recruitment of microglial cells in response to beta-amyloid deposition in APP/PS1 double transgenic Alzheimer mice. Neurobiol Dis $\underline{18}, 134-142$

Malm TM, livonen $\mathrm{H}$, Goldsteins $\mathrm{G}$, Keksa-Goldsteine V, Ahtoniemi T, Kanninen K, Salminen A, Auriola S, Van Groen T, Tanila H, Koistinaho J (2007): Pyrrolidine dithiocarbamate activates Akt and improves spatial learning in APP/PS1 mice without affecting beta-amyloid burden. J Neurosci $\underline{27}, 3712-3721$

Malm TM, Magga J, Kuh GF, Vatanen T, Koistinaho M, Koistinaho J (2008): Minocycline Reduces Engraftment and Activation of Bone Marrow-Derived Cells but Sustains Their Phagocytic Activity in a Mouse Model of Alzheimer's Disease. Glia $\underline{56}$, 1767-1779

Malm T, Koistinaho M, Muona A, Magga J, Koistinaho J (2010): The role and therapeutic potential of monocytic cells in Alzheimer's disease. Glia $\underline{8}, 889-900$

Mandrekar S, Jiang QG, Lee CYD, Koenigsknecht-Talboo J, Holtzman DM, Landreth GE (2009): Microglia Mediate the Clearance of Soluble A beta through Fluid Phase Macropinocytosis. J Neurosci $\underline{29}$, 4252-4262

Marchi N, Teng QS, Nguyen MT, Franic L, Desai NK, Masaryk T, Rasmussen P, Trasciatti S, Janigro D (2010): Multimodal investigations of trans-endothelial cell trafficking under condition of disrupted blood-brain barrier integrity. BMC Neurosci 11 
Martins IC, Kuperstein I, Wilkinson H, Maes E, Vanbrabant M, Jonckheere W, Van Gelder P, Hartmann D, D'Hooge R, De Strooper B, Schymkowitz J, Rousseau F (2008): Lipids revert inert Abeta amyloid fibrils to neurotoxic protofibrils that affect learning in mice. EMBO J 1, 224-233

Mc Geer EG, McGeer PL (2001): Innate immunity in Alzheimer's disease: a model for local inflammatory reactions. Mol Interv 1, 22-29

Meilandt WJ, Cisse M, Ho K, Wu T, Esposito LA, Scearce - Levie K, Cheng IH, Yu GQ, Mucke L (2009): Neprilysin Overexpression Inhibits Plaque Formation But Fails to Reduce Pathogenic A beta Oligomers and Associated Cognitive Deficits in Human Amyloid Precursor Protein Transgenic Mice. J Neurosci 29, 1977-1986

Meyer - Luehmann M, Spires - Jones TL, Prada C, Garcia - Alloza M, de Calignon A, Rozkalne A, Koenigsknecht - Talboo J, Holtzman DM, Bacskai BJ, Hyman BT (2008): Rapid appearance and local toxicity of amyloid-beta plaques in a mouse model of Alzheimer's disease. Nature $\underline{451}, 720-7$ U5

Mildner A, Schmidt H, Nitsche M, Merkler D, Hanisch UK, Mack M, Heikenwalder M, Bruck W, Priller J, Prinz M (2007): Microglia in the adult brain arise from Ly6C(hi)CCR2(+) monocytes only under defined host conditions. Nat Neurosci $\underline{10}$, 1544-1553

Mirra SS, Hart MN, Terry RD (1993): Making the diagnosis of Alzheimer's disease. A primer for practicing pathologists. Arch Pathol Lab Med 117, 132-144

Möller H, Laux G, Deister A: Psychiatrie Psychotherapie. (Duale Reihe), 4. Auflage; Georg Thieme Verlag, Stuttgart 2009

Monje ML, Toda H, Palmer TD (2003): Inflammatory blockade restores adult hippocampal neurogenesis. Science $\underline{302}, 1760-1765$

Morris RG, Salmon DP (2007): The Centennial of Alzheimer's disease and the publication of "Uber eine eigenartige Erkankung der Hirnrinde" by Alois Alzheimer. Cortex $\underline{43}, 821-825$

Mortimer JA, Borenstein AR, Gosche KM, Snowdon DA (2005): Very early detection of Alzheimer neuropathology and the role of brain reserve in modifying its clinical expression. J Geriatr Psychiatry Neurol 18, 218-223

Mullan M, Houlden H, Windelspecht M, Fidani L, Lombardi C, Diaz P, Rossor M, Crook R, Hardy J, Duff K, Crawford F (1992): A Locus for Familial Early-Onset Alzheimers-Disease on the Long Arm of Chromosome 14, Proximal to the Alpha-1Antichymotrypsin Gene. Nat Genet 2, 340-342

Nimmerjahn A, Kirchhoff F, Helmchen F (2005): Resting microglial cells are highly dynamic surveillants of brain parenchyma in vivo. Science $\underline{308}, 1314-1318$

Oh ES, Savonenko AV, King JF, Tucker SMF, Rudow GL, Xu GL, Borchelt DR, Troncoso JC (2009): Amyloid precursor protein increases cortical neuron size in transgenic mice. Neurobiol Aging $\underline{30}, 1238-1244$ 
O'Leary TP, Brown RE (2009): Visuo-spatial learning and memory deficits on the Barnes maze in the 16-month-old APPswe/PS1dE9 mouse model of Alzheimer's disease. Behav Brain Res 201, 120-127

O'Neil JN, Mouton PR, Tizabi Y, Ottinger MA, Lei DL, Ingram DK, Manaye KF (2007): Catecholaminergic neuronal loss in locus coeruleus of aged female dtg APP/PS1 mice. J Chem Neuroanat $\underline{34}, 102-107$

Paresce DM, Ghosh RN, Maxfield FR (1996): Microglial cells internalize aggregates of the Alzheimer's disease amyloid beta-protein via a scavenger receptor. Neuron $\underline{17}$, 553-565

Perrin RJ, Fagan AM, Holtzman DM (2009): Multimodal techniques for diagnosis and prognosis of Alzheimer's disease. Nature 461, 916-922

Pfaffl MW (2001): A new mathematical model for relative quantification in real-time RT-PCR. Nucleic Acids Res $\underline{29}$

Priller J, Flugel A, Wehner T, Boentert M, Haas CA, Prinz M, Fernandez-Klett F, Prass K, Bechmann I, de Boer BA, Frotscher M, Kreutzberg GW, Persons DA, Dirnagl U (2001): Targeting gene-modified hematopoietic cells to the central nervous system: Use of green fluorescent protein uncovers microglial engraftment. Nat Med $\underline{7}, 1356-1361$

Prinz M, Mildner A (2011): Microglia in the CNS: immigrants from another world. Glia 2, $177-187$

Qiu CX, De Ronchi D, Fratiglioni L (2007): The epidemiology of the dementias: an update. Curr Opin Psychiatry 20, 380-385

Qiu WQ, Walsh DM, Ye Z, Vekrellis K, Zhang JM, Podlisny MB, Rosner MR, Safavi A, Hersh LB, Selkoe DJ (1998): Insulin-degrading enzyme regulates extracellular levels of amyloid beta-protein by degradation. J Biol Chem $\underline{273}, 32730-32738$

Querfurth HW, LaFerla FM (2010): Mechanisms of Disease Alzheimer's Disease. N Engl J Med 362, 329-344

Raber J, Rola R, LeFevour A, Morhardt D, Curley J, Mizumatsu S, VandenBerg SR, Fike JR (2004): Radiation-induced cognitive impairments are associated with changes in indicators of hippocampal neurogenesis. Radiat Res $\underline{162}, 39-47$

Raivich G, Bohatschek M, Kloss CUA, Werner A, Jones LL, Kreutzberg GW (1999): Neuroglial activation repertoire in the injured brain: graded response, molecular mechanisms and cues to physiological function. Brain Res Rev $\underline{30}, 77-105$

Ransohoff RM, Perry VH (2009): Microglial Physiology: Unique Stimuli, Specialized Responses. Annu Rev Immunol 27, 119-145

Rapoport M, Dawson HN, Binder LI, Vitek MP, Ferreira A (2002): Tau is essential to beta-amyloid-induced neurotoxicity. Proc Natl Acad Sci U S A $\underline{99}$, 6364-6369 
Reed - Geaghan EG, Savage JC, Hise AG, Landreth GE (2009): CD14 and Toll-Like Receptors 2 and 4 Are Required for Fibrillar A beta-Stimulated Microglial Activation. J Neurosci 29, 11982-11992

Rivest S (2009): Regulation of innate immune responses in the brain. Nat Rev Immunol $\underline{9}$, 429-439

Rodrigue KM, Kennedy KM, Park DC (2009): Beta-Amyloid Deposition and the Aging Brain. Neuropsychol Rev $\underline{19}$, 436-450

Rogers J, Lue LF (2001): Microglial chemotaxis, activation, and phagocytosis of amyloid beta-peptide as linked phenomena in Alzheimer's disease. Neurochem Int $\underline{39}, 333-340$

Rola R, Raber J, Rizk A, Otsuka S, VandenBerg SR, Morhardt DR, Fike JR (2004): Radiation-induced impairment of hippocampal neurogenesis is associated with cognitive deficits in young mice. Exp Neurol $\underline{188}, 316-330$

Ruan LF, Kang ZJ, Pei G, Le YY (2009): Amyloid Deposition and Inflammation in APPswe/PS1dE9 Mouse Model of Alzheimer's Disease. Curr Alzheimer Res $\underline{6}, 531$ 540

Savonenko A, Xu GM, Melnikova T, Morton JL, Gonzales V, Wong MPF, Price DL, Tang F, Markowska AL, Borchelt DR (2005): Episodic-like memory deficits in the APPswe/PS1dE9 mouse model of Alzheimer's disease: Relationships to betaamyloid deposition and neurotransmitter abnormalities. Neurobiol Dis $\underline{18}, 602-617$

Serbina NV, Pamer EG (2006): Monocyte emigration from bone marrow during bacterial infection requires signals mediated by chemokine receptor CCR2. Nat Immunol $\underline{7}, 311-317$

Serrano - Pozo A, William CM, Ferrer I, Uro-Coste E, Delisle MB, Maurage CA, Hock C, Nitsch RM, Masliah E, Growdon JH, Frosch MP, Hyman BT (2010): Beneficial effect of human anti-amyloid-beta active immunization on neurite morphology and tau pathology. Brain 133, 1312-1327

Shaftel SS, Kyrkanides S, Olschowka JA, Miller JNH, Johnson RE, O'Banion MK (2007): Sustained hippocampal IL-1 beta overexpression mediates chronic neuroinflammation and ameliorates Alzheimer plaque pathology. J Clin Invest 117, 1595-1604

Shankar GM, Li SM, Mehta TH, Garcia-Munoz A, Shepardson NE, Smith I, Brett FM, Farrell MA, Rowan MJ, Lemere CA, Regan CM, Walsh DM, Sabatini BL, Selkoe DJ (2008): Amyloid-beta protein dimers isolated directly from Alzheimer's brains impair synaptic plasticity and memory. Nat Med $\underline{14}$, 837-842

Shechter R, London A, Varol C, Raposo C, Cusimano M, Yovel G, Rolls A, Mack M, Pluchino S, Martino G, Jung S, Schwartz M (2009): Infiltrating Blood-Derived Macrophages Are Vital Cells Playing an Anti-inflammatory Role in Recovery from Spinal Cord Injury in Mice. PLoS Med $\underline{6}$ 
Si Y, Tsou CL, Croft K, Charo IF (2010): CCR2 mediates hematopoietic stem and progenitor cell trafficking to sites of inflammation in mice. J Clin Invest 120, 11921203

Simard AR, Soulet D, Gowing G, Julien JP, Rivest S (2006): Bone marrow-derived microglia play a critical role in restricting senile plaque formation in Alzheimer's disease. Neuron $\underline{49}$, 489-502

Spiegler BJ, Bouffet E, Greenberg ML, Rutka JT, Mabbott DJ (2004): Change in neurocognitive functioning after treatment with cranial radiation in childhood. J Clin Oncol $\underline{22}, 706-713$

Spires TL, Meyer-Luehmann M, Stern EA, Mclean PJ, Skoch J, Nguyen PT, Bacskai BJ, Hyman BT (2005): Dendritic spine abnormalities in amyloid precursor protein transgenic mice demonstrated by gene transfer and intravital multiphoton microscopy. J Neurosci $\underline{25}, 7278-7287$

Stalder AK, Ermini F, Bondolfi L, Krenger W, Burbach GJ, Deller T, Coomaraswamy J, Staufenbiel M, Landmann R, Jucker M (2005): Invasion of hematopoietic cells into the brain of amyloid precursor protein transgenic mice. J Neurosci $\underline{25}, 11125-11132$

Stern EA, Bacskai BJ, Hickey GA, Attenello FJ, Lombardo JA, Hyman BT (2004): Cortical synaptic integration in vivo is disrupted by amyloid-beta plaques. $\mathrm{J}$ Neurosci $\underline{24}, 4535-4540$

Stokin GB, Lillo C, Falzone TL, Brusch RG, Rockenstein E, Mount SL, Raman R, Davies P, Masliah E, Williams DS, Goldstein LSB (2005): Axonopathy and transport deficits early in the pathogenesis of Alzheimer's disease. Science $\underline{307}, 1282-1288$

Stozicka Z, Zilka N, Novak M (2007): Risk and protective factors for sporadic Alzheimer's disease. Acta Virol $\underline{51}$, 205-222

Strittmatter WJ, Weisgraber KH, Huang DY, Dong LM, Salvesen GS, Pericakvance M, Schmechel D, Saunders AM, Goldgaber D, Roses AD (1993): Binding of Human Apolipoprotein-e to Synthetic Amyloid-Beta Peptide - Isoform-Specific Effects and Implications for Late-Onset Alzheimer-Disease. Proc Natl Acad Sci U S A $\underline{90}$, 80988102

Tanzi RE, Bertram L (2005): Twenty years of the Alzheimer's disease amyloid hypothesis: A genetic perspective. Cell $\underline{120}, 545-555$

Thal DR, Rub U, Schultz C, Sassin I, Ghebremedhin E, Del Tredici K, Braak E, Braak $H$ (2000): Sequence of Abeta-protein deposition in the human medial temporal lobe. J Neuropathol Exp Neurol $\underline{59}$, 733-748

Thal DR, Rub U, Orantes M, Braak H (2002): Phases of A beta-deposition in the human brain and its relevance for the development of AD. Neurology $\underline{58}, 1791-1800$

Town T, Laouar Y, Pittenger C, Mori T, Szekely CA, Tan J, Duman RS, Flavell RA (2008): Blocking TGF-beta-Smad2/3 innate immune signaling mitigates Alzheimerlike pathology. Nat Med $\underline{14}, 681-687$ 
Tsai J, Grutzendler J, Duff K, Gan WB (2004): Fibrillar amyloid deposition leads to local synaptic abnormalities and breakage of neuronal branches. Nat Neurosci $\underline{7}$, $1181-1183$

Walsh DM, Klyubin I, Fadeeva JV, Cullen WK, Anwyl R, Wolfe MS, Rowan MJ, Selkoe DJ (2002): Naturally secreted oligomers of amyloid beta protein potently inhibit hippocampal long-term potentiation in vivo. Nature $\underline{416}, 535-539$

Weiner HL, Frenkel D (2006): Immunology and immunotherapy of Alzheimer's disease. Nat Rev Immunol $\underline{6}, 404-416$

Weldon DT, Rogers SD, Ghilardi JR, Finke MP, Cleary JP, O'Hare E, Esler WP, Maggio JE, Mantyh PW (1998): Fibrillar beta-amyloid induces microglial phagocytosis, expression of inducible nitric oxide synthase, and loss of a select population of neurons in the rat CNS in vivo. J Neurosci $\underline{18}, 2161-2173$

Whitwell JL, Josephs KA, Murray ME, Kantarci K, Przybelski SA, Weigand SD, Vemuri P, Senjem ML, Parisi JE, Knopman DS, Boeve BF, Petersen RC, Dickson DW, Jack CR (2008): MRI correlates of neurofibrillary tangle pathology at autopsy - A voxel-based morphometry study. Neurology $\underline{71}, 743-749$

Wirenfeldt M, Dissing - Olesen L, Babcock AA, Nielsen M, Meldgaard M, Zimmer J, Azcoitia I, Leslie RGQ, Dagnaes-Hansen F, Finsen B (2007): Population control of resident and immigrant microglia by mitosis and apoptosis. Am J Pathol 171, 617-631

Wisniewski T, Sadowski M (2008): Preventing beta-amyloid fibrillization and deposition: beta-sheet breakers and pathological chaperone inhibitors. BMC Neurosci $\underline{9}$

Wyss - Coray T, Loike JD, Brionne TC, Lu E, Anankov R, Yan FR, Silverstein SC, Husemann J (2003): Adult mouse astrocytes degrade amyloid-beta in vitro and in situ. Nat Med $\underline{9}, 453-457$

Yamamoto M, Horiba M, Buescher JL, Huang DR, Gendelman HE, Ransohoff RM, Ikezu T (2005): Overexpression of monocyte chemotactic protein-1/CCL2 in betaamyloid precursor protein transgenic mice show accelerated diffuse beta-amyloid deposition. Am J Pathol 166, 1475-1485

Yuan H, Gaber MW, McColgan T, Naimark MD, Kiani MF, Merchant TE (2003): Radiation-induced permeability and leukocyte adhesion in the rat blood-brain barrier: modulation with anti-ICAM-1 antibodies. Brain Res 969, 59-69

Yong VW, Rivest S (2009): Taking Advantage of the Systemic Immune System to Cure Brain Diseases. Neuron $\underline{64}, 55-60$

Zhu CL, Huang ZH, Gao JF, Zhang Y, Wang XY, Karlsson N, Li Q, Lannering B, Bjork-Eriksson T, Kuhn HG, Blomgren K (2009): Irradiation to the immature brain attenuates neurogenesis and exacerbates subsequent hypoxic-ischemic brain injury in the adult. J Neurochem $111,1447-1456$ 


\section{Danksagungen}

An erster Stelle möchte ich Herrn Prof. Dr. med. M. Prinz für die Bereitstellung dieses hochaktuellen, spannenden Themas danken, das zudem ein breites Spektrum an zu erlernenden Methoden beinhaltete. Er steckte mich mit seiner Begeisterung für das Thema an und half mir so über kleinere experimentelle Rückschläge hinweg. Für Fragen und Hilfestellungen stand er jederzeit zur Verfügung.

Ohne die exzellente und freundschaftliche Betreuung durch Herrn Dr. rer. nat. A. Mildner wäre diese Arbeit nie entstanden. Durch inn erlernte ich das wissenschaftliche Arbeiten und hatte einen zuverlässigen Ansprechpartner bei allen Fragen des Laboralltags und der Planung von Experimenten auch nach Fortzug der Arbeitsgruppe Prinz nach Freiburg.

Des Weiteren gilt mein Dank Herrn Prof. Dr.med. W. Brück, in dessen Institut die Experimente $\mathrm{zu}$ dieser Dissertation unter sehr guten Arbeitsbedingungen durchgeführt wurden.

Zu Dank verpflichtet bin ich außerdem sämtlichen Doktoranden der Abteilung Neuropathologie Göttingen für die gute Stimmung und Unterstützung im Labor sowie für die gemeinsamen Freizeitunternehmungen. Namentlich hervorgehoben seien die Mitglieder der AG Prinz Angela Dann, Markus Knust und Katrin Kierdorf sowie die MTAs Olga Kowatsch und Katja Schulz.

Meinen Eltern danke ich für ihre fortwährende Unterstützung, die mir erst das Freisemester ermöglichte. Zusätzlich haben sie Korrektur gelesen und durch ihre konstruktive Kritik viel zur Lesbarkeit dieser Arbeit beigetragen.

Schließlich möchte ich meiner lieben Freundin Silvia danken, die mich häufig darum bat, die Zusammenhänge dieser Arbeit zu erklären und mir dadurch neue, ungeahnte Blickweisen auf die Thematik eröffnete. 


\section{Publikationen}

Mildner $A^{\#}$, Schlevogt $B^{\#}$, Kierdorf $K^{\#}$, Böttcher C, Erny D, Kummer M, Quinn M, Bechmann I, Brück W, Heneka M, Priller J" und Prinz $\mathrm{M}^{\#}$ (2011): Distinct and nonredundant roles of microglia and myeloid subsets in mouse models of Alzheimer's disease. J Neurosci (in press)

\# these authors contributed equally 